\title{
Intensive Math Instruction and Educational Attainment
}

\section{Citation}

Cortes, Kalena E., Joshua S. Goodman, and Takako Nomi. 2015. "Intensive Math Instruction and Educational Attainment." Journal of Human Resources 50 (1): 108-158. doi:10.3368/jhr.50.1.108.

\section{Published Version}

10.3368/jhr.50.1.108

\section{Permanent link}

http://nrs.harvard.edu/urn-3:HUL.InstRepos:34298862

\section{Terms of Use}

This article was downloaded from Harvard University's DASH repository, and is made available under the terms and conditions applicable to Open Access Policy Articles, as set forth at http:// nrs.harvard.edu/urn-3:HUL.InstRepos:dash.current.terms-of-use\#OAP

\section{Share Your Story}

The Harvard community has made this article openly available.

Please share how this access benefits you. Submit a story.

Accessibility 


\title{
Intensive Math Instruction and Educational Attainment: Long-Run Impacts of Double-Dose Algebra
}

\author{
Kalena Cortes \\ Texas A\&M University \\ kcortes@tamu.edu \\ Joshua Goodman* \\ Harvard University \\ joshua_goodman@hks.harvard.edu \\ Takako Nomi \\ St. Louis University \\ tnomi@slu.edu
}

February 13, 2014

\begin{abstract}
We study an intensive math instruction policy that assigned low-skilled 9th graders to an algebra course that doubled instructional time, altered peer composition and emphasized problem solving skills. A regression discontinuity design shows substantial positive impacts of double-dose algebra on credits earned, test scores, high school graduation and college enrollment rates. Test score effects under-predict attainment effects, highlighting the importance of long-run evaluation of such a policy. Perhaps because the intervention focused on verbal exposition of mathematical concepts, the impact was largest for students with below average reading skills, emphasizing the need to target interventions toward appropriately skilled students.
\end{abstract}

\footnotetext{
*Corresponding author.
} 
JEL Classifications: I20, I21, I24, J15, J24

Keywords: Double-dose algebra, instructional time, peer effects, math curriculum, educational attainment, high school graduation, college enrollment

Acknowledgments: We are indebted to Chicago Public Schools for sharing their data with us and to Sue Sporte, Director of Research Operations, Consortium on Chicago School Research (CCSR) for facilitating this sharing. Special thanks for helpful comments from Richard Murnane, Bridget Terry Long, Jeffrey D. Kubik, Lori Taylor, Jacob Vigdor, Caroline Hoxby, Martin West, Kevin Stange, and Nora Gordon, as well as seminar and conference participants at Harvard's Program on Education Policy and Governance, the State of Texas Education Research Center at Texas A\&M University, the Association for Education Finance and Policy, the NBER Economics of Education Program, UT-Austin's Economics Department and the Stanford Graduate School of Education. Colin Sullivan, Heather Sarsons and Shelby Lin provided outstanding research assistance. This research was funded by the Institute of Education Sciences under award R305A120466. Institutional support from Texas A\&M University and Harvard's Taubman Center for State and Local Government are also gratefully acknowledged. Research results, conclusions and all errors are our own. 


\section{Introduction}

The high school graduation rate for American students has declined since the 1970s to about 75 percent, with black and Hispanic graduation rates hovering around 65 percent (Heckman and LaFontaine 2010). Poor academic preparation of students entering high school is often cited as a major source of such high dropout rates. Results from the 2011 National Assessment of Educational Progress suggest that only 35 percent of students enter high school with math skills that are considered proficient. Black and Hispanic students' proficiency rates are even lower, at 13 and 20 percent, respectively. These low academic skills may explain observed high failure rates in 9th grade coursework, particularly in algebra (Herlihy 2007, Horwitz and Snipes 2008).

Such high failure rates are particularly worrying because of their close association with dropout rates in later grades. Early course failures prevent students from progressing to more advanced coursework and from earning the credits needed to graduate (Allensworth and Easton 2007). In the Chicago Public Schools (CPS), the focus of this study, roughly half of high school freshmen fail at least one course, with the highest failure rates in math courses (Allensworth and Easton 2005). Concern about this fact and the apparent failure of remediating students before entering high school led CPS to implement a double-dose algebra policy starting with students entering high school in the fall of 2003. Under this policy, students scoring below the national median on an 8th grade math test were subsequently assigned to two periods of freshman algebra rather than the usual one period. CPS hoped that this doubling of instructional time, along with an increased emphasis on problem solving skills and increased instructional support for teachers, would improve algebra passing rates in the short-run and high school graduation rates in the long-run.

To analyze the effect of the double-dose policy, we employ a regression discontinuity design comparing students just above and below the threshold for assignment to additional instructional

\footnotetext{
${ }^{1}$ Similarly large skill gaps by income are also apparent. Students poor enough to qualify for free lunch under the National School Lunch Program have a proficiency rate of 17 percent, compared to a 47 percent proficiency rate among students who do not qualify for such subsidies. See "The Nations Report Card: Mathematics 2011" published by the National Center for Education Statistics.
} 
time. Using longitudinal data that tracks students from 8th grade through college, we first show that the treatment doubled instructional time in math, replaced largely elective courses, such as music and art, so that total coursework was unchanged, increased the homogeneity of algebra classrooms, and exposed students to lower-skilled peers in algebra class. We then show positive and substantial long-run impacts of double-dose algebra on credits earned, test scores, high school graduation and college enrollment rates. Attainment effects were larger than test score effects would predict, highlighting the importance of evaluating educational interventions on longer-run outcomes. Perhaps because the intervention focused on verbal exposition of mathematical concepts, the impact was largest for students with below average reading skills, emphasizing the need to target interventions toward appropriately skilled students. This is the first evidence we know of demonstrating the long-run impacts of such intensive math instruction.

Our study contributes to four strands of the research literature. First, given that the intervention studied here doubled the amount of time students were exposed to 9th grade algebra, our study adds to the literature on the importance of instructional time to student achievement. Some education reformers have pushed U.S. schools to lengthen school days and years, noting that students in many academically successful nations, particularly in Asia, spend substantially more time in school than do American students. Proponents of this view point to evidence on summer learning loss (Cooper et al. 1996), the impact of snow days (Marcotte and Hemelt 2008), the association between charter school effectiveness and instructional time (Dobbie and Fryer 2013, Hoxby and Murarka 2009, Angrist et al. 2013), and other such patterns linking student achievement to hours spent learning (Lavy 2010, Fitzpatrick et al. 2011). Another set of studies suggests this evidence is weaker than it first appears, with Fryer and Levitt (2004) observing little differential summer learning loss, Goodman (2012a) showing little impact of snow days on achievement, and Checkoway et al. (2011) showing little effect of an intervention that substantially increased schools' instructional times. The emerging consensus from this literature is that increasing instructional time is no guarantee of better student outcomes if such time is not well spent in the classroom. 
Second, this study adds to the literature concerning the short-run impact of curricular interventions, particularly for students struggling in mathematics. Recent years have seen three main curriculum approaches tried by American schools. Remediation, which diverts students into basic courses prior to taking regular courses, has generally had little discernible impact on student achievement, particularly at the college level where it has most often been studied (Jacob and Lefgren 2004, Lavy and Schlosser 2005, Calcagno and Long 2008, Bettinger and Long 2009. Martorell and McFarlin 2011, Boatman and Long 2010, Scott-Clayton and Rodriguez 2012). Algebra "for all", which pushes students to take algebra courses in earlier grades than they otherwise would have, actually harms student achievement by forcing students into subjects for which they are not sufficiently prepared (Clotfelter et al. 2012, Allensworth et al. 2009). Double-dosing, which places students in regular courses but supplements those courses with additional instructional time, has generated short-run gains similar to the ones we estimate here in some settings (Nomi and Allensworth 2009, Nomi and Allensworth 2010, Taylor 2012, Dougherty 2013) and no gains in others (Fryer 2011). Perhaps because of perceived effectiveness at raising short-run achievement levels, the double-dose strategy has become increasingly common, with half of large urban districts reporting it as their most common form of support for struggling students. ${ }^{2}$

Third, we contribute to the literature on the long-run impacts of curriculum on student outcomes. Nearly all such research points to a close association between coursework completed in high school and later outcomes such as college enrollment and labor market earnings (Altonji 1995, Levine and Zimmerman 1995, Rose and Betts 2004, Attewell and Domina 2008, Long et al. 2009, Long et al. 2012). Most such papers attempt to deal with the bias generated by selection into coursework by controlling for a rich set of covariates, either through OLS or propensity score matching. Such methods leave open, however, the possibility that the remaining unobservables are still important factors. The few papers that use quasi-experimental methods to convincingly elimi-

\footnotetext{
${ }^{2}$ See "Urban Indicator: High School Reform Survey, School Year 2006-2007", by the Council of Great City Schools, 2009.
} 
nate such selection bias also find strong associations between completed coursework and long-run outcomes, suggesting that such selection bias is not generating the central findings (Joensen and Nielsen 2009, Goodman 2012b). Our paper is one of the better identified links between high school coursework and educational attainment.

Fourth, and finally, our results align with recent evidence that peer effects may matter less than earlier research had suggested and that tracking may have substantial benefits. We will show that double-dosed students are exposed to a much lower-skilled group of peers in their algebra classes but nonetheless benefit substantially from the additional instructional time and improved pedagogy. Recent papers on elite exam schools in the U.S. (Abdulkadiroglu et al. 2011, Dobbie and Fryer 2011) and Kenya (Lucas and Mbiti 2013), as well as gifted and talented programs (Bui et al. 2011), all find surprisingly few positive impacts of being exposed to a very different set of peers because of discontinuities in admissions processes. Our results are also consistent with the findings of Duflo et al. (2011) that the benefits of tracking and the better-targeted pedagogy that results from it may outweigh the impact of being exposed to lower-skilled classmates.

The structure of our paper is as follows. In section 2, we describe in detail the double-dose algebra policy. In section 3, we describe the data and offer descriptive statistics about students in our sample. In section 4, we explain the regression discontinuity underlying our identification strategy. In sections 5 and 6, we describe the impact of double-dosing on students' educational experiences, coursework, test scores and educational attainment. In section 7, we discuss the extent to which the policy's impacts varied by student characteristics or schools' adherence to implementation guidelines. In section 8 , we conclude.

\section{Implementing Double-Dose Algebra}

Since the late 1990s, Chicago Public Schools (CPS) have been at the forefront of curriculum reform designed to increase the rigor of student coursework and prepare students for college en- 
trance. Starting with students entering high school in the fall of 1997, CPS raised its graduation requirements to align with the New Basics Curriculum $]^{3}$ CPS eliminated lower-level and remedial courses so that all first-time freshmen would enroll in algebra in 9th grade, geometry in 10th grade and algebra II or trigonometry in 11th grade. Soon after these reforms, CPS officials realized that students were unable to master the new college-prep curriculum. Passing rates in 9th grade algebra were quite low, largely because students entered high school with such poor math skills (Roderick and Camburn 1999).

In response to these low passing rates in 9th grade algebra, CPS launched the double-dose algebra policy for students entering high school in the fall of 2003. Instead of reinstating the traditional remedial courses from previous years, CPS required enrollment in two periods of algebra coursework for all first-time 9th graders testing below the national median on the math portion of the 8th grade Iowa Tests of Basic Skills (ITBS). Such students enrolled for two math credits, a fullyear regular algebra class plus a full-year algebra support class. Double-dose algebra students thus received 90 minutes of math class time every day for a full academic year. The first math course, regular algebra, consisted mostly of class lectures. The second math course, algebra with support or algebra problem solving, focused on building math skills that students lacked. Extended instructional time allowed flexibility in instructional activities for double-dose teachers. For example, the teachers covered materials in a different order than the textbook and used various instructional activities, such as working in small groups, asking probing and open-ended questions, and using board work (Wenzel et al. 2005, Starkel et al. 2006). Our analysis focuses on the first two cohorts of students because the test score-based assignment rule was not followed closely after the second year. We will refer to these as the 2003 and 2004 cohorts.

Prior to the double-dose policy, algebra curricula had varied considerably across CPS high

\footnotetext{
${ }^{3}$ The New Basics Curriculum was a minimum curriculum recommended by the National Commission of Excellence in Education in 1983, which consists of four years of English, three years each of mathematics, science, and social studies, and one-half year of computer science. CPS has more requirements than the New Basics Curriculum, including two years of a foreign language and specific courses in mathematics (i.e., algebra, geometry, advanced algebra and trigonometry).
} 
schools due to the fairly decentralized nature of the district. Conversely, CPS offered teachers of double-dose algebra two specific curricula called Agile Mind and Cognitive Tutor, stand-alone lesson plans they could use, and thrice annual professional development workshops where teachers were given suggestions about how to use the extra instructional time..$^{4}$ Though it is difficult to know precisely what occurred in these extra classes, Nomi and Allensworth (2010) analyzed survey data to learn more about the classroom learning environment. They found that students assigned to double-dose algebra reported much more frequently: writing sentences to explain how they solved a math problem; explaining how they solved a problem to the class; writing math problems for other students to solve; discussing possible solutions with other students; and applying math to situations in life outside of school. Thus, the additional time thus focused on building verbal and analytical skills in the context of learning algebra, and may have conferred benefits in subjects other than math.

In order to provide coherent instruction to students, CPS also strongly advised schools to schedule their algebra support courses in three specific ways. First, double-dose algebra students should have the same teacher for their two periods of algebra. Second, the two algebra periods should be offered consecutively. Third, double-dose students should take their algebra support class with the same students who are in their regular algebra class. Most CPS schools followed these recommendations in the initial year (Nomi and Allensworth 2009). For the 2003 cohort, 80 percent of double-dose students had the same teacher for both courses, 72 percent took the two courses consecutively, and rates of overlap between the two classes' rosters exceeded 90 percent. By 2004,

\footnotetext{
${ }^{4}$ The district made the new double-dose curricula and professional development available only to teachers teaching double-dose algebra courses, but there was a possibility of spillover effects for teachers in regular algebra. However, the professional development was geared towards helping teachers structure two periods of algebra instruction. Moreover, based on CPS officials and staff members' observations of double-dose classrooms, they found that even teachers who taught both single-period and double-dose algebra tended to differentiate their instruction between the two types of classes. Specifically, teachers tended to use new practices with the double-period class, but continued to use traditional methods with the single-period class. Teachers said that they did not feel they needed to change methods with the advanced students (i.e., non double-dose students), and that they were hesitant to try new practices that may be more time-consuming with just a single period. The double period of algebra allowed these teachers to feel like they had the time to try new practices (e.g., cooperative groups).
} 
schools began to object to the scheduling difficulties of assigning the same teacher to both periods, so CPS removed that recommendation. For the 2004 cohort, only 54 percent of double-dose students had the same teacher for both courses and only 48 percent took the two courses consecutively. Overlap between the rosters remained, however, close to 90 percent. Near the end of our analysis, we also explore whether the program's impacts vary by cohort in part because of this variation in implementation.

The treatment under consideration here therefore had multiple components. Assignment to double-dose algebra doubled the amount of instructional time and exposed students to the curricula and activities discussed above. As we will show, the recommendation that students take the two classes with the same set of peers caused tracking by skill to increase, thus reducing classroom heterogeneity. All of these factors were likely to, if anything, improve student outcomes (Duflo et al. 2011). We will also show, however, that the increased tracking by skill placed double-dosed students among substantially lower skilled peers than non-double-dosed students. This factor is likely to, if anything, hurt student outcomes. Our estimates capture the net impact of all of these components.

\section{Data and Descriptive Statistics}

We use longitudinal data from CPS that tracks students from 8th grade through college enrollment. These data include demographic information, detailed high school transcripts, numerous standardized test scores, and graduation and college enrollment information. Our main sample consists of students entering 9th grade for the first time in the fall of 2003 and 2004. We include only students who have valid 8th grade math scores and who enroll in freshman algebra. We include only high schools in which at least one classroom of students was assigned to double-dose algebra. We exclude a small number of selective magnet schools, alternative schools, special education schools and those for older students, as a result of which the final sample includes 73 high schools. For 
continuous outcomes such as test scores, students leaving CPS are missing those values and are excluded from the relevant regressions .55 For binary outcomes, students who leave the CPS school system for any reason are coded as zeroes in some specifications and treated as missing in others. CPS attempts to track students' reasons for leaving though the accuracy of such measures is unclear. In our sample, students who leave CPS are about evenly divided between those who are known dropouts, those who leave for other schools (private schools or public schools outside of Chicago), and those whose reasons for leaving are unknown. For many of the later outcomes, we will estimate impacts of the policy conditional on students still being present in the school system, in order to test the sensitivity of those estimates to potentially selective attrition.

The summary statistics of the analytic sample are shown in Table 1 . The first two columns include the entire sample and the last two include only students in our default regression discontinuity sample, construction of which we detail further below. Panel A shows the full set of available demographic controls, which we include in later regressions. Over 90 percent of CPS students are black or Hispanic and a similar proportion are low income as indicated by participation in the federal subsidized lunch program. Continuous and standardized measures of socioeconomic and poverty status are constructed based on each student's residential block group from the 2000 Census. Only 8 percent of students in the RD sample are in special education because such students tend to score far below the 50th percentile in 8th grade math. The average CPS student is nearly 15 years old on September 1 of the first year of high school. The sample is evenly split between students entering high school in fall of 2003 and fall of 2004. Finally, the average CPS student scores around the 43rd percentile on the 8th grade ITBS reading exam, or the 46th percentile for students in the RD sample.

The first row of panel B shows our running variable, each student's 8th grade score on the math portion of the ITBS, which all CPS 8th graders are required to take. We use each student's first score on the exam to avoid possible endogeneity of scores due to re-testing behavior. Re-testing

\footnotetext{
${ }^{5} \mathrm{We}$ do, however, test the sensitivity of our test score estimates to imputing values for those with missing outcomes.
} 
is, however, unlikely to be problematic as re-testing occurred only for students scoring below the 35th percentile, a threshold for grade promotion. ${ }^{6}$ We also note here that the ITBS exam was taken in April, months after decisions about which Chicago high school to attend are made. The mean CPS 8th grade student scores around the 45th percentile on this nationally normed exam. About 56 percent of CPS students score below the 50th percentile and are thus double-dose eligible. The transcript data reveal, however, that only 45 percent enroll in double-dose algebra, suggesting imperfect compliance with the rule. As a result of double-dosing, the average CPS freshman in our sample takes 1.4 math courses freshman year.

The transcript data also allow for detailed exploration of the treatment itself. We construct variables, shown in the last three rows of panel B, showing the extent to which schools were complying with CPS' guidelines for implementing double-dose algebra. Of double-dosed students, 62 percent had their two algebra courses during consecutive periods and 66 percent had the same teacher for both courses, with 92 percent of double-dosed students' regular algebra classmates themselves in double-dose algebra. Though not shown here, compliance with those guidelines was substantially lower in 2004 than in 2003, consistent with schools' complaints about the difficulty of scheduling double-dose algebra for consecutive periods and with the same teacher.

We focus on two primary sets of outcomes. In panel C, we measure students' academic achievement by constructing a variety of variables measuring grades and standardized test scores. Only 62 percent of the sample receive a D or higher and thus pass algebra freshman year. A similar proportion pass geometry in their second year of high school. Only 50 percent pass trigonometry by their third year of high school. This drop-off is due both to the fact that freshman algebra is a prerequisite for such courses and that substantial numbers of students drop out between freshman and junior years. We also use a variety of test scores standardized by cohort to measure students' mathematical knowledge, including the PLAN exam, which all CPS students take in September of

${ }^{6}$ For more information on this promotion policy, see page 14 of http://ccsr.uchicago.edu/sites/ default/files/publications/p70.pdf. 
both 10th and 11th grade, and the ACT exam, which all CPS students take in April of 11th grade and is commonly used in the Midwest for college applications.

In panel D, we measure educational attainment by constructing measures of high school graduation and college enrollment rates. Students are coded as high school graduates if they received a CPS diploma within four or five years of starting high school. Only 48 percent of CPS students in our sample graduate high school within four years, with another five percent graduating in their fifth year. CPS has matched its data on high school graduates with the National Student Clearinghouse (NSC) data on college enrollment, allowing us to observe initial college enrollment for any CPS student with a high school diploma. The match quality is very high because the vast majority of CPS students who attend college do so at colleges covered by the NSC database. Only 3 percent of CPS high school graduates who enroll in college do so at institutions not covered by NSC.7 We construct indicators for enrollment in college by October 1 of the fifth year after starting high school. Only 28 percent of the sample both graduate from a CPS high school and enroll in college within this time frame, more than half of whom enroll in two-year colleges. We cannot explore college completion rates because many of the two-year colleges CPS students attend report only enrollment and not graduation information to NSC.

\section{Empirical Strategy}

Comparison of the outcomes of students who are and are not assigned to double-dose algebra would yield biased estimates of the policy's impacts given large differences in unobserved characteristics between the two groups of students. To eliminate this potential bias, we exploit the fact that students scoring below the 50th percentile on the 8th grade ITBS math test were required to enroll in double-dose algebra. This rule allows us to identify the impact of double-dose algebra

\footnotetext{
${ }^{7}$ See p. 15 of the Consortium on Chicago School Research's April 2006 publication "From High School to the Future", available at http://ccsr.uchicago.edu/sites/default/files/publications/ Postsecondary.pdf
} 
using a regression discontinuity design applied to the treated cohorts. We use the assignment rule as an exogenous source of variation in the probability that a given student will be double-dosed.

Our empirical specification implements the regression discontinuity approach using the following student-level equations:

$$
\begin{aligned}
Y_{i t} & =\alpha_{0}+\alpha_{1} \text { LowScoring }_{i t}+\alpha_{2} \text { Math }_{i t}+\alpha_{3} \text { LowScoring }_{i t} * \text { Math }_{i t}+\epsilon_{i t} \\
\text { DoubleDose }_{i t} & =\gamma_{0}+\gamma_{1} \text { LowScoring }_{i t}+\gamma_{2} \text { Math }_{i t}+\gamma_{3} \text { LowScoring }_{i t} * \text { Math }_{i t}+\eta_{i t} \\
Y_{i t} & =\beta_{0}+\beta_{1} \text { DoubleDose }_{i t}+\beta_{2} \text { Math }_{i t}+\beta_{3} \text { LowScoring }_{i t} * \text { Math }_{i t}+\mu_{i t}
\end{aligned}
$$

where $Y$ represents an outcome of interest for student $i$ in cohort $t$ and DoubleDose is an indicator for assignment to the extra algebra period. Our running variable is Math8, each student's 8th grade math score re-centered around the eligibility threshold. Because 8th grade math scores are measured by thirds of a percentile, we actually re-center the running variable around 49.5, the midway point between the highest-scoring eligibles and the lowest-scoring ineligibles. Our instrument is LowScoring, an indicator for an 8th grade math score below the 50th percentile.

In equation (1), the LowScoring coefficient $\left(\alpha_{1}\right)$ estimates the reduced form impact of doubledose eligibility on outcomes. Equation (2) represents a first-stage regression in which the LowScoring coefficient $\left(\gamma_{1}\right)$ estimates the impact of double-dose eligibility on the probability of being assigned to the extra algebra period. Though we present a number of graphical versions of the reduced form equations, our tables focus on estimates of the DoubleDose coefficient $\left(\beta_{1}\right)$ from equation (3), in which assignment to double-dose algebra has been instrumented with eligibility. This approach estimates a local average treatment effect, the impact of double-dose algebra on those students treated as a result of the assignment rule. The validity of these estimates depends in part on the assumption that assignment to the treatment or control group affects only compliers, those whose participation is affected by the assignment rule. This assumption would be violated if, for example, the signal of a low 8th grade math score had stigmatizing or other effects on never-takers, those 
who would not enroll in double-dose algebra regardless of the assignment rule. We do not think this is a substantial concern in this context and later placebo tests on untreated cohorts confirm this.

Our default specification runs local linear regressions on either side of the eligibility threshold, as suggested by Imbens and Lemieux (2008). We use an edge kernel of bandwidth determined by the cross-validation method described in Ludwig and Miller (2007). The bandwidth generated by this method for the first stage equation is nine percentiles, which is always lower than the bandwidth generated by the reduced form equations. We thus use nine percentiles as our default bandwidth in instrumental variable specifications, but show that our results are robust to other choices of bandwidth, including the slightly larger optimal bandwidth of 12.7 generated by the method described in Imbens and Kalyanaraman (2012) 8 We include controls for gender, race, free and reduced price lunch status, special education status, the Census block poverty and socioeconomic status measures described above, 8th grade reading score and cohort, and show later that our results are robust to exclusion of such controls. We show results for the full sample and also explore heterogeneity by reading skill. To do so, we separately analyze impacts on poor and good readers, defined as those whose 8th grade reading scores are below and above the 50th percentile. Finally, heteroskedasticity robust standard errors are clustered by value of the running variable to account for its coarse nature, as suggested by Lee and Card (2008).

Before moving onto our main analysis, we perform checks of the validity of the regression discontinuity strategy, as shown in Table 2. In column 1, we check whether the double-dose eligibility threshold is associated with a change in the probability that a given student appears in our main analysis sample. To do so, we construct for all students with valid 8th grade math scores an indicator for appearing in the sample we will use in subsequent analysis. Near the double-dose threshold, 85 percent of students with valid 8th grade math scores appear in our main analysis sample. The remaining 15 percent consist of students who are held back in 8th grade, who leave

\footnotetext{
${ }^{8}$ The optimal bandwidth generated by the method recently proposed by Calonico et al. (2012) is just under 10 , so we do not bother to show it separately.
} 
the CPS system for private schools or other jurisdictions, and who enter the small number of high schools excluded from the sample. The estimates in column 1 suggest little relationship between double-dose eligibility and the probability of appearing in our main analysis sample, implying that eligibility did not impact student decisions about when and where to attend high school. In column 2, we check that the density of 8th grade math scores is smooth around the eligibility threshold, as suggested by McCrary (2008). To do so, we estimate discontinuities in the frequency of 8th grade math scores near the threshold in our main analysis sample. The coefficient estimates suggest the density is quite smooth, providing further evidence both that the eligibility threshold does not affect decisions about high school attendance and that there is no observable manipulation of these test scores by students, teachers or schools. A graphical version of the raw data and regressions predictions corresponding to these two columns can be seen in Figure A.1.

The remaining columns of Table 2 test for discontinuities in any of the observed student-level covariates, to explore whether the eligibility threshold affected the characteristics of students appearing in the main analysis sample. Figure 1 graphs these covariates as a function of 8 th grade math scores. The regression estimates and the figures suggest no clear differences across the threshold for students' race/ethnicity, poverty status, special education status or high school starting age.$^{9}$ Barely eligible students are, however, 4.6 percentage points less likely to be female and score 1.2 percentiles lower in 8th grade reading than do barely ineligible students. We use the untreated 2001 and 2002 cohorts to estimate the relationship between all of these covariates and high school graduation within five years, then use these estimates to generate a predicted probability of high school graduation for the treated cohorts. Column 10 of Table 2 and the last panel of Figure 1 show a marginally significant discontinuity in this predicted outcome, suggesting that the treatment group is slightly more disadvantaged than their 8th grade math scores alone would predict. This is partially an artifact of the bandwidth being used, with larger bandwidths showing

\footnotetext{
${ }^{9}$ For brevity, we omit from this table a few covariates that show no discontinuity, including reduced price lunch status, Census block poverty and socioeconomic status measures, and cohort indicators.
} 
no statistically significant covariate imbalance. Because of this slight imbalance, which would cause slight underestimation of any positive impacts of double-dosing, we choose to include the demographic controls described above in our default regression specification. We show later that our main results are robust to this choice.

\section{The Treatment}

We first explore the treatment itself to learn more about how the double-dose algebra policy changed students' freshman year experiences. Panel A of Figure 2 shows the first-stage relationship between 8th grade math scores, the running variable, and the probability of being double-dosed, the endogenous treatment. We see a large but fuzzy discontinuity, suggesting strong but imperfect compliance, with assignment rates reaching a maximum of about 80 percent for students in the 2040th percentiles. Students in the lowest percentiles had lower double-dose rates because they were more likely to be supported through other, special education programs. ${ }^{10}$ Students in the 40-49th percentiles had slightly lower compliance rates, likely because some were determined to be close enough to the threshold as to not require such intervention. Some students above the threshold were double-dosed, likely because teachers thought they would benefit from the course or because schools could not perfectly divide students into appropriately sized classes by the assignment rule.

Column 1 of Table 3 shows the regression estimate of that first-stage discontinuity, with a graphical version in panel B of Figure 2. Students just below the eligibility threshold are 38.4 percentage points more likely to be double-dosed than students just above the threshold. The F-test of the excluded instrument exceeds 250 , well above the threshold needed for a strong instrument. The magnitude of the discontinuity is nearly identical for poor and good readers 11

\footnotetext{
${ }^{10}$ Our central results are unchanged if special education students are excluded from the regression discontinuity analysis, in part because such students tend to be far below the eligibility threshold.

${ }^{11}$ Table A.1 shows first-stage results for various sub-samples of students. The discontinuity in assignment to doubledose algebra is 50.8 percentage points in fall 2003, about twice as large as the 25.8 percentage point discontinuity in fall 2004, suggesting that the assignment rule was followed more strictly in the first year of the policy than in the second. The remainder of the table shows no apparent first-stage heterogeneity by gender or income. Black and
} 
The remaining columns of the Table 3 show instrumental variables estimates of various aspects of the double-dose treatment itself. Column 2 shows the most obvious impact, namely that doubledosed students took one additional math course as a result of the policy ${ }^{12}$ Columns 3-8 show that this additional course came at the expense of other coursework. Relatively few of those replaced courses were in the core subjects of science, English and social studies. Many more were music and art courses and, to a lesser extent, vocational education and foreign language courses. Doubledose algebra did not replace physical education or health courses. As a result, double-dosing did not significantly change the total number of courses taken by students. Columns 9 and 10, as well as Figure 3, show how the requirement that double-dosed students have the same classmates in both their double-dose and regular algebra periods substantially increased tracking by math skill, where skill is measured by peers' 8 th grade math scores. Double-dosing lowered the mean math skill of students' regular algebra peers by nearly 20 percentiles and reduced the standard deviation of peers' math skills by over 3 percentiles. These changes in peer composition were quite similar for poor and good readers.

In summary, double-dosing doubled instructional time in math, replaced largely elective courses, so that total coursework was unchanged, increased the homogeneity of algebra classrooms, and exposed students to lower-skilled peers in algebra class. The net effect of these changes is theoretically unclear, given prior evidence that increased instructional time and peer homogeneity may be helpful while decreased peer quality may be harmful. Students may also be discouraged by the replacement of elective courses that some enjoy more than traditional academic courses. We now turn to empirical analysis of the overall impact of these various channels on coursework, test scores and educational attainment.

Hispanic students show similar first stages, though the small number of white students in CPS are about half as likely to be double-dosed as a result of the assignment rule. We later show that, though the first-stage estimates vary by cohort and for white students, instrumental variables estimates of the program's effect on various outcomes do not.

${ }^{12}$ These estimates would be exactly equal to one if not for a small number of students who complete only a semester of double-dose algebra, rather than a full year. 


\section{Educational Outcomes}

\subsection{Coursework}

The theory behind the double-dose policy is that additional instructional time and other aspects of the treatment should improve students' performance in their freshman algebra classes, with the hope that such improvement leads to success in later coursework. We explore this in Table 4. which presents estimates of the impact of double-dosing on a variety of freshman coursework measures. The estimates from column 1 suggest that double-dosing improved students' grades in their regular freshman algebra classes by over 0.4 points on a 4.0 scale. Nearly all of this improvement was driven by poor readers, who experienced more than 0.6 point rise in algebra GPA. The reduced form versions of these estimates are presented graphically in Figure 4. This improvement in algebra grades occurred across the grade distribution, as shown in columns 2-5. Perhaps most importantly, double-dosed students were a marginally significant 9.3 percentage points more likely to pass freshman algebra. Poor readers' pass rates increased by an even larger and statistically significant 13.2 percentage points. The reduced form versions of these estimates are presented graphically in Figure 5. Given an overall 62 percent algebra pass rate for barely ineligible students, these estimates suggest that double-dosing reduced failure rates by about one-fourth (9.3/38), or more than one-third among poor readers (13.2/36). Double-dosing also substantially improved the fraction of students receiving B's and C's, though had little effect on the receipt of A's.

Though it is difficult to measure spillover effects onto other subjects because the composition of non-math coursework changed as a result of the policy, columns 6 and 7 show little evidence that assignment to double-dose algebra either increased or decreased grade point averages in other types of classes. Perhaps most relevant to the ultimate outcome of high school graduation is the number of credits students earned, shown in columns 8 and 9. Double-dosed students, unsurprisingly, earned nearly a full additional math credit, most of which is due to the additional double-dose period and some of which is due to the increased pass rates in regular algebra. Poor readers' math 
credits increased more than did good readers', in part because good readers' pass rates in regular algebra were not improved by the intervention and because good readers were more likely than poor readers to have earned credits in the classes replaced by double-dose algebra. The net result is that poor readers earned a marginally significant additional 0.6 total credits during freshman year, while good readers earned 0.4 fewer credits.

Because of the tracking induced by this policy, these RD estimates compare barely eligible students, who on average are high-skilled relative to their algebra peers, to barely ineligible students, who on average are low-skilled relative to their algebra peers. That double-dosing improved freshman algebra grades may thus reflect actual performance in class or may reflect teachers' use of a grading curve. To distinguish these explanations, we turn to course performance in subsequent years of high school, when the tracking induced by the policy was no longer a factor in classroom assignment. Table 5 examines outcomes in the second year of high school. In column 1, we see no evidence that double-dosing changed the probability that a student would be present in the second year of high school, where presence is defined by enrolling in at least one credit of coursework ${ }^{13}$ Columns 2 and 3 estimate the impact of double-dosing on the probability of taking geometry in the second year, which indicates a student is on track to graduate. Column 2 assigns zeroes to students no longer present in CPS, whereas column 3 conditions the sample on being present. Both sets of estimates tell a consistent story that double-dosed students were 7-9 percentage points more likely to take geometry in their second year of high school, a result driven entirely by a 13-16 percentage point increase for poor readers. These magnitudes are nearly identical to the improved pass rates in freshman algebra, suggesting that students prevented from freshman failure by the double-dose policy continued to be on track to graduate in their second year of high school.

Columns 4-6 estimate the impact of double-dosing on the probability of passing geometry in a student's second year of high school. We assign zeroes to all students not present in CPS or who are in CPS but not taking geometry, usually because they are being required to repeat algebra. Column

\footnotetext{
${ }^{13}$ The reduced form versions of these estimates are presented graphically in Figure A.2.
} 
4 thus includes all students, column 5 conditions the sample on being present in CPS, and column 6 conditions the sample on being present in CPS and taking geometry. The first two columns indicate the double-dosing increased the geometry pass rate by a substantial and significant 12-14 percentage points, driven largely by an 18-21 percentage point increase for poor readers. Figure 6 shows this clear discontinuity, graphing the reduced form version of column 4. The estimates in column 6 are roughly two-thirds that size, suggesting that about one-third of the improvement is due to the increase in the fraction of students taking geometry, while the remaining two-thirds comes from students who would, in the absence of the double-dose policy, have taken but failed geometry.

As a result of these increased geometry pass rates, students who were double-dosed in their first year of high school earn 0.07-0.09 additional math credits in their second year, as seen in columns 7 and 8 . All of this increase is driven by poor readers, who earned $0.15-0.18$ additional second-year math credits as a result of double-dosing. There also seem to be positive spillovers into non-math subjects. Columns 9 and 10 suggest that double-dosed students earn a total of 0.43-0.57 additional total credits, all of which is driven by poor readers earning more than one full additional second-year credit. These magnitudes are roughly six times the size of the impacts on math credits, suggesting that double-dosing had substantial positive spillover effects onto other subjects.

Table 6 summarizes the impact of double-dosing in the third and fourth years of high school. Double-dosing increases the probability of being present in the third year by a large but statistically insignificant 5.9 percentage points, or 7.9 percentage points for poor readers.$^{14}$ There is no statistically significant indication of increased math credit earning, though the magnitude of the impact on poor readers is a fairly large 0.65 credits. Fourth year results are similar, with doubledosing increasing the probability of being present in the fourth year by 6.8 percentage points, or 10.3 percentage points for poor readers.$^{15}$ Double-dosed students earn a marginally significant 0.6

\footnotetext{
${ }^{14}$ The reduced form versions of these estimates are presented graphically in Figure A.3

${ }^{15}$ The reduced form versions of these estimates are presented graphically in Figure A.4
} 
more credits in their fourth year, or a significant 0.78 credits for poor readers, relatively little of which consists of additional math credits. In both the third and the fourth years, roughly half of the increase in credits earned stems from the increased probability of being present at all, as can been by comparing column 4 to column 5 and column 9 to column 10 .

In summary, double-dose algebra had large and positive impacts on a variety of coursework measures. Double-dosed students, and particularly poor readers, performed substantially better in freshman algebra and were more likely to pass that course. There is little evidence that the policy affected performance in freshman non-math courses. Second-year performance also improved substantially, with double-dosed students more likely to take and pass geometry, as well as earn more total credits. The magnitude of the estimates also suggests that double-dosing increased the probability that a student was present in CPS in their third and fourth year of high school, though those estimates are not statistically significant.

\subsection{Test Scores}

Further evidence of the benefits of the treatment comes from Table 7, which explores the impact of double-dosing on math test scores, as measured by the PLAN exams taken in October of 10th and 11th grades and the ACT exam taken in April of 11th grade. Each of these exams test a variety of algebra and geometry concepts. For each exam, we explore three outcomes, the probability that a student took the math portion of the exam (a noisy indicator of being on track to graduate), standardized exam scores conditional on taking the exam, and standardized scores on the verbal portion of the exam. Column 1 shows that double-dosed students were a statistically insignificant 4.5 percentage points more likely to take the fall 10th grade exam, driven by a marginally significant 10.2 percentage point increase for poor readers. For those who took the exam, double-dosing raised math scores by a statistically insignificant 0.09 standard deviations, driven by a marginally significant 0.18 standard deviation increase for poor readers $\sqrt{16}$ Verbal scores rose by a statistically

\footnotetext{
${ }^{16}$ The reduced form versions of these estimates are presented graphically in Figure A.5
} 
insignificant 0.11 standard deviations.

Larger positive impacts are seen in the fall 11th grade and spring 11th grade exams, perhaps consistent with the dramatically improved second-year coursework performance previously discussed. Double-dosed students were a marginally significant 6.5 percentage points more likely to take the fall 11th grade exam (consistent with the magnitude of the increased probability of being present in the third year), and those who took the exam improved by a significant 0.24 standard deviations. Poor readers improved by 0.32 standard deviations. The reduced form versions of these estimates are presented graphically in Figure 7. ACT math scores improved by a similar and highly significant 0.18 standard deviations. ${ }^{17}$ Interestingly, improvements on the ACT math exam were quite similar for poor and good readers. ACT verbal scores increased by a highly significant 0.27 standard deviations, driven largely by a 0.45 standard deviation improvement for good readers. The ACT exam is one measure of achievement that, unlike coursework, double-dosing greatly improved for good readers.

One potential concern with these estimates is that differential selection into test-taking caused by double-dosing might generate bias in these results. We check this possibility in Table A.2 by re-estimating the effects of double-dose algebra on all three math scores, under three different assumptions about attrition. Under the first assumption, we assign each student missing a test score to the z-score equivalent of their 8th grade math percentile score, assuming no change in their overall place in the distribution. Under the second assumption, we assign those missing scores a 40th percentile score, equivalent to the bottom end of the RD sample used here. Under the third assumption, we assign those missing scores a 60th percentile score, equivalent to the top end of the RD sample used here. We thus test the sensitivity of our estimates to different assumptions about the achievement of attriting students. These assumptions tend to lower the magnitude of the estimated impacts. The fall 11th grade PLAN and ACT exam scores improvements, for example, now fall into the 0.08-0.14 range, about half of the previous estimates. Nonetheless, all but one of

\footnotetext{
${ }^{17}$ The reduced form version of this estimate is presented graphically in Figure A.6
} 
these estimates is statistically significant, which we take as strong evidence of small improvements in math achievement as measured by these exams.

\subsection{Educational Attainment}

We have seen clear evidence that double-dosing substantially improves freshman and sophomore course performance and credits earned, and has small positive effects on standardized exam performance. We have also seen suggestive evidence that double-dosing increases the probability of students being present in their third and fourth years of high school, as measured by rates of credit-taking and test-taking. We now turn to evidence about the impact of double-dose algebra on educational attainment.

Table 8 explores the impact of double-dosing on high school graduation rates. The first three columns estimate credit accumulation over the first four years of high school, with dropouts coded as earning zero credits in years when they are not present in high school. The estimates in column 1 suggest that double-dosing increased by one the total number of math credits students earned in the first four years of high school. Much of this increase was due to the double-dose period itself but poor readers, whose credits increased by 1.25 , also benefited from increased passing rates in algebra and geometry. In total, double-dosing raised total credits earned by a statistically insignificant 1.47 , driven by poor readers earning a significant three additional credits. The reduced form versions of these estimates are presented graphically in Figure 8. Measured differently, double-dosing increased by a highly significant 8.5 percentage points the probability that a student completed at least 24 credits, the minimum necessary to graduate from a CPS high school. This was driven by a 12.9 percentage point rise for poor readers.

The last three columns of Table 8 estimate impacts on high school graduation within four or five years of entering high school. The first two of these columns code as zeroes any student who fails to graduate from CPS, including those who may have attrited to other school districts. The last columns limit the sample to students present in their fourth year of high school. Double- 
dosing raises the four-year graduation rates by 9.8 percentage points, driven largely by a 13.7 percentage point increases for poor readers. These magnitudes are quite similar to those in column 3, suggesting that the extent of increased credit accumulation is comparable to the high school graduation effect. Five-year graduation rates increase even more than do four-year rates, suggesting that some of the marginal students affected by double-dosing use a fifth year to earn their final credits. The reduced form versions of these estimates are presented graphically in Figure 9. Finally, estimates in column 6 are about one-third the magnitude of those in column 5. This suggests that most of the impact on high school graduation comes not from helping fourth-year students earn their final credits but instead from helping students reach their third and fourth year at all.

Because CPS has linked its high school graduates with records from the National Student Clearinghouse, we can also observe the impact of double-dose algebra on college enrollment. The first four columns of the table treat any student not enrolling in college as a zero, including students who fail to graduate from CPS and are thus not linked to NSC records. Double-dosing increases by 10.8 percentage points the probability that students enroll in any type of college within five years of starting high school (i.e. within one year of on-time high school graduation). The reduced form version of this estimate is presented graphically in Figure 10 . Columns 2 and 3 show that most of this effect comes from enrollment in two-year community colleges, particularly part-time enrollment, an expected result given the relatively low academic skills and high poverty rates of CPS students near the double-dose threshold. Within eight years of entering high school (that is, within four years of on-time high school graduation), double-dosing increases by a marginally significant 0.63 the number of semesters students have been enrolled in college 18

This observed college enrollment increase is, unlike most of the prior credit-earning measures, driven fairly equally by both poor and good readers. If anything, good readers' college enrollment is more dramatically affected, with double-dosing increasing the number of semesters enrolled by

\footnotetext{
${ }^{18}$ Technically, the NSC allows measurement of enrollment spells, not semesters. Here we weight such spells by 0.5 for half-time enrollment and 0.25 for less than half-time enrollment.
} 
nearly one. This may be related to the observed increase in good readers' ACT scores. Doubledose algebra may have helped poor readers largely through the credit-earning and high school graduation channel, while good readers' benefited more through the achievement channel. Conditioning the sample on high school graduation in columns 5-8, rather than assigning zeroes to those who fail to graduate, has relatively little effect on the overall point estimates, with those of poor readers falling but those of good readers rising.

\subsection{Heterogeneity, Robustness and Implementation}

Our primary results suggest that double-dose algebra improved a variety of student outcomes. Most of this improvement was driven by the sub-group of students we have identified as poor readers, perhaps because of the emphasis on building verbal and analytical skills in the context of learning freshman algebra. We focus on this particular dimension of heterogeneity in part because we find little evidence that other dimensions are interesting. In Table A.3, we explore heterogeneity by other student characteristics by taking our default specification and interacting both the instrument (double-dose eligibility) and the endogenous regressor (double-dose assignment) with indicators for three types of students. The top panel divides students by gender, the second divides them by those living above and below the median Census block poverty level within CPS, and the third divides students by race, with the white category including a small number of Asian students and those listing race as "other". At the bottom of each column is a p-value from a test of the equality of the coefficients. There is no evidence of heterogeneity by gender or income across any of the six major outcomes examined here, nor across many other outcomes explored but not shown here. There is no evidence of differential effects on algebra passing rates by race, with nearly identical point estimates for black, Hispanic and white students. There is evidence that black students' geometry pass rates increased more than those of Hispanic and white students, though no evidence that total credits earned were differentially affected by race. Double-dosing improved black students' high school graduation rates by 12.6 percentage points, a magnitude 
marginally significantly different from the 7.6 percentage point increase seen for Hispanic students. Black students' college enrollment rates increased by a highly significant 15.3 percentage points, a magnitude significantly different from Hispanic students, who saw no increase, but statistically indistinguishable from white students. Overall, these results suggest that black students benefited more from double-dosing than did other students, but only with respect to some outcomes.

Table A.4 tests the robustness of our main results to a variety of changes in regression specification, with panel A showing results for all students and panel B focusing on poor readers. The top row of each panel repeats our estimates from the default specification using the cross-validation (CV) bandwidth of nine percentiles and including demographic controls. The second row uses the same specification but removes the demographic controls. The third row repeats the default specification but expands the bandwidth to 12.7, that suggested as optimal by the Imbens-Kalyanaraman (IK) procedure applied to the first stage. The fourth row shows a bandwidth of 5, roughly $50 \%$ of the cross-validation bandwidth. The magnitude and statistical significance of our main results is largely robust to this variety of specifications. The fifth and final row of each panel shows reduced form versions of our default specification using the untreated 2001 and 2002 cohorts who entered CPS prior the double-dose policy's enactment. None of those estimates are statistically significant. This placebo test reassures us that the observed discontinuities in outcomes start appearing only in the years after the policy was enacted.

Finally, Table A.5 explores how the impact of double-dose algebra varied by the extent to which schools adhered to CPS' recommendation that schools schedule the two periods consecutively, with the same teacher and with the same students in each class. We construct a compliance measure that represents a school-level average of the fraction of double-dosed students with the same teacher for both algebra periods, the fraction with the two periods consecutive, and the fraction of peers in algebra who were also double-dosed. The measure thus takes a value of one in schools with perfect compliance and less than one otherwise, though we re-center the measure around the average compliance level. We then interact that re-centered measure with the instrument 
and the endogenous regressor in panel A to produce two estimates. The main coefficient estimates the impact of double-dose algebra on students in a school with an average compliance level. The interaction coefficient measures the extent to which the treatment effects varies in schools with higher compliance rates. We see no clear evidence of differential effectiveness in schools with higher compliance rates. In panel B, we interact the instrument and endogenous regressor with an indicator for being in the 2004 cohort, so that the main coefficient estimates impacts on the 2003 cohort and the interaction estimates differences between the two cohorts. We see no clear evidence of differential impact by cohort. Given that schools in 2004 were much less likely to adhere to the implementation guidelines, these panels together tell a consistent story that such guidelines were not particularly important to the policy's success.

\section{Conclusion}

The double-dose strategy has become an increasingly popular way to aid students struggling in mathematics. Today, nearly half of large urban districts report doubled math instruction as the most common form of support for students with lower skills (Council of Great City Schools 2009). The central concern of urban school districts is that algebra may be a gateway for later academic success, so that early high school failure in math may have large effects on subsequent academic achievement and graduation rates. As the current policy environment calls for algebra for all in 9th grade or earlier grades, providing an effective and proactive intervention is particularly critical for those who lack foundational mathematical skills. A successful early intervention may have the greatest chance of having long-term effects on students' academic outcomes.

We provide evidence of positive and substantial long-run impacts of one particular form of intensive math instruction on credits earned, test scores, high school graduation and college enrollment rates. We show that this intensive math instruction was more successful for students with relatively low reading skills. There are two potential explanations for this. First, the intervention's 
focus on verbal exposition of mathematical concepts may have been particularly important for poor readers. Second, the intervention may have been more effective for those with poorer underlying math skills. Our regression discontinuity coefficients estimate a local average treatment effect for students near the 50th percentile of math skill as measured by their 8th grade math exam. That single measure is necessarily a noisy measure of true math skill, so that a low reading score may signal that a student is weaker in math than his math score suggests. Either way, these results highlight the importance of carefully targeting such interventions to students most likely to benefit from them.

Also, like other recent studies, we find that the test score impacts of this policy dramatically understate its long-run benefits as measured by educational attainment (Deming 2009, Chetty et al. 2011). In our sample, OLS estimates suggest that a 0.2 standard deviation increase in fall grade 11 math scores, the upper end of our estimated treatment effect, is associated with a 2 percentage point increase in college enrollment rates. We observe college enrollment effects roughly four times that size, highlighting the fact that long-run analyses of such interventions may yield very different conclusions than short-run analyses.

Finally, our finding that the policy's effectiveness is not associated with the adherence to the implementation guidelines encouraged by CPS suggests that these impacts could be replicated in other urban school districts across the United States. Districts looking to adopt the double-dose strategy could likely reap its benefits without needing to radically restructure their school days, a welcome fact given the need to boost math performance in an environment with substantial resource constraints. 


\section{References}

Abdulkadiroglu, A., J. D. Angrist, and P. A. Pathak (2011). The elite illusion: Achievement effects at Boston and New York exam schools. Working Paper 17264, National Bureau of Economic Research.

Allensworth, E. and J. Q. Easton (2005). The On-Track Indicator as a Predictor of High School Graduation. Chicago: University of Chicago Consortium on Chicago School Research.

Allensworth, E. and J. Q. Easton (2007). What Matters for Staying on Track and Graduating in Chicago Public High Schools, Volume 17. Chicago: University of Chicago Consortium on Chicago School Research.

Allensworth, E., T. Nomi, N. Montgomery, and V. E. Lee (2009). College preparatory curriculum for all: Academic consequences of requiring algebra and English I for ninth graders in Chicago. Educational Evaluation and Policy Analysis 31(4), 367-391.

Altonji, J. G. (1995). The effects of high school curriculum on education and labor market outcomes. The Journal of Human Resources 30(3), 409-438.

Angrist, J. D., P. A. Pathak, and C. R. Walters (2013). Explaining charter school effectiveness. American Economic Journal: Applied Economics, forthcoming.

Attewell, P. and T. Domina (2008). Raising the bar: Curricular intensity and academic performance. Educational Evaluation and Policy Analysis 30(1), 51-71.

Bettinger, E. P. and B. T. Long (2009). Addressing the needs of underprepared students in higher education. The Journal of Human Resources 44(3), 736-771.

Boatman, A. and B. T. Long (2010). Does remediation work for all students? How the effects of postsecondary remedial and developmental courses vary by level of academic preparation. Working paper, National Center for Postsecondary Research.

Bui, S. A., S. G. Craig, and S. A. Imberman (2011). Is gifted education a bright idea? Assessing the impact of gifted and talented programs on achievement. Working Paper 17089, National Bureau of Economic Research.

Calcagno, J. C. and B. T. Long (2008). The impact of postsecondary remediation using a regression discontinuity approach: Addressing endogenous sorting and noncompliance. Working Paper 14194, National Bureau of Economic Research.

Calonico, S., M. D. Cattaneo, and R. Titiunik (2012). Robust nonparametric bias-corrected inference in the regression discontinuity design. Technical report, Working paper, University of Michigan. 
Checkoway, A., B. Boulay, B. Gamse, M. Caven, L. Fox, K. Kliorys, R. Luck, K. Maree, M. Velez, and M. Woodford (2011). Evaluation of the expanded learning time initiative year four integrated report: 2009-10. Annual report, Abt Associates Inc., Cambridge, Mass.

Chetty, R., J. N. Friedman, N. Hilger, E. Saez, D. Schanzenbach, and D. Yagan (2011). How does your kindergarten classroom affect your earnings? Evidence from project STAR. The Quarterly Journal of Economics 126(4), 1593-1660.

Clotfelter, C. T., H. F. Ladd, and J. L. Vigdor (2012). The aftermath of accelerating algebra: Evidence from a district policy initiative. Working Paper 18161, National Bureau of Economic Research.

Cooper, H., B. Nye, K. Charlton, J. Lindsay, and S. Greathouse (1996). The effects of summer vacation on achievement test scores: A narrative and meta-analytic review. The Review of Educational Research 66(3), 227-268.

Deming, D. (2009). Early childhood intervention and life-cycle skill development: Evidence from head start. American Economic Journal: Applied Economics 1(3), 111-134.

Dobbie, W. and R. G. Fryer (2011). Exam high schools and academic achievement: Evidence from New York City. Working Paper 17286, National Bureau of Economic Research.

Dobbie, W. and R. G. Fryer (2013). Getting beneath the veil of effective schools: Evidence from New York City. American Economic Journal: Applied Economics, forthcoming.

Dougherty, S. M. (2013). Bridging the discontinuity in adolescent literacy: Evidence of an effective middle grades intervention. Education Finance and Policy, forthcoming.

Duflo, E., P. Dupas, and M. Kremer (2011). Peer effects, teacher incentives, and the impact of tracking: Evidence from a randomized evaluation in Kenya. The American Economic Review 101, 1739-1774.

Fitzpatrick, M., D. Grissmer, and S. Hastedt (2011). What a difference a day makes: Estimating daily learning gains during kindergarten and first grade using a natural experiment. Economics of Education Review 30(2), 269-279.

Fryer, R. G. (2011). Injecting successful charter school strategies into traditional public schools: Early results from an experiment in Houston. Working Paper 17494, National Bureau of Economic Research.

Fryer, R. G. and S. D. Levitt (2004). Understanding the black-white test score gap in the first two years of school. The Review of Economics and Statistics 86(2), 447-464.

Goodman, J. (2012a). Flaking out: Snowfall, disruptions of instructional time, and student achievement. Working paper, HKS Faculty Research Working Paper Series. 
Goodman, J. (2012b). The labor of division: Returns to compulsory math coursework. Working paper, HKS Faculty Research Working Paper Series.

Heckman, J. J. and P. A. LaFontaine (2010). The American high school graduation rate: Trends and levels. The Review of Economics and Statistics 92(2), 244-262.

Herlihy, C. (2007). State and district-level support for successful transitions into high school. Policy brief, National High School Center.

Horwitz, A. and J. Snipes (2008). Supporting Successful Transitions to High School. Washington, DC: Council of Great City Schools.

Hoxby, C. M. and S. Murarka (2009). Charter schools in New York City: Who enrolls and how they affect their students' achievement. Working Paper 14852, National Bureau of Economic Research.

Imbens, G. and K. Kalyanaraman (2012). Optimal bandwidth choice for the regression discontinuity estimator. The Review of Economic Studies 79(3), 933-959.

Imbens, G. W. and T. Lemieux (2008). Regression discontinuity designs: A guide to practice. Journal of Econometrics 142(2), 615-635.

Jacob, B. A. and L. Lefgren (2004). Remedial education and student achievement: A regressiondiscontinuity analysis. The Review of Economics and Statistics 86(1), 226-244.

Joensen, J. S. and H. S. Nielsen (2009). Is there a causal effect of high school math on labor market outcomes? The Journal of Human Resources 44(1), 171-198.

Lavy, V. (2010). Do differences in school's instruction time explain international achievement gaps in math, science, and reading? Evidence from developed and developing countries. Working Paper 16227, National Bureau of Economic Research.

Lavy, V. and A. Schlosser (2005). Targeted remedial education for underperforming teenagers: Costs and benefits. Journal of Labor Economics 23(4), pp. 839-874.

Lee, D. S. and D. Card (2008). Regression discontinuity inference with specification error. Journal of Econometrics 142(2), 655-674.

Levine, P. B. and D. J. Zimmerman (1995). The benefit of additional high-school math and science classes for young men and women. Journal of Business \& Economic Statistics 13(2), 137-149.

Long, M. C., D. Conger, and P. Iatarola (2012). Effects of high school course-taking on secondary and postsecondary success. American Educational Research Journal 49(2), 285-322.

Long, M. C., P. Iatarola, and D. Conger (2009). Explaining gaps in readiness for college-level math: The role of high school courses. Education Finance and Policy 4(1), 1-33. 
Lucas, A. M. and I. M. Mbiti (2013). Effects of school quality on student achievement: Discontinuity evidence from Kenya. American Economic Journal: Applied Economics, forthcoming.

Ludwig, J. and D. L. Miller (2007). Does head start improve children's life chances? evidence from a regression discontinuity design. The Quarterly Journal of Economics 122(1), 159-208.

Marcotte, D. E. and S. W. Hemelt (2008). Unscheduled school closings and student performance. Education Finance and Policy 3(3), 316-338.

Martorell, P. and I. McFarlin (2011). Help or hindrance? The effects of college remediation on academic and labor market outcomes. The Review of Economics and Statistics 93(2), 436-454.

McCrary, J. (2008). Manipulation of the running variable in the regression discontinuity design: A density test. Journal of Econometrics 142(2), 698-714.

Nomi, T. and E. Allensworth (2009). Double-Dose algebra as an alternative strategy to remediation: Effects on students' academic outcomes. Journal of Research on Educational Effectiveness 2(2), 111-148.

Nomi, T. and E. Allensworth (2010). The effects of tracking with supports on instructional climate and student outcomes in high school algebra. Working paper, University of Chicago Consortium on Chicago School Research.

Roderick, M. and E. Camburn (1999). Risk and recovery from course failure in the early years of high school. American Educational Research Journal 36(2), 303-343.

Rose, H. and J. R. Betts (2004). The effect of high school courses on earnings. The Review of Economics and Statistics 86(2), 497-513.

Scott-Clayton, J. and O. Rodriguez (2012). Development, diversion, or discouragement? A new framework and new evidence on the effects of college remediation. Working Paper 18328, National Bureau of Economic Research.

Starkel, R., J. Martinez, and K. Price (2006). Two-Period Algebra in the 05-06 School Year: Implementation Report. Chicago: Chicago Public Schools.

Taylor, E. (2012). Allocating more of the school day to math: Regression-discontinuity estimates of returns and costs. Working paper, Stanford University.

Wenzel, S. A., K. Lawal, B. Conway, C. R. Fendt, and S. R. Stoelinga (2005). Algebra problem solving teachers talk about their experiences, december 2004. Data brief, UIC CMSI Evaluation Project. 
Figure 1: Covariates as a Function of 8th Grade Math Scores
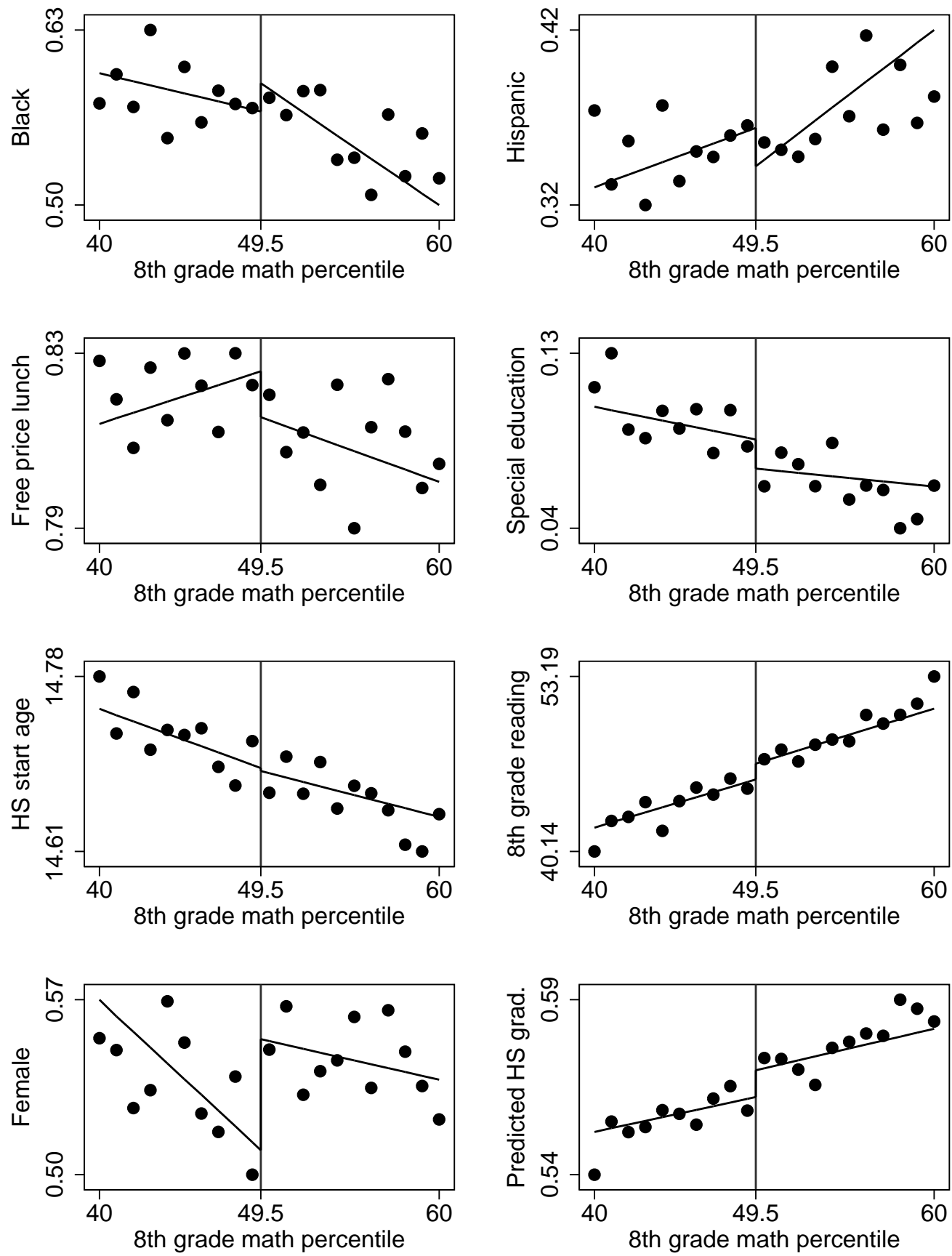

Notes: Each panel shows mean value of a given covariate by 8th grade math score, as well as the predicted values generated by the default regression specification described in the text. 
Figure 2: The Probability of Being Double-Dosed

(A) Full sample

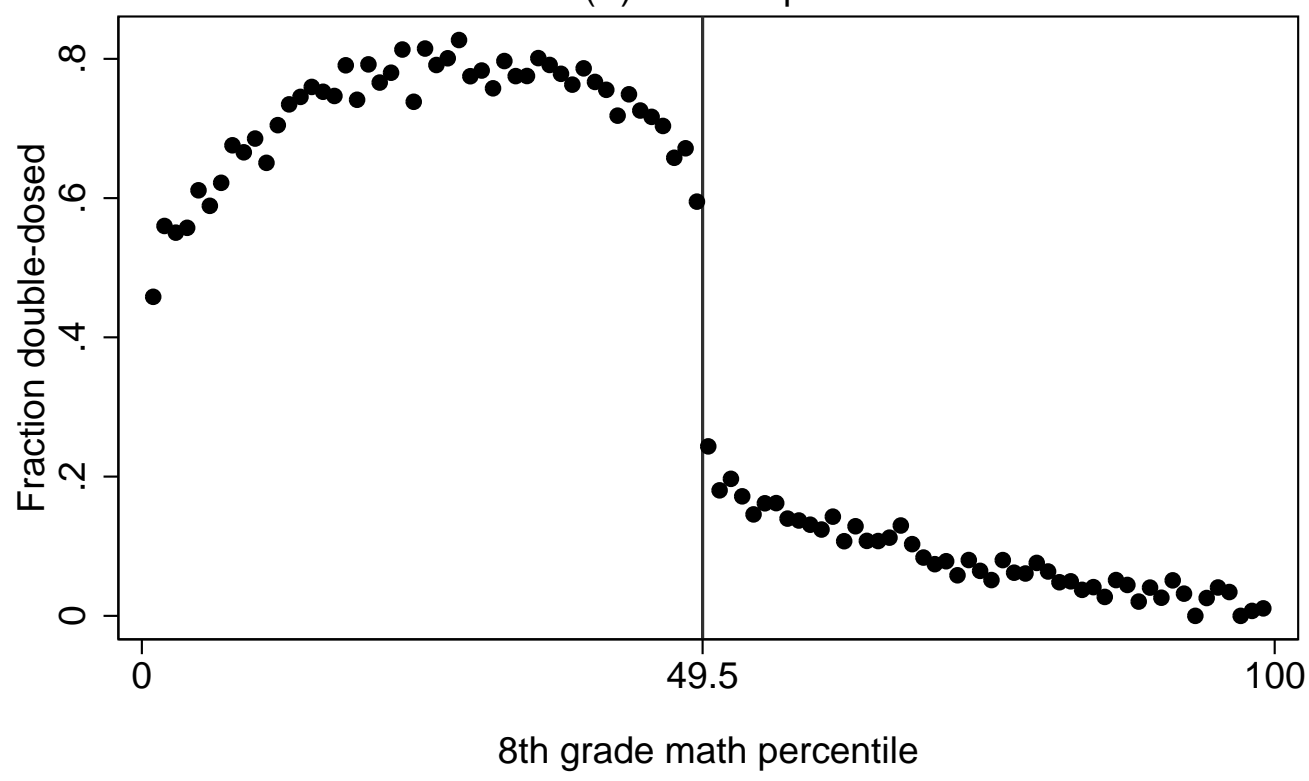

(B) Near eligibility threshold

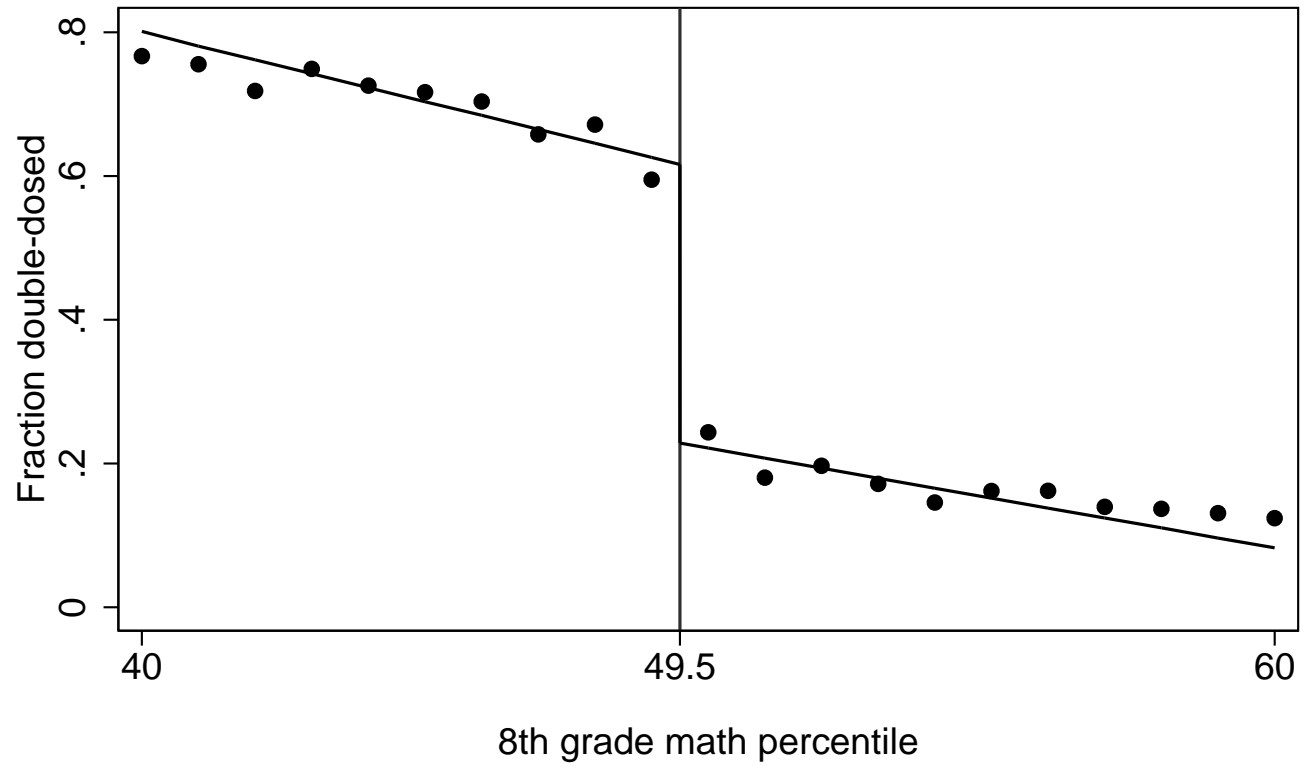

Notes: Panel A shows the fraction of students double-dosed by 8th grade math score for the full sample. Panel B limits the sample to students near the eligibility threshold and shows predicted values generated by the default regression specification described in the text. 
Figure 3: Peer Composition of Freshman Algebra Class

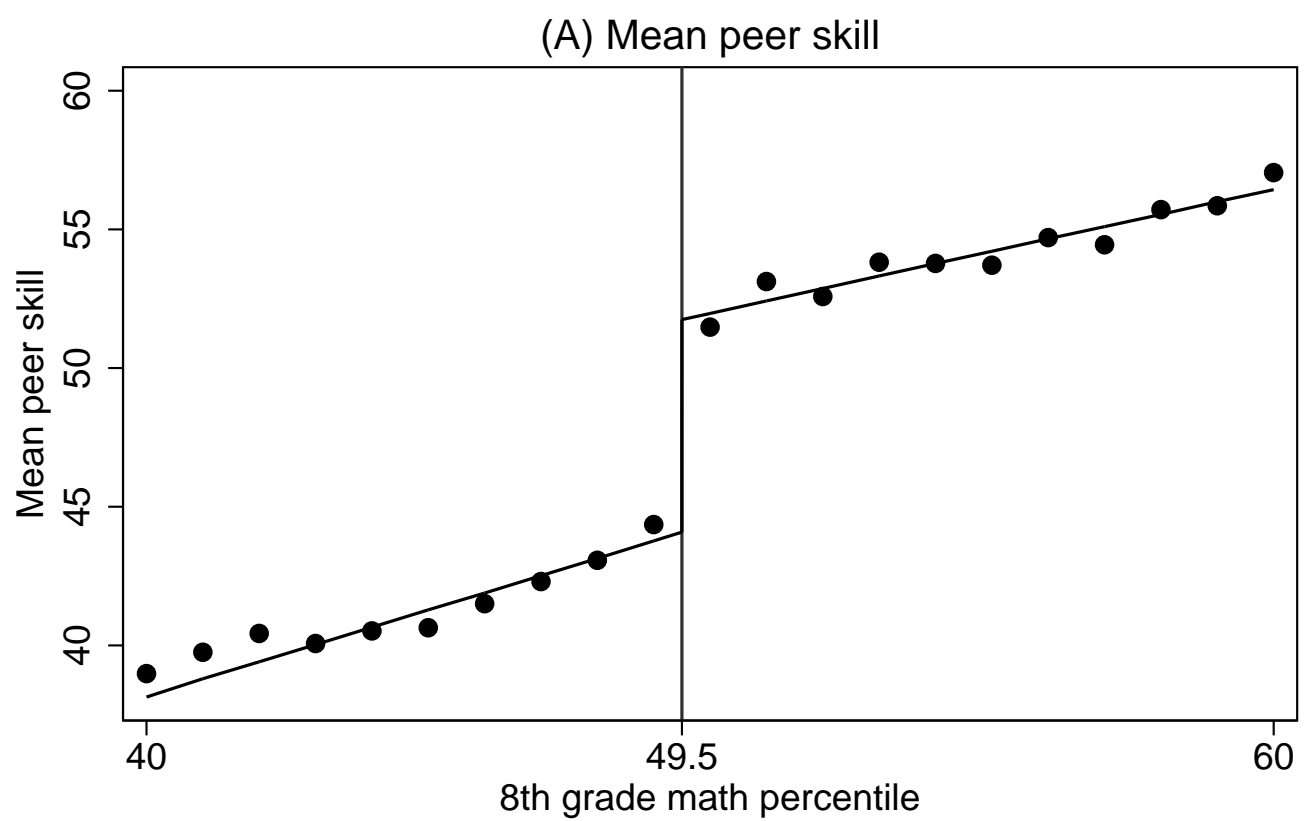

(B) SD of peer skill

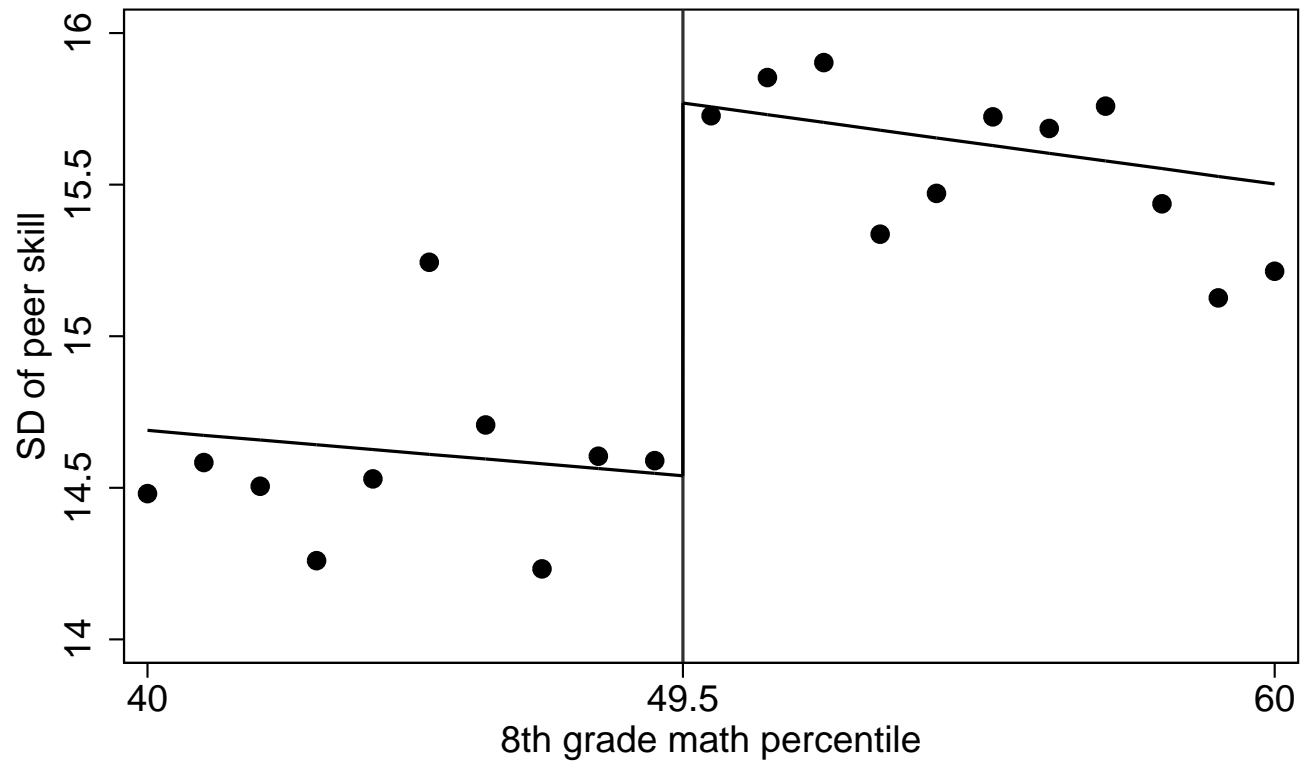

Notes: Panel A shows the mean 8th grade math percentile of each student's freshman algebra peers, by each student's own 8th grade math score. Panel B shows the standard deviation of each student's freshman algebra peers' 8th grade math percentiles. Both panels show predicted values generated by the default regression specification described in the text. 
Figure 4: Freshman Algebra GPA

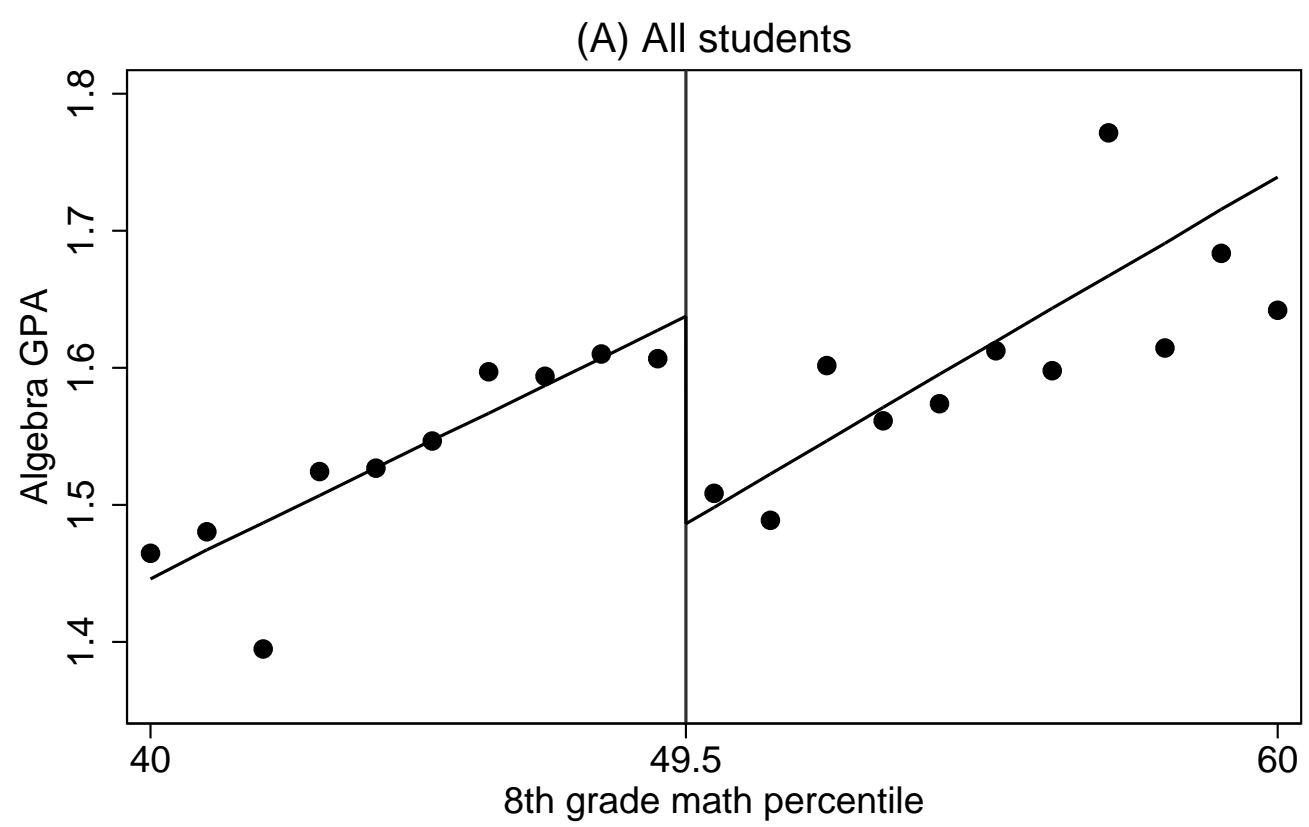

(B) Poor readers

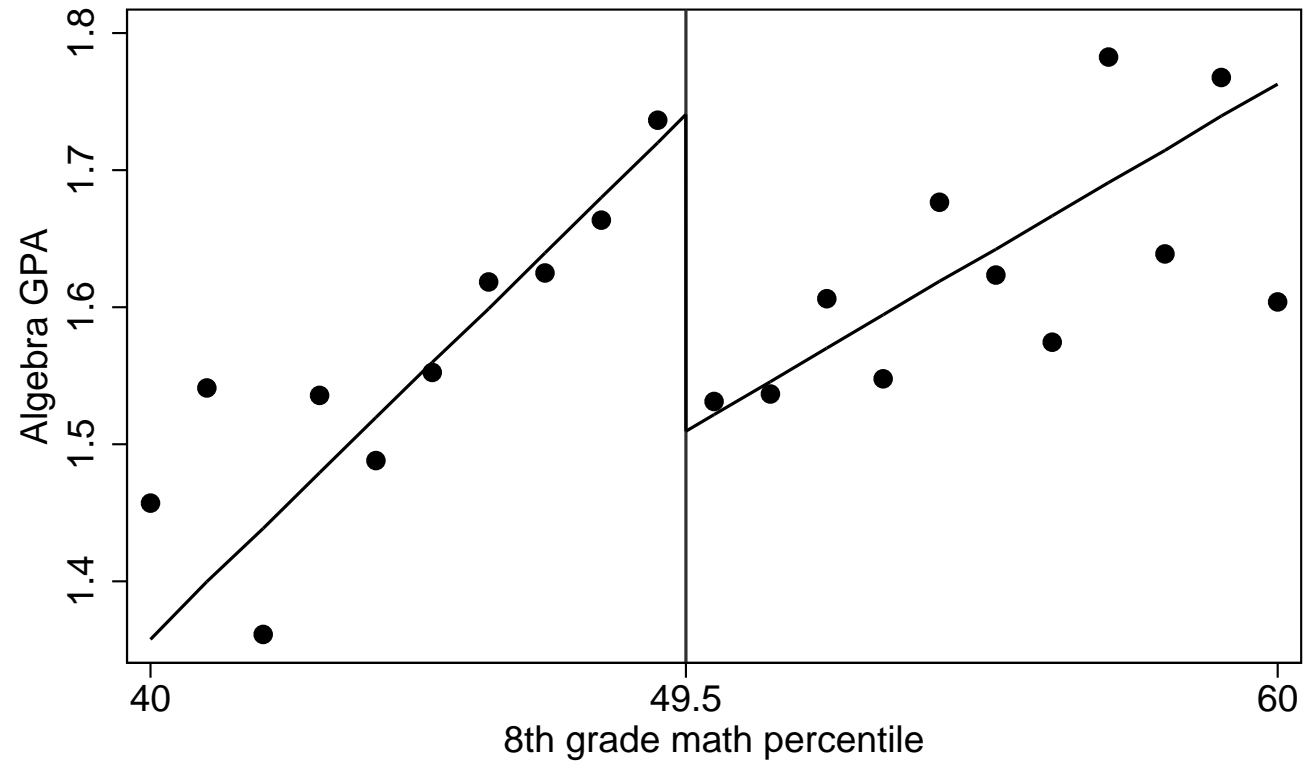

Notes: Panel A shows the mean freshman algebra GPA by 8th grade math score for all students. Panel B limits the sample to students with 8th grade reading scores below the 50th percentile. Both panels show predicted values generated by the default regression specification described in the text. 
Figure 5: Freshman Algebra Pass Rates

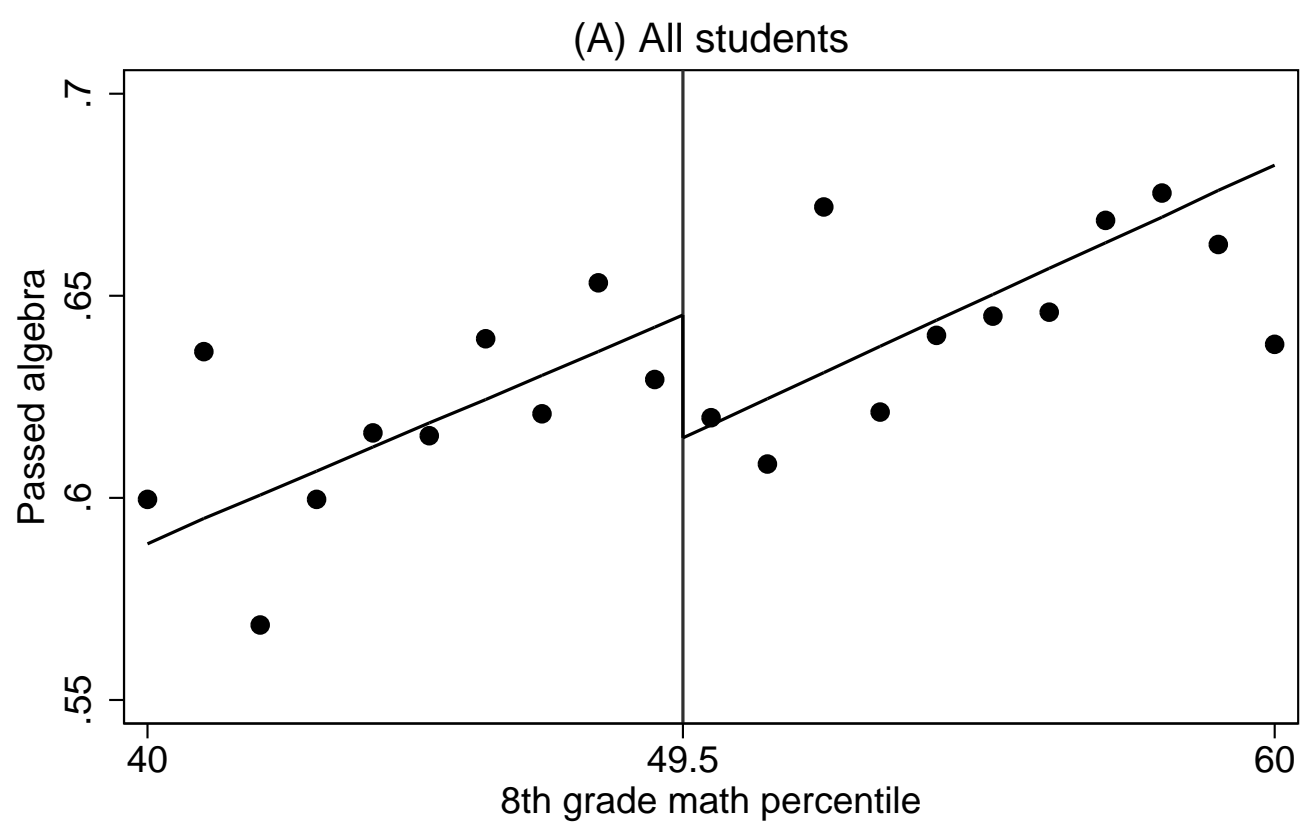

(B) Poor readers

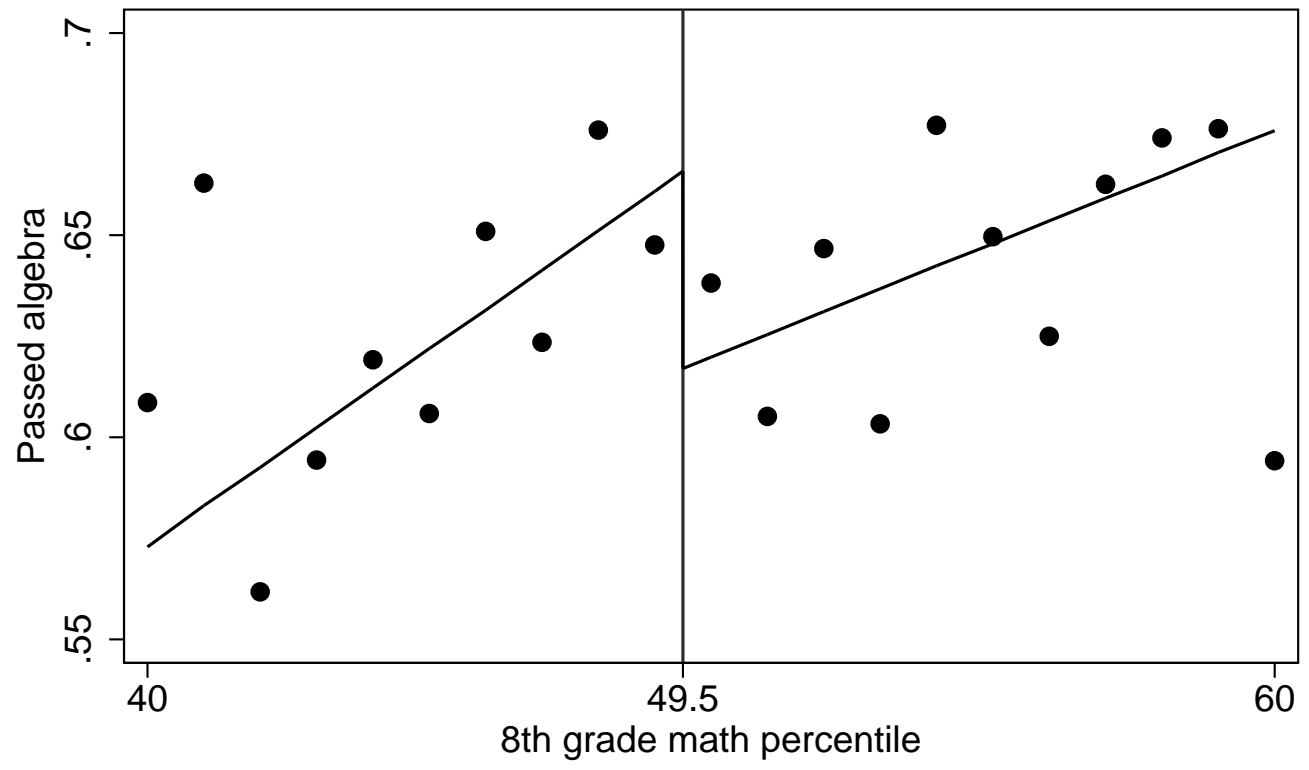

Notes: Panel A shows the mean rate of passing freshman algebra by 8th grade math score for all students. Panel B limits the sample to students with 8th grade reading scores below the 50th percentile. Both panels show predicted values generated by the default regression specification described in the text. 
Figure 6: Second-Year Geometry Pass Rates

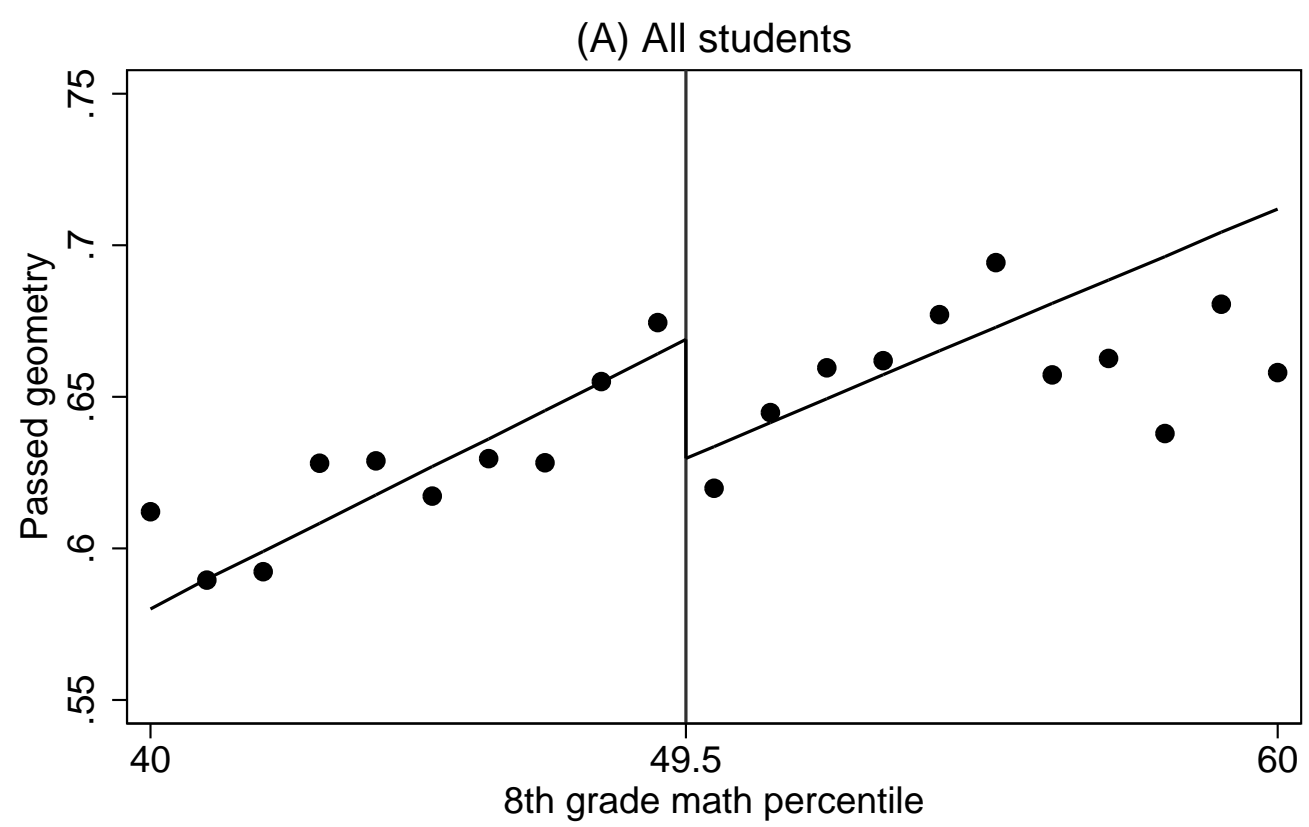

(B) Poor readers

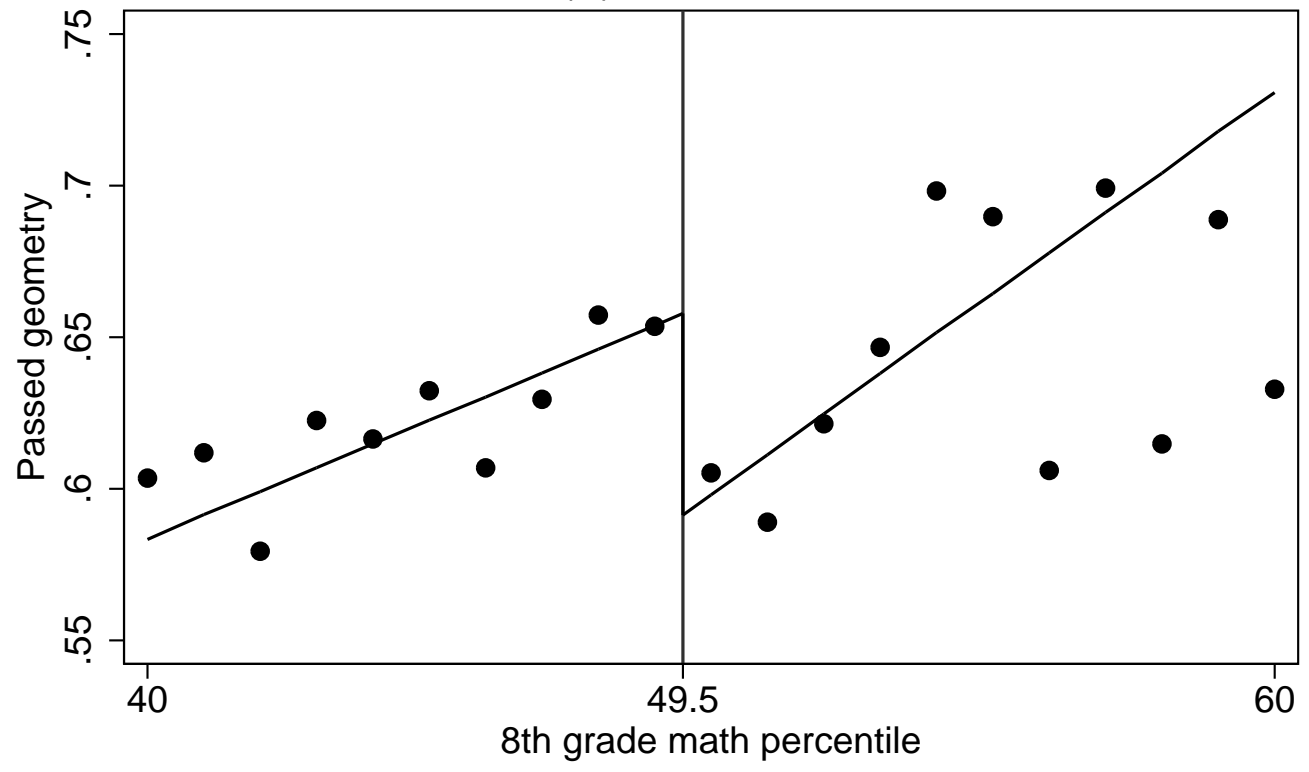

Notes: Panel A shows the mean rate of passing second-year geometry by 8th grade math score for all students. Panel B limits the sample to students with 8th grade reading scores below the 50th percentile. Both panels show predicted values generated by the default regression specification described in the text. 
Figure 7: Math Test Scores, Fall 11th Grade

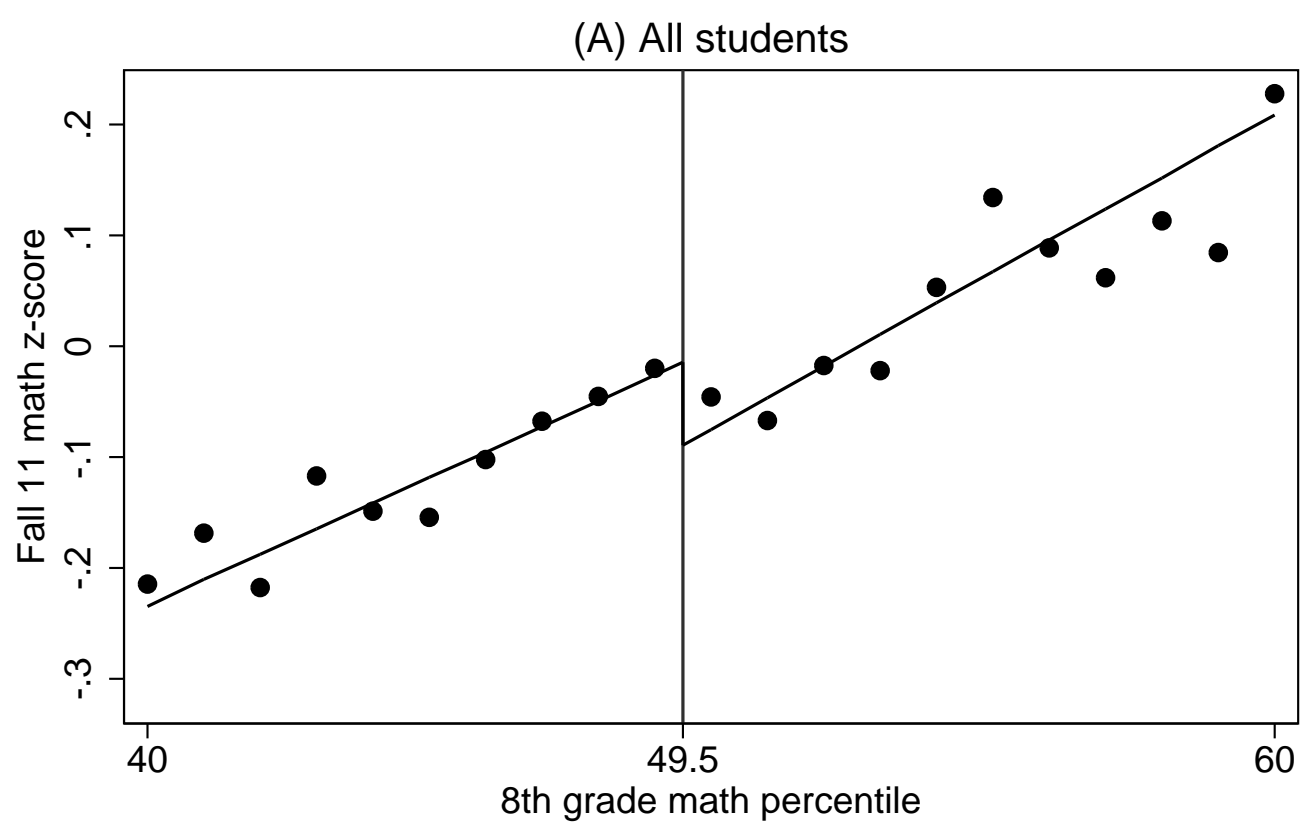

(B) Poor readers

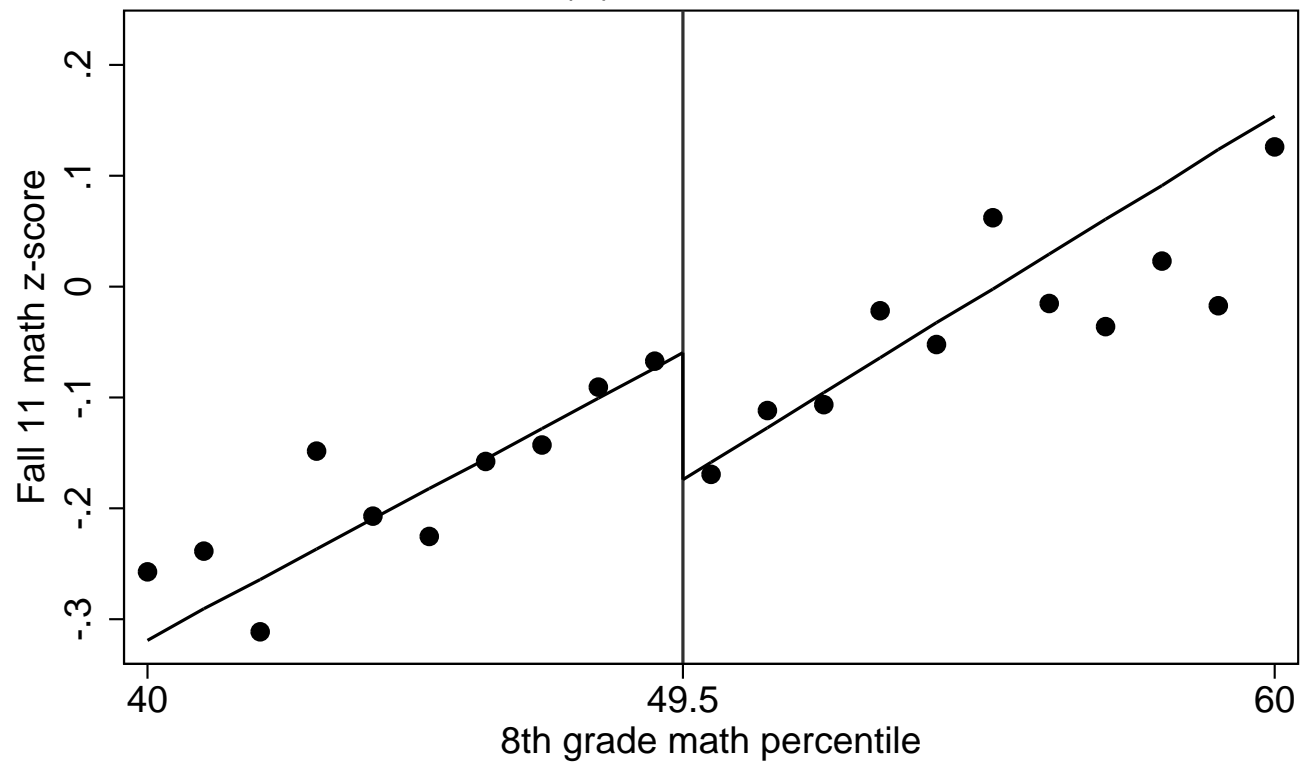

Notes: Panel A shows the mean fall 11th grade math score by 8th grade math score for all students who took the exam. Panel B limits the sample to students with 8th grade reading scores below the 50th percentile. Both panels show predicted values generated by the default regression specification described in the text. 
Figure 8: Credits Earned through Fourth Year of High School

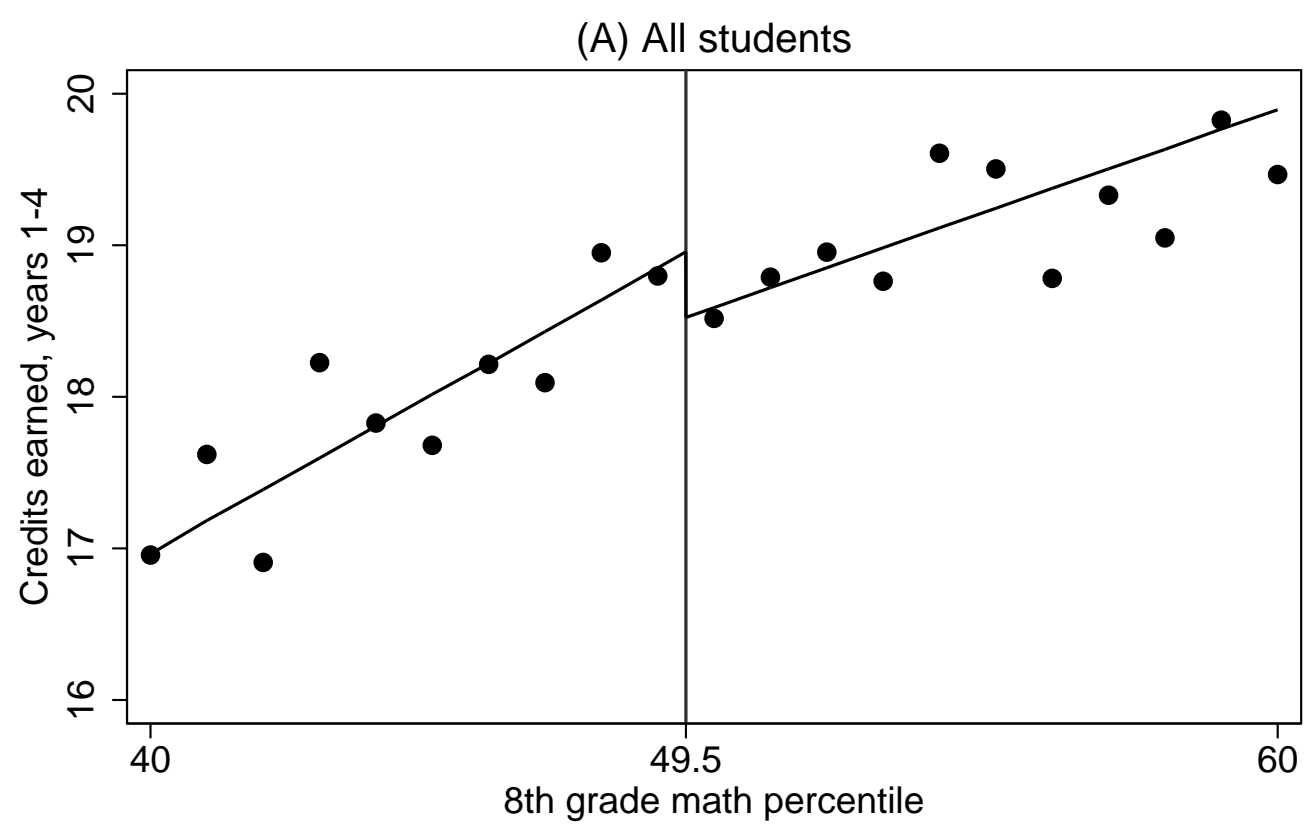

(B) Poor readers

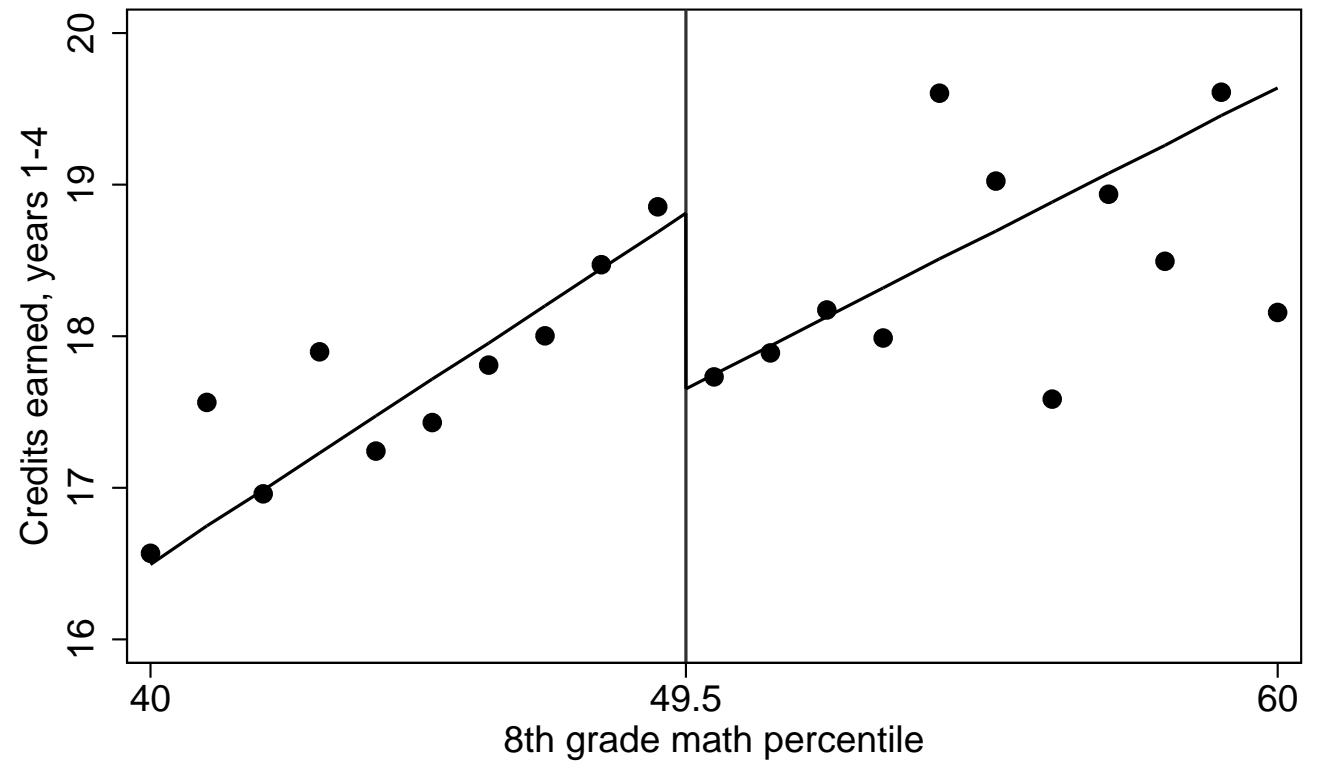

Notes: Panel A shows the mean number of credits earned through the fourth year of high school by 8th grade math score for all students. Panel B limits the sample to students with 8th grade reading scores below the 50th percentile. Both panels show predicted values generated by the default regression specification described in the text. 
Figure 9: High School Graduation, within Five Years

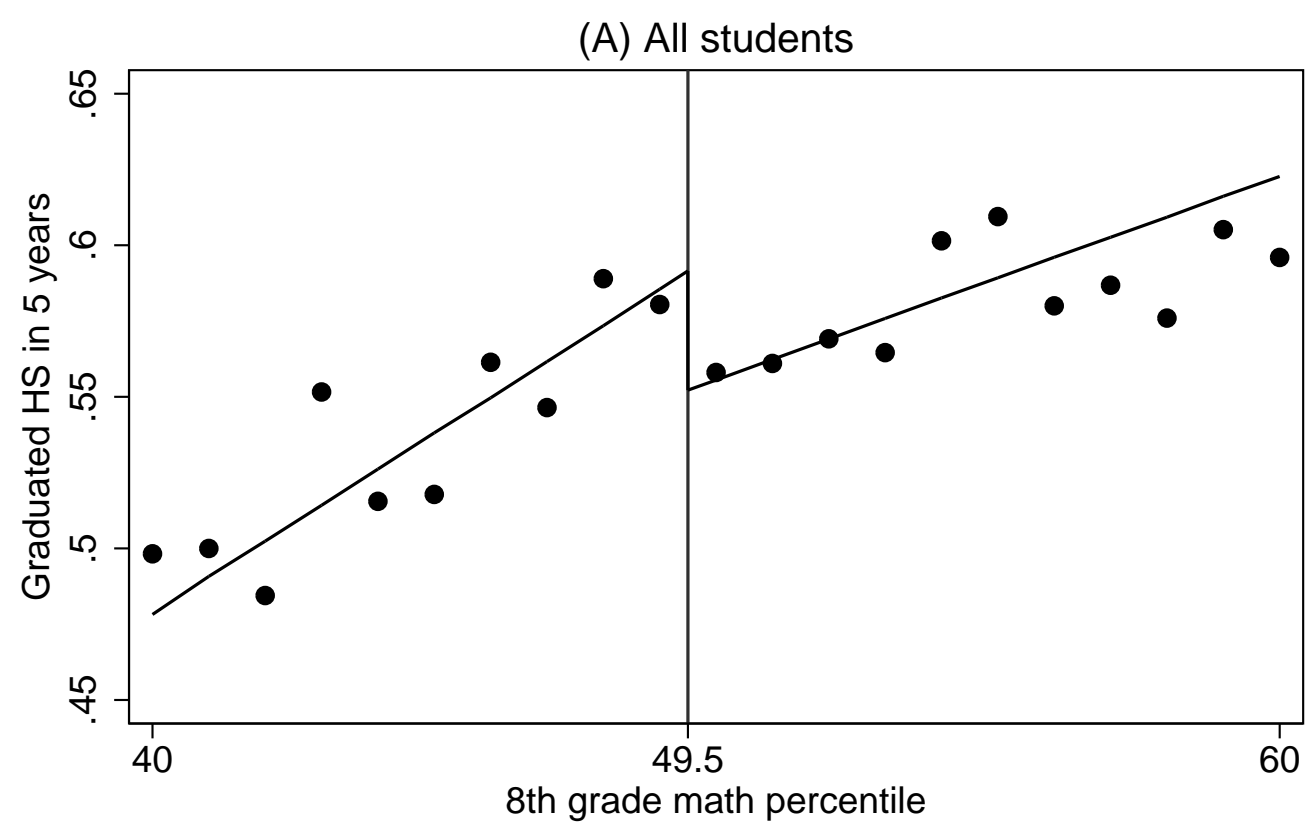

(B) Poor readers

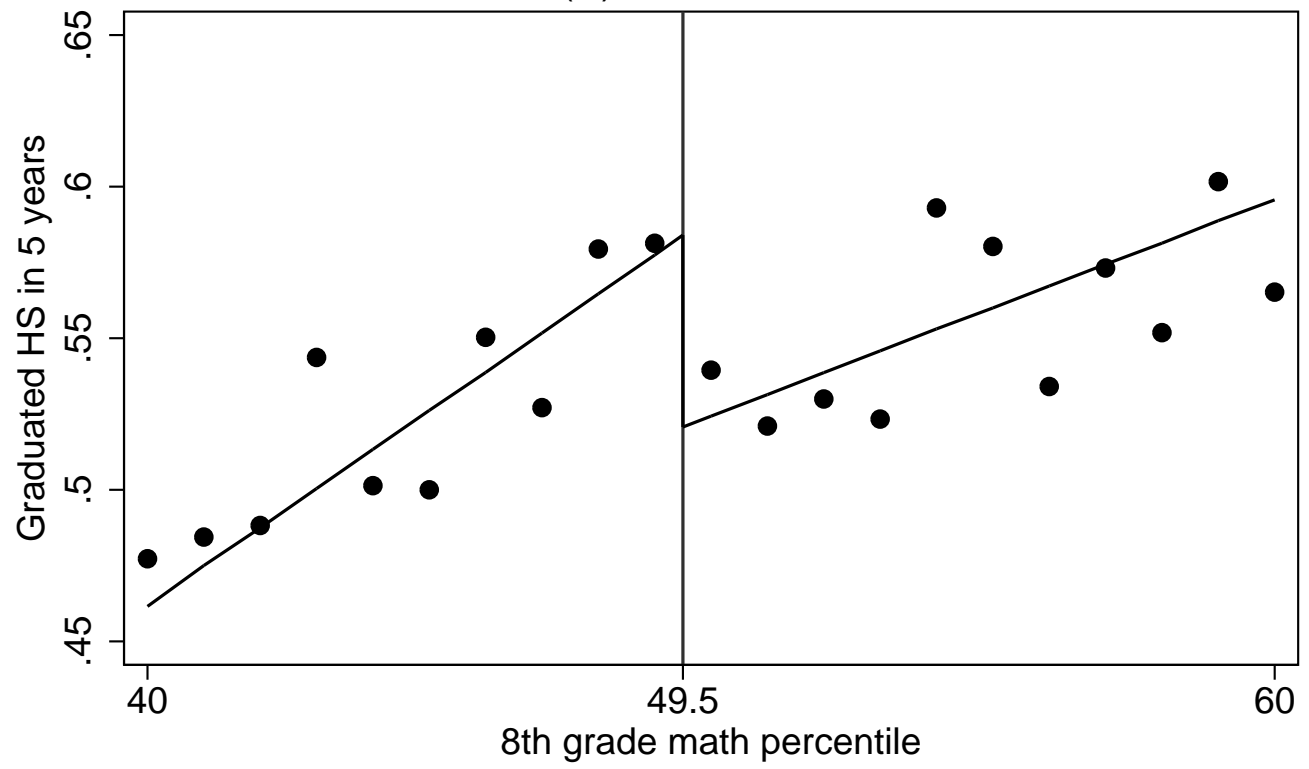

Notes: Panel A shows the probability of graduating high school within five years by 8th grade math score for all students. Panel B limits the sample to students with 8th grade reading scores below the 50th percentile. Both panels show predicted values generated by the default regression specification described in the text. 
Figure 10: College Enrollment, within Five Years of Starting High School

(A) All students

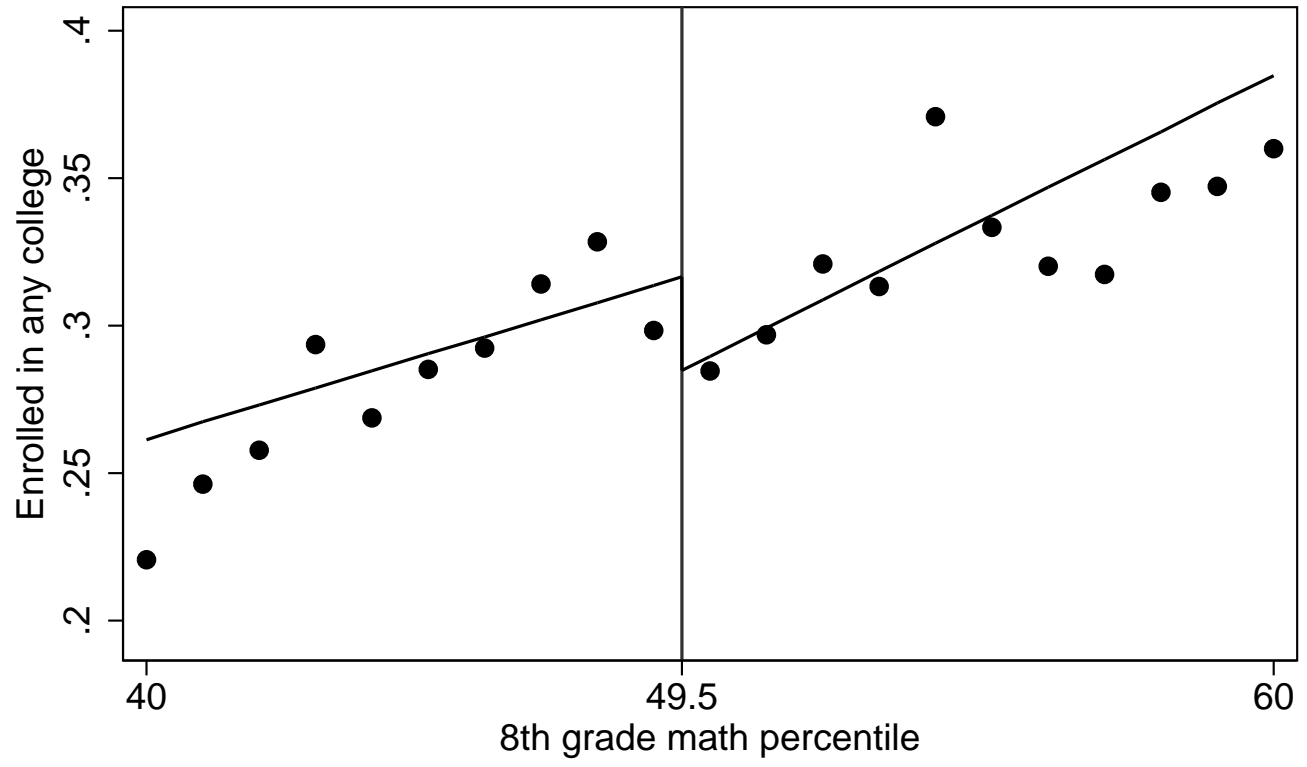

(B) Poor readers

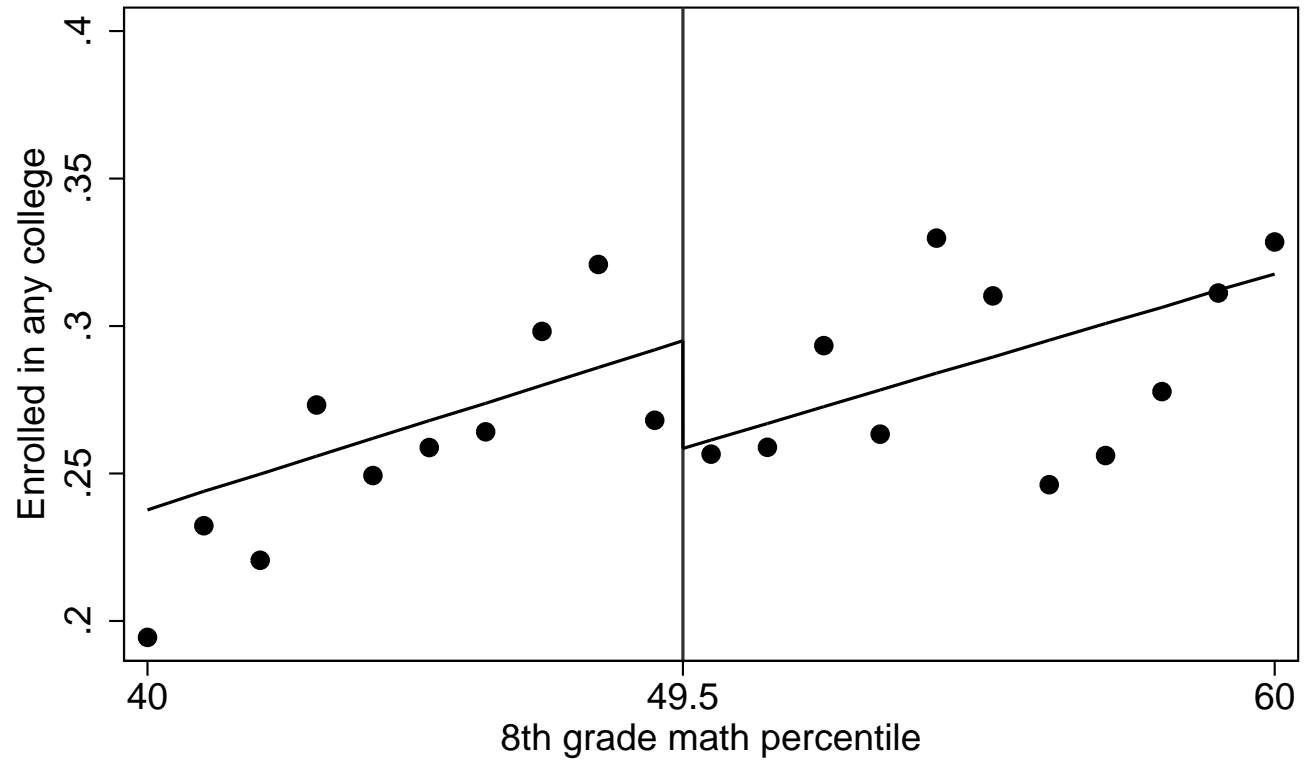

Notes: Panel A shows the probability of enrolling in any college within five years of starting high school by 8th grade math score for all students. Panel B limits the sample to students with 8th grade reading scores below the 50th percentile. Both panels show predicted values generated by the default regression specification described in the text. 
Table 1: Summary Statistics

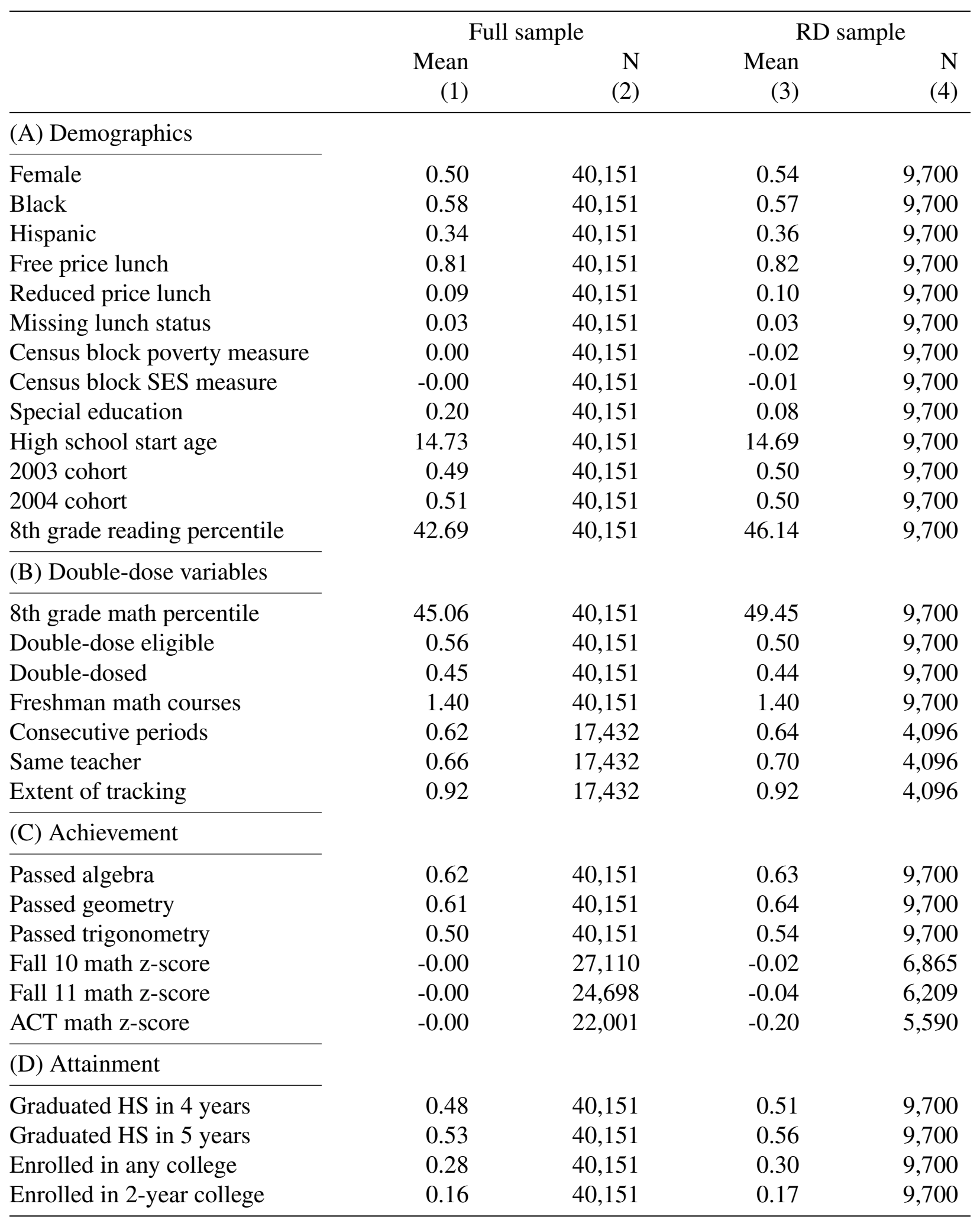

Notes: Odd-numbered columns show mean values of each variable for the given sample. Even-numbered columns show sample sizes. Columns (1) and (2) contain all students from the 2003 and 2004 cohorts. Columns (3) and (4) limit the sample to students whose 8th grade scores are within 9 percentiles of the eligibility threshold, the default regression discontinuity sample. 


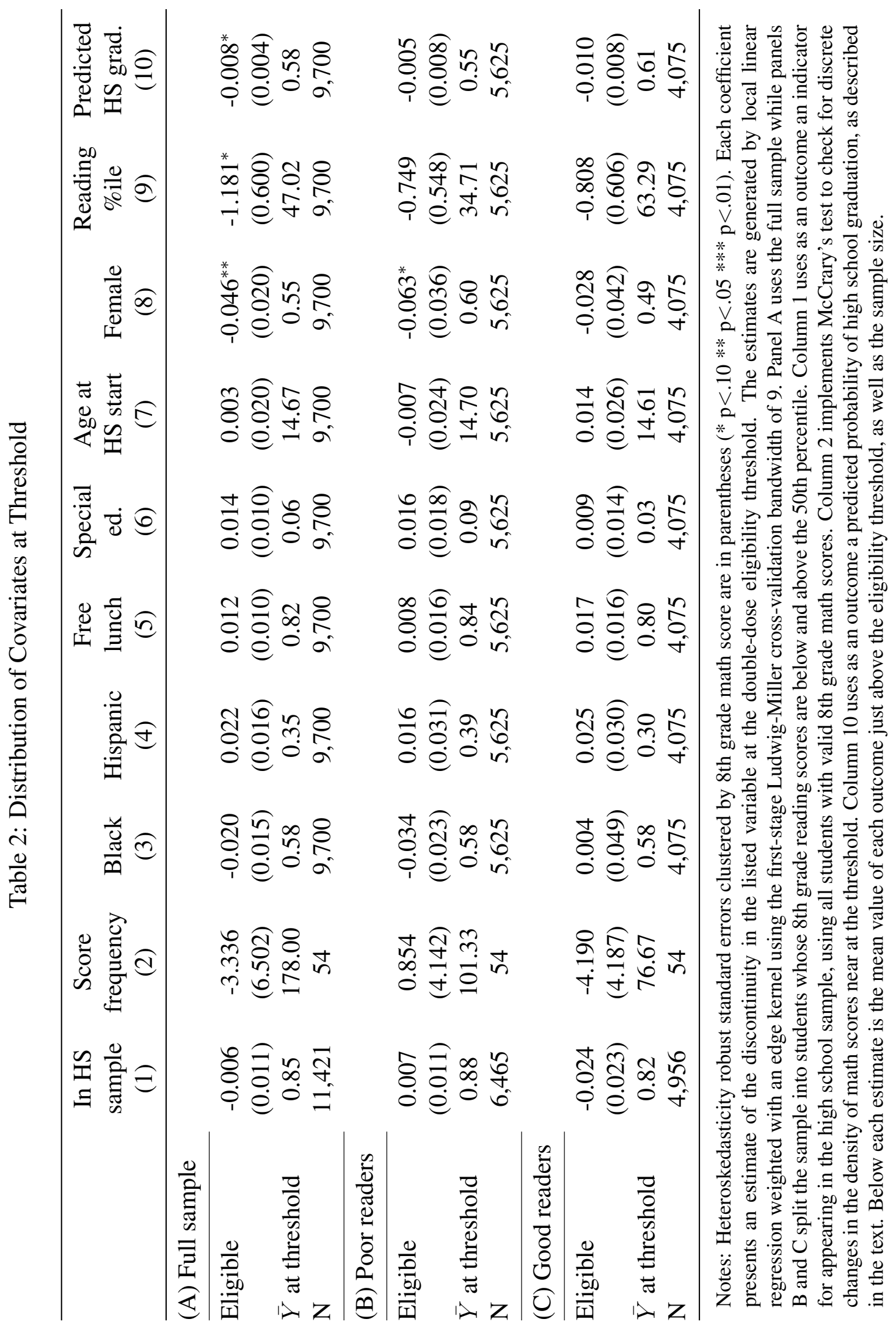




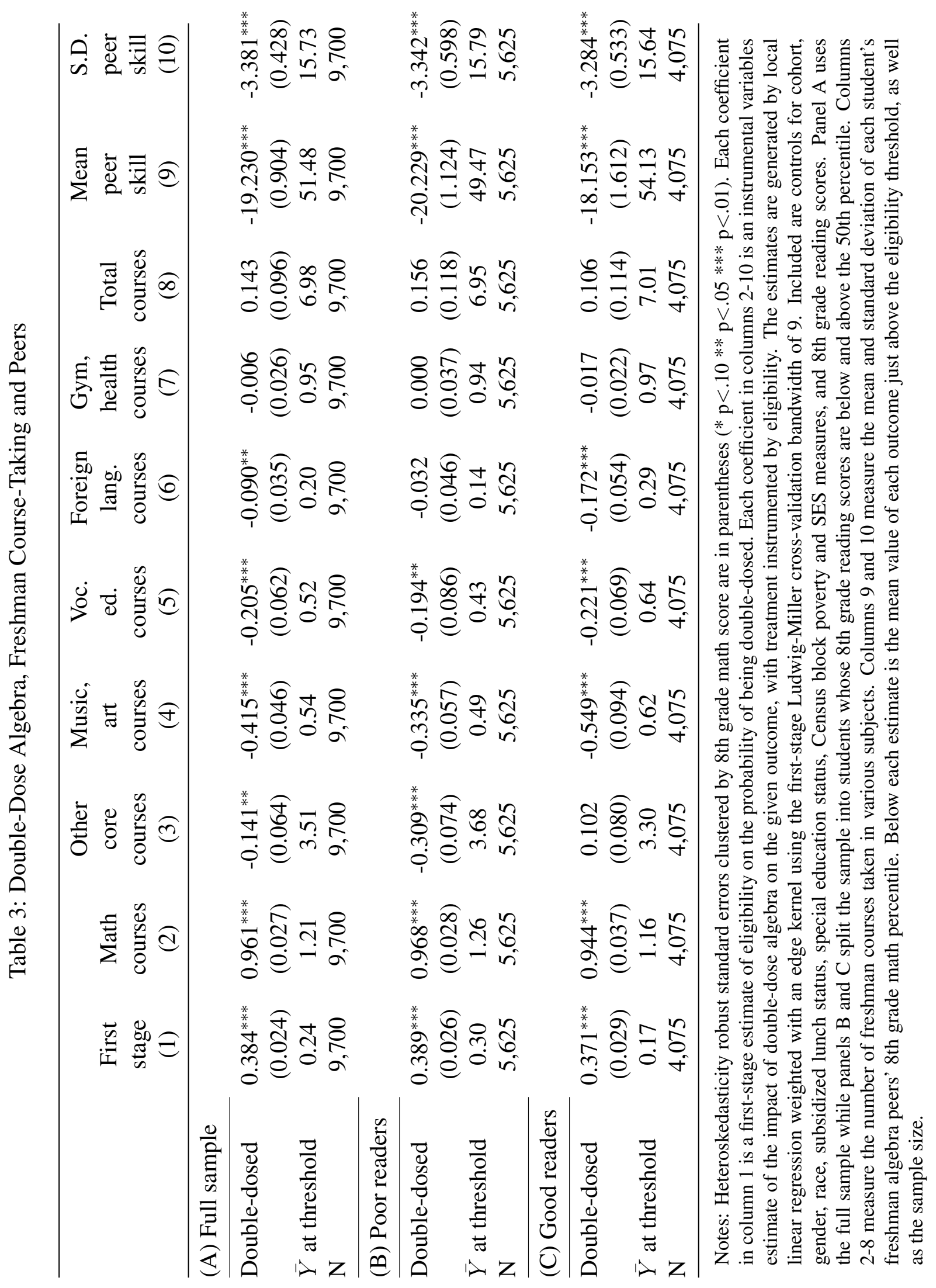




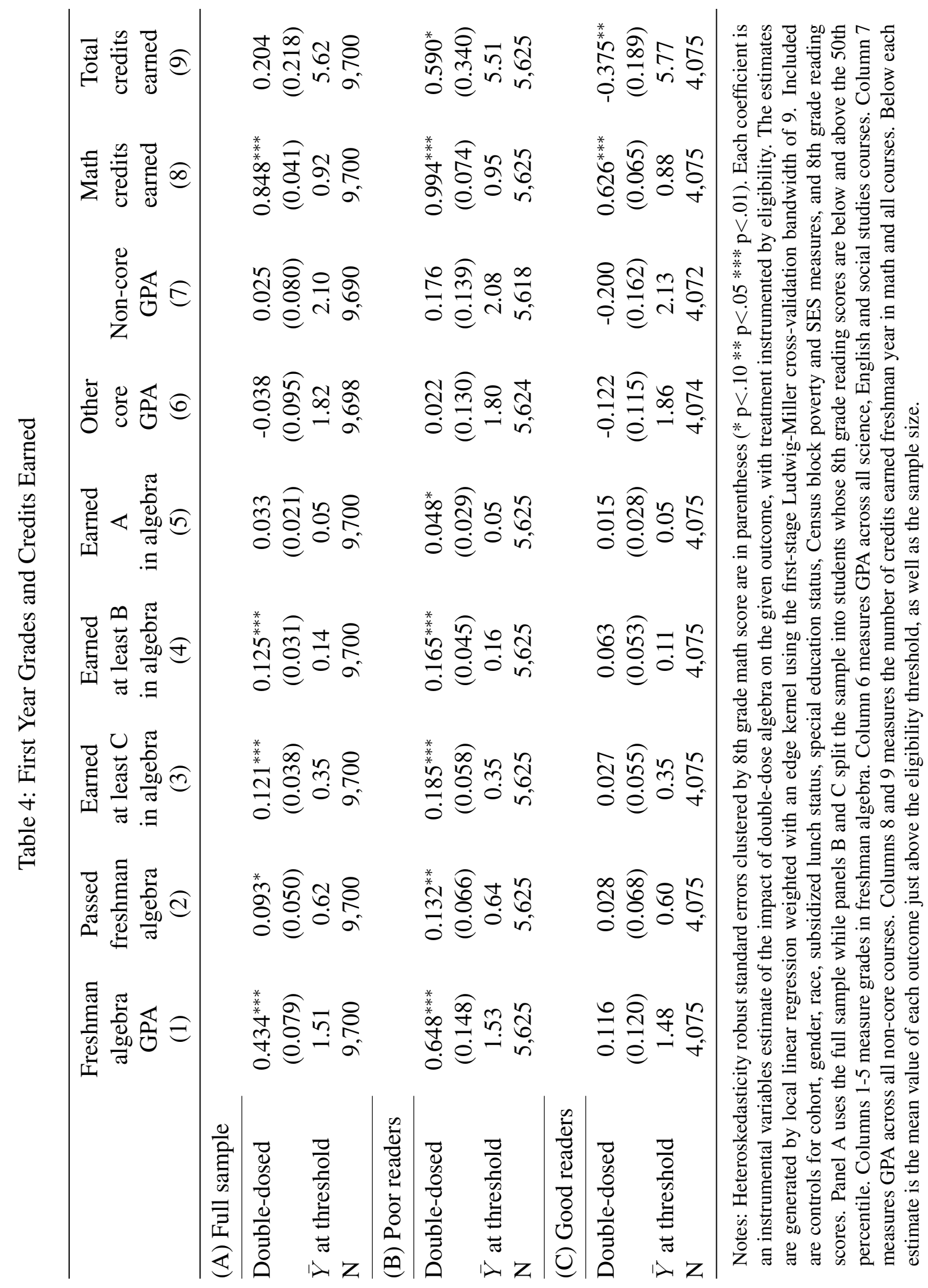




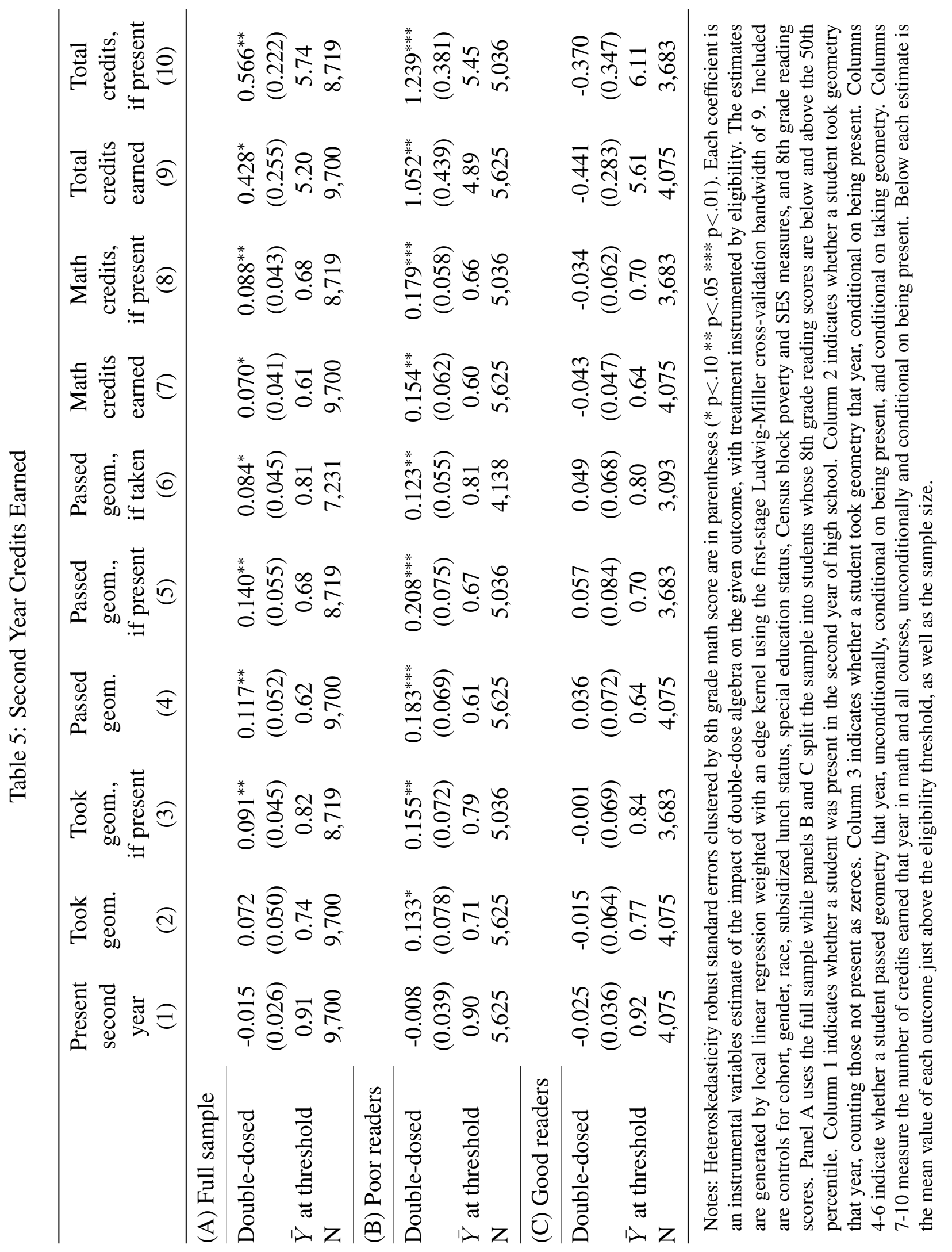




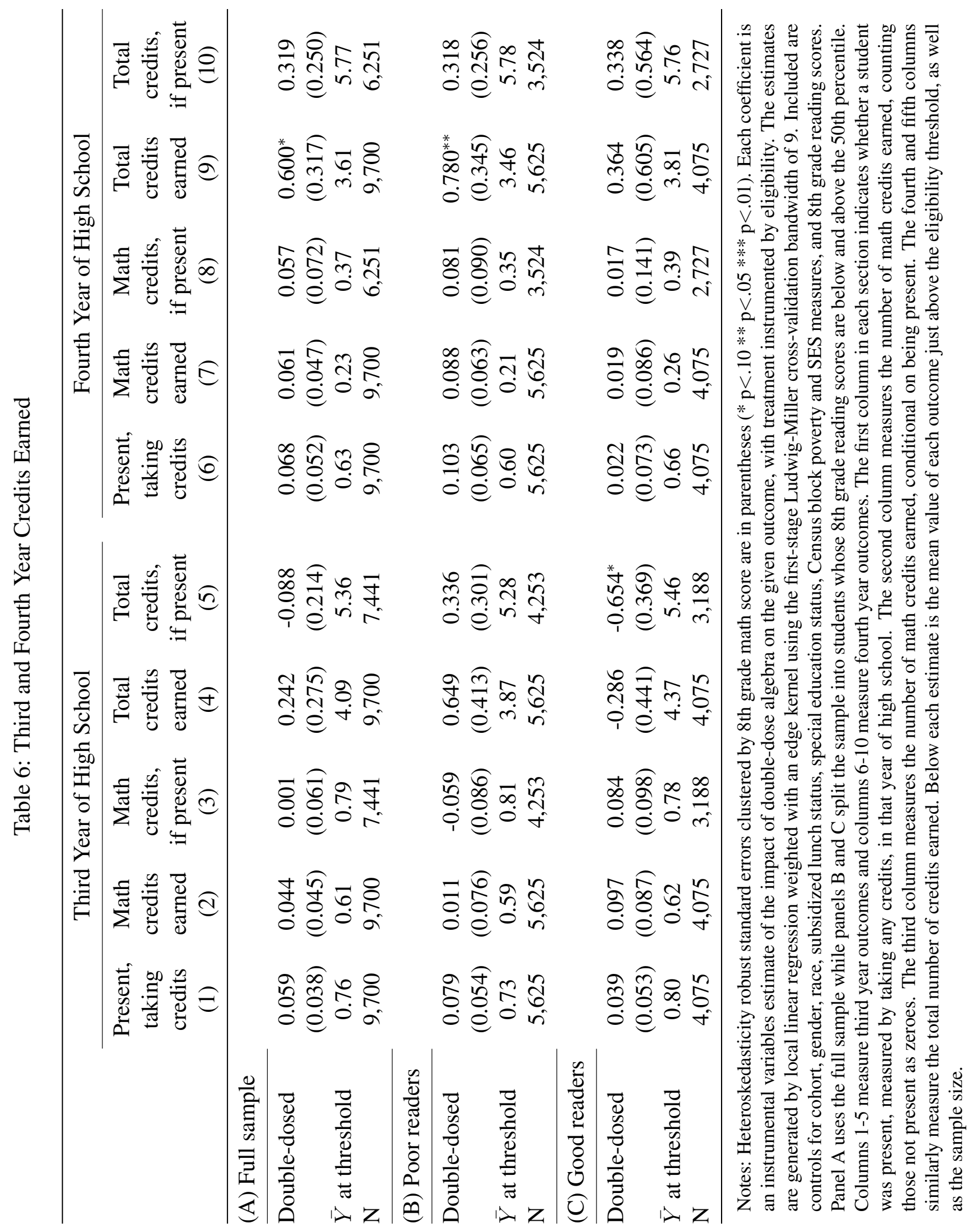




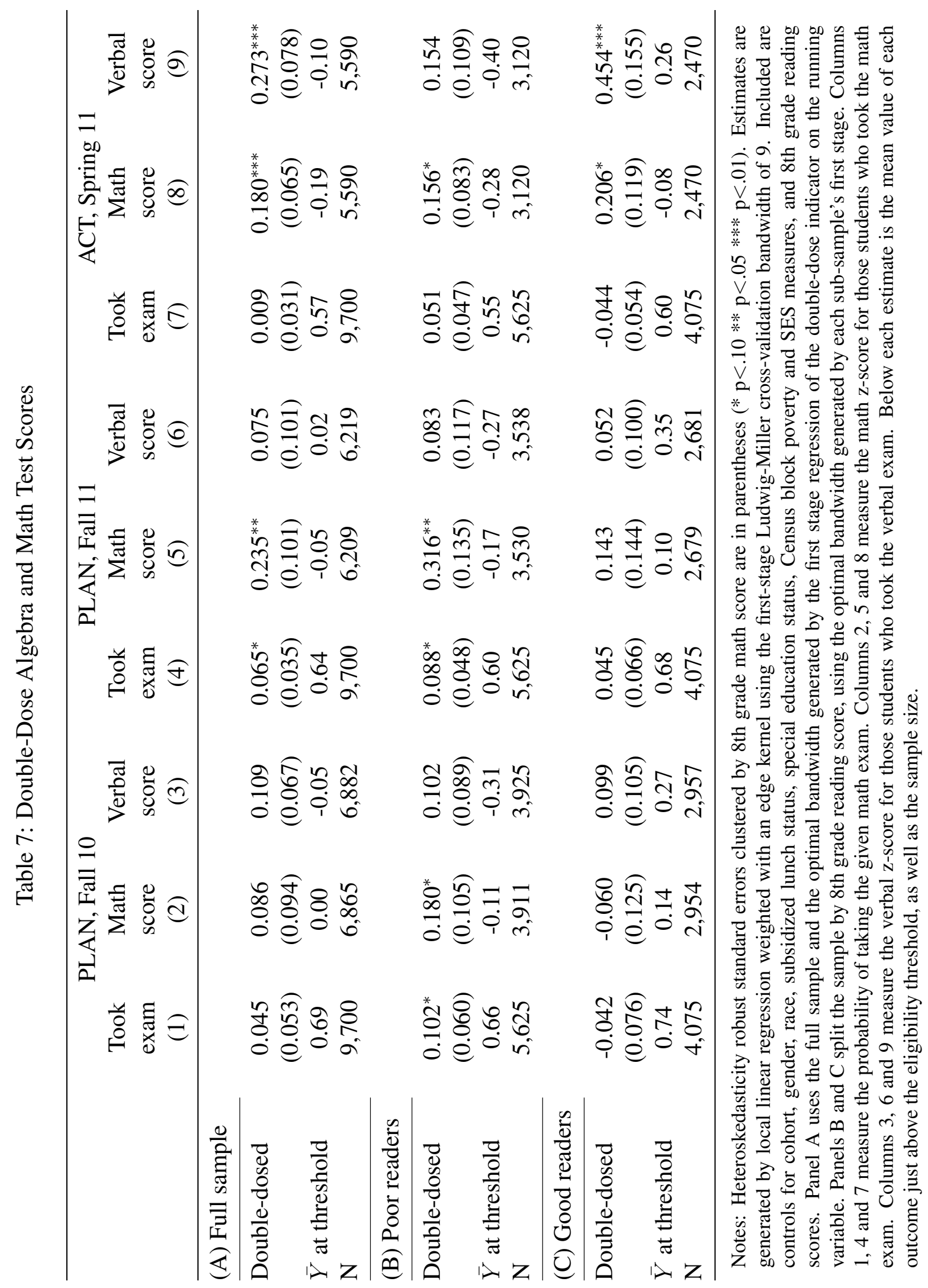




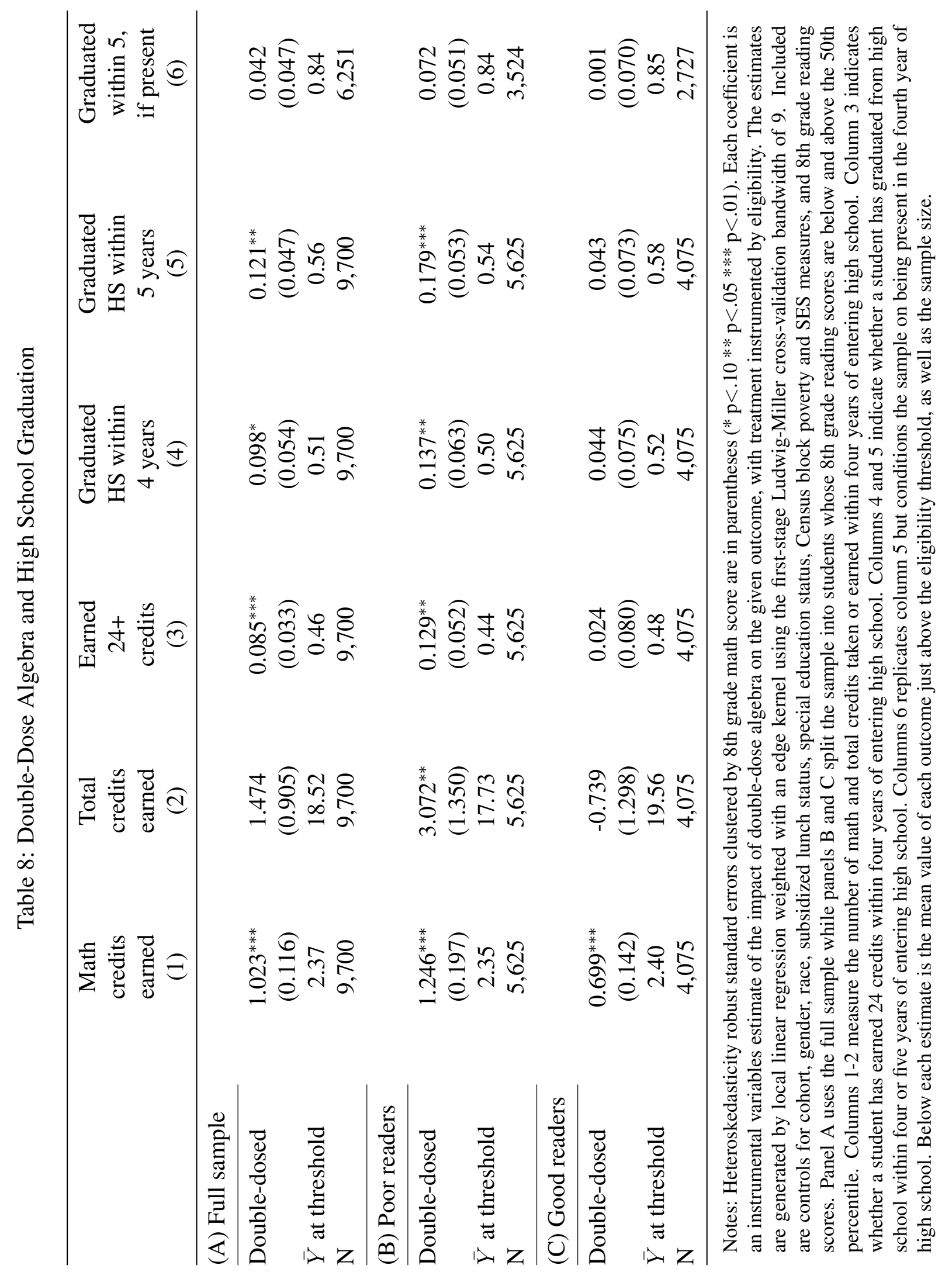




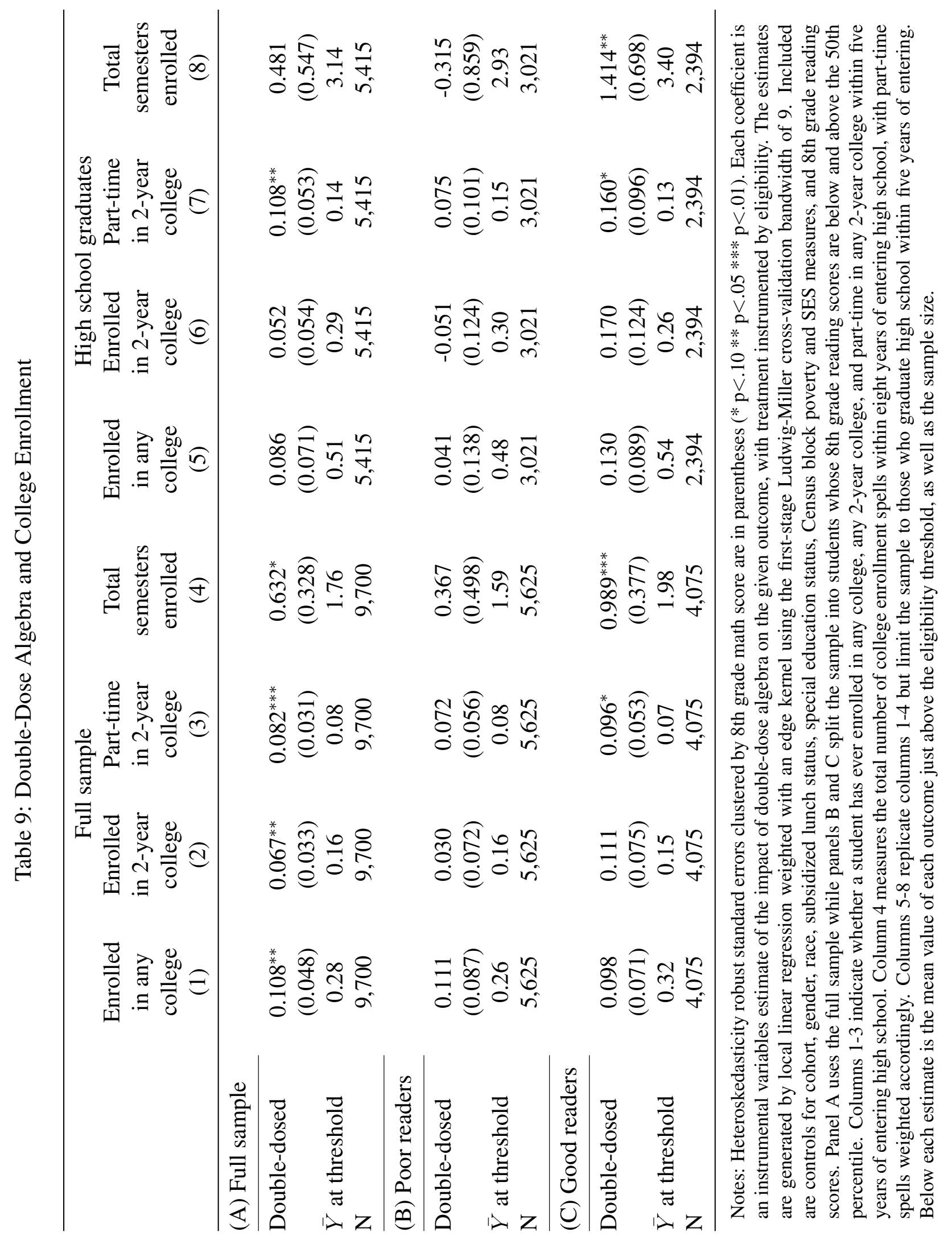


Figure A.1: The Distribution of 8th Grade Math Scores

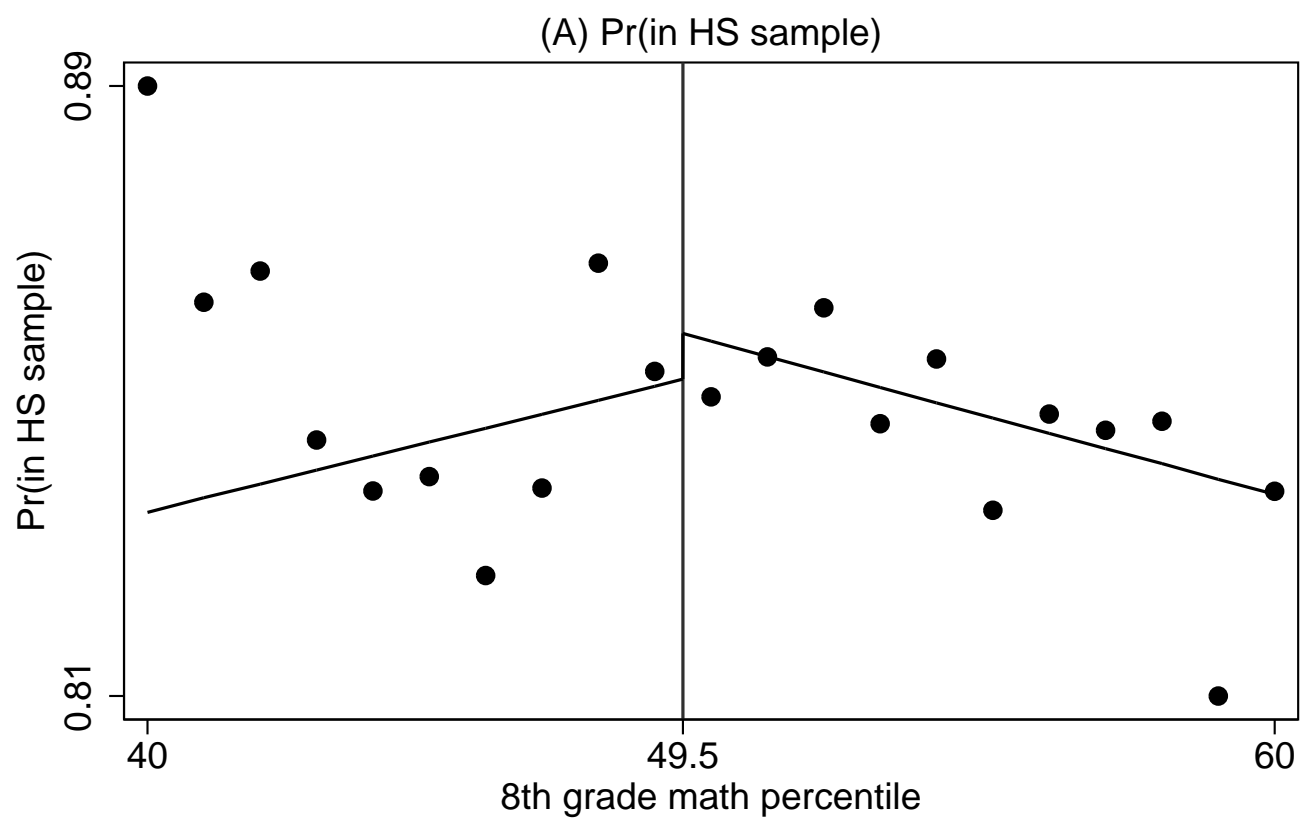

(B) Number of observations

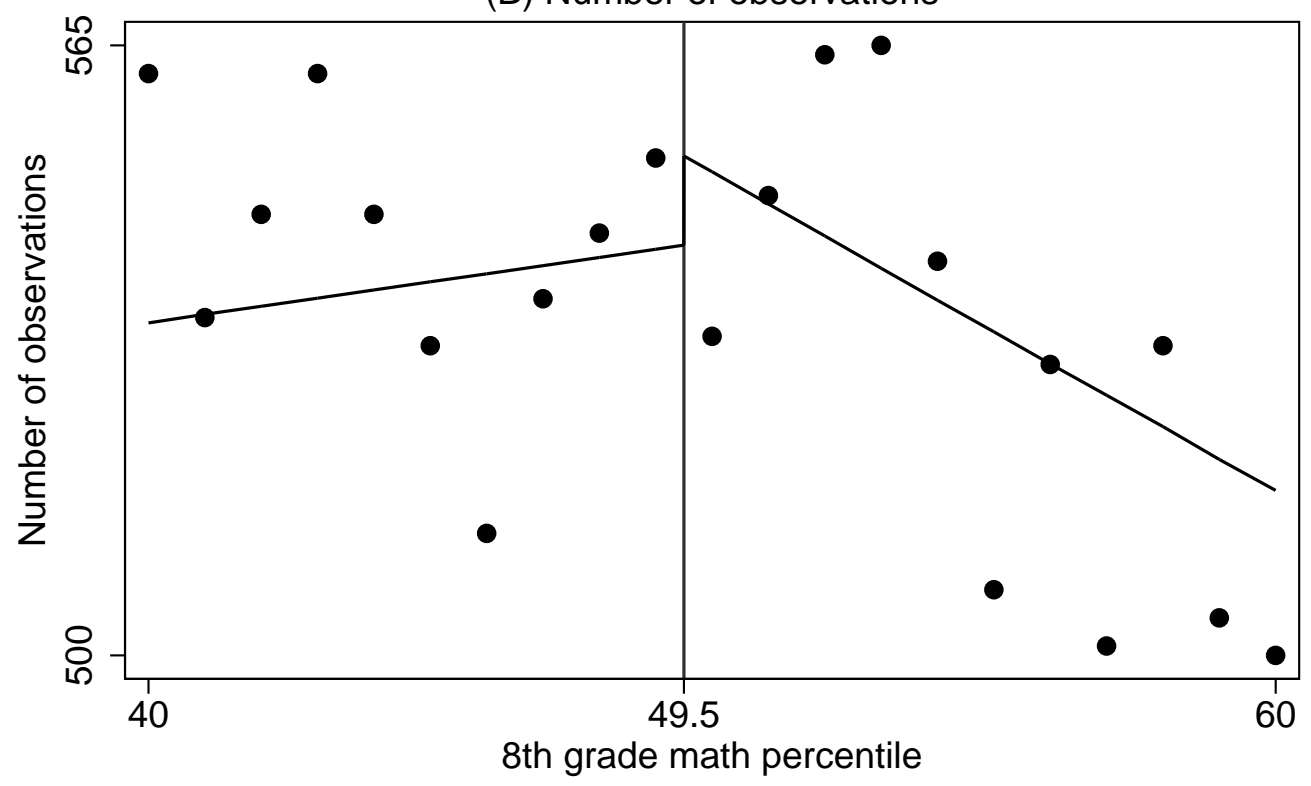

Notes: Panel A shows the probability of being in the analysis sample, conditional on having a valid 8th grade math score. Panel B shows the number of observations for each 8th grade math score, conditional on being in the analysis sample. Both panels show the predicted values generated by the default regression specification described in the text. 
Figure A.2: Being Present in The Second Year of High School

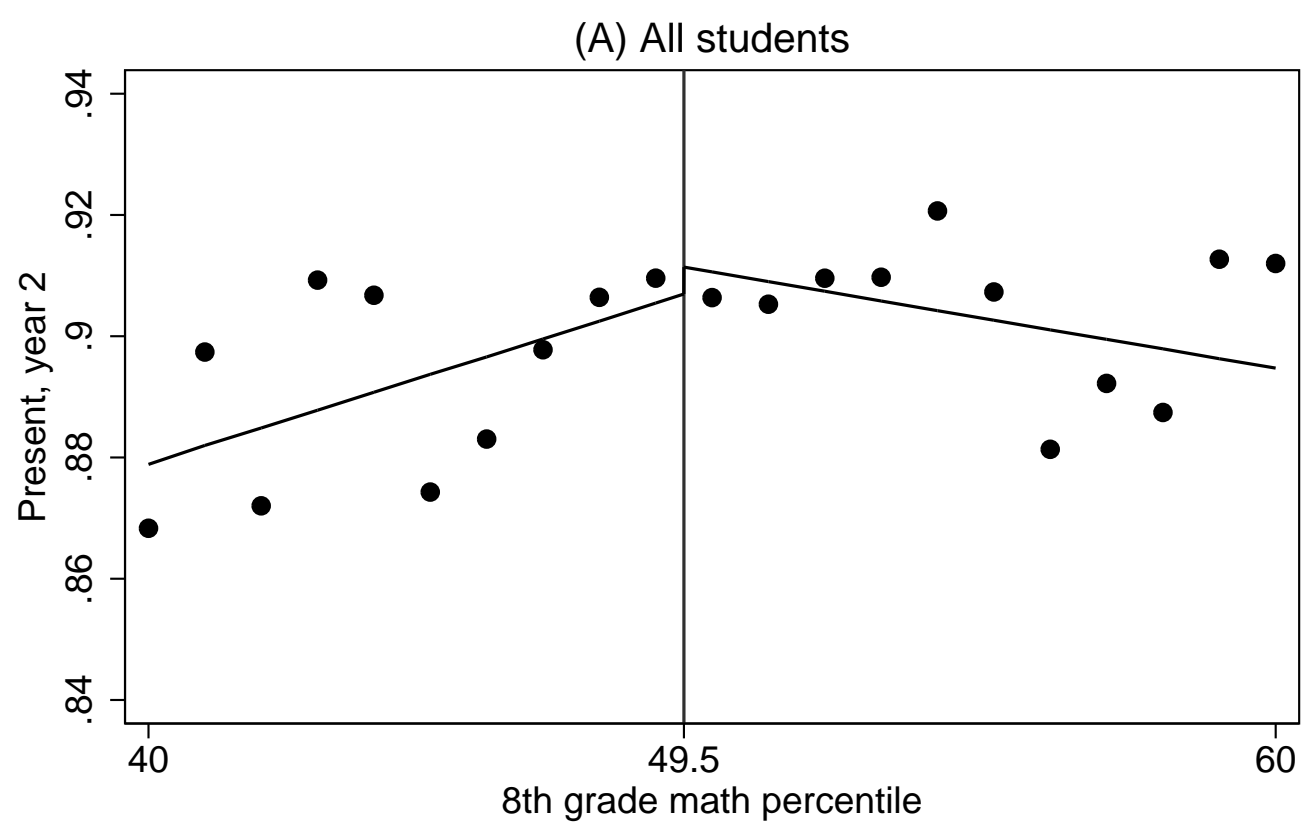

(B) Poor readers

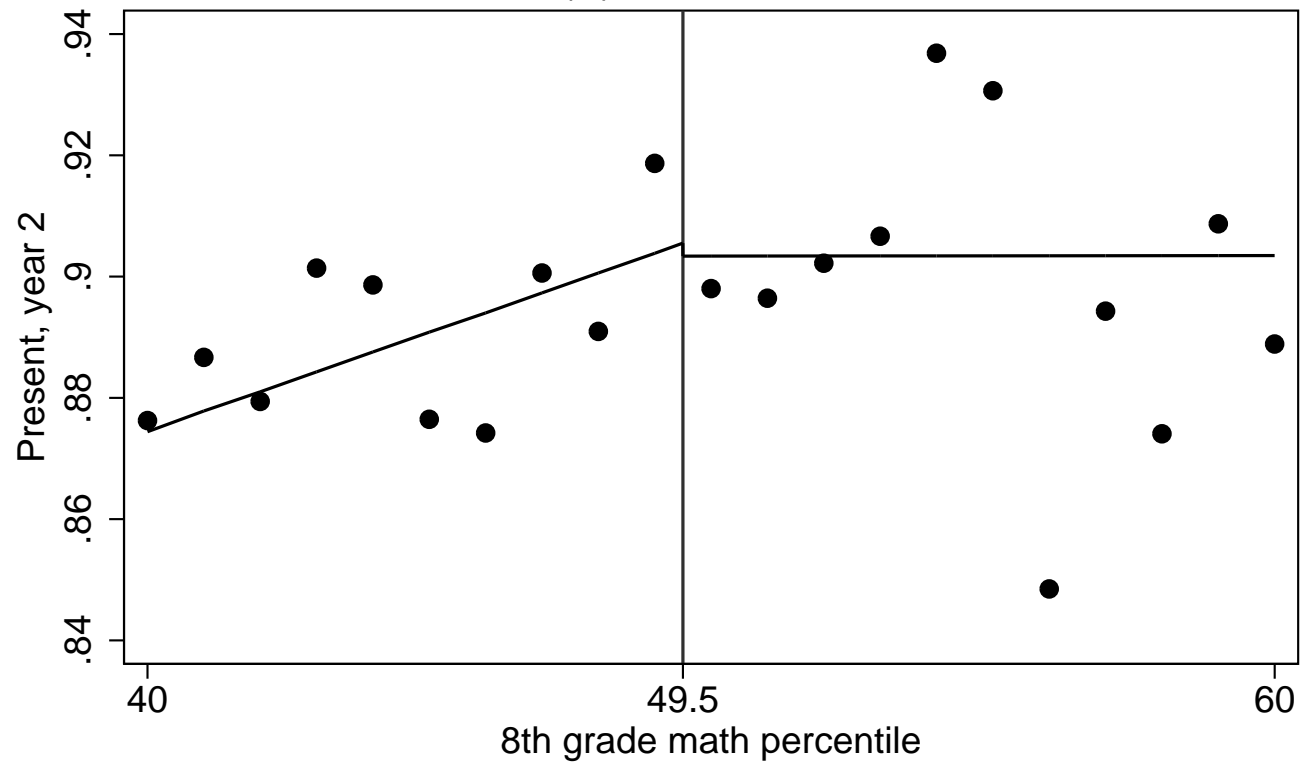

Notes: Panel A shows the probability of being present in the second year of high school by 8th grade math score for all students. Panel B limits the sample to students with 8th grade reading scores below the 50th percentile. Both panels show predicted values generated by the default regression specification described in the text. 
Figure A.3: Being Present in The Third Year of High School

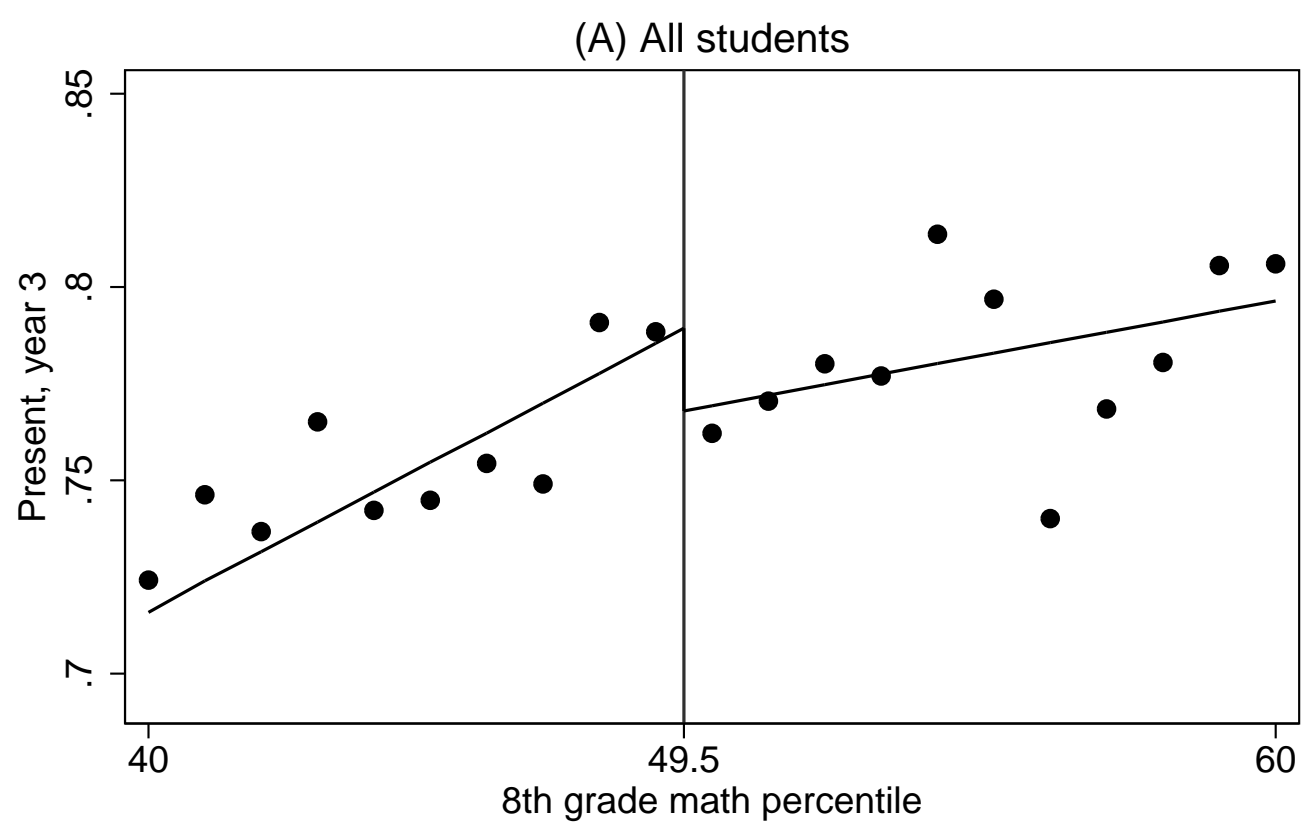

(B) Poor readers

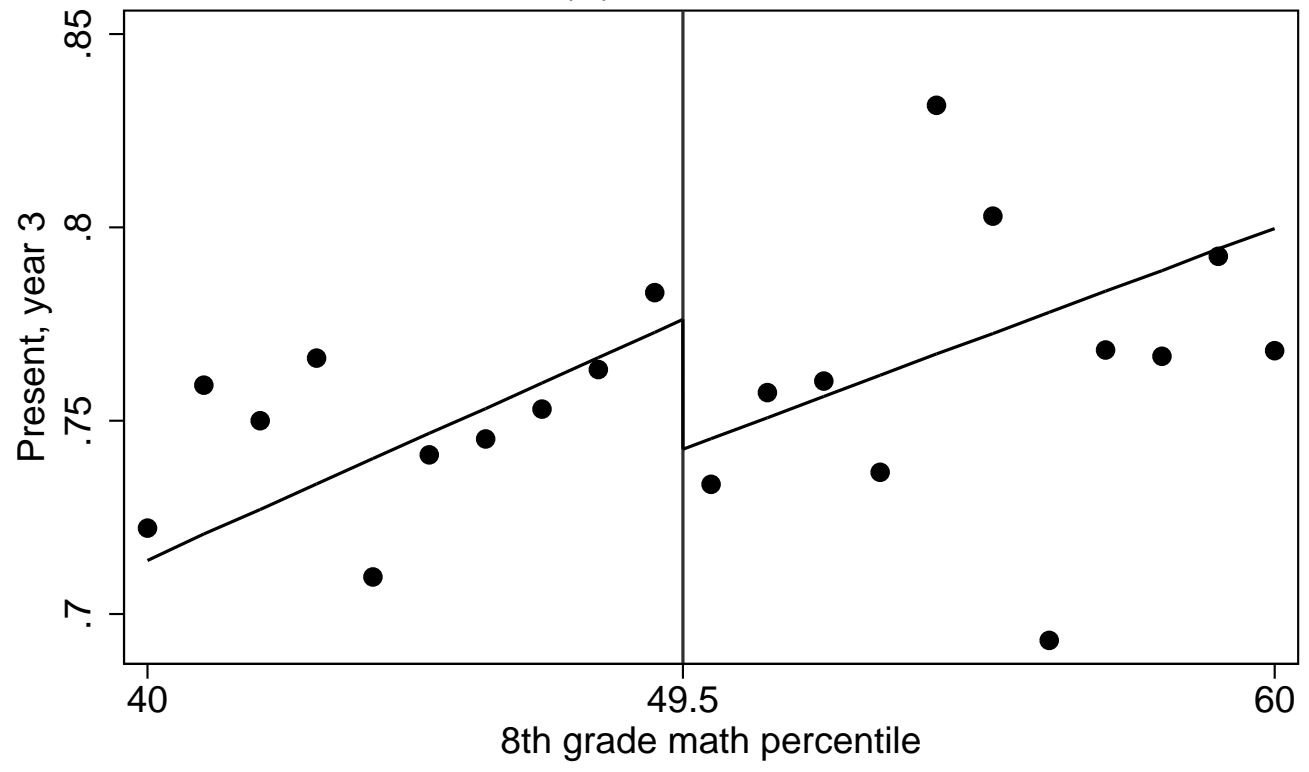

Notes: Panel A shows the probability of being present in the third year of high school by 8th grade math score for all students. Panel B limits the sample to students with 8th grade reading scores below the 50th percentile. Both panels show predicted values generated by the default regression specification described in the text. 
Figure A.4: Being Present in The Fourth Year of High School

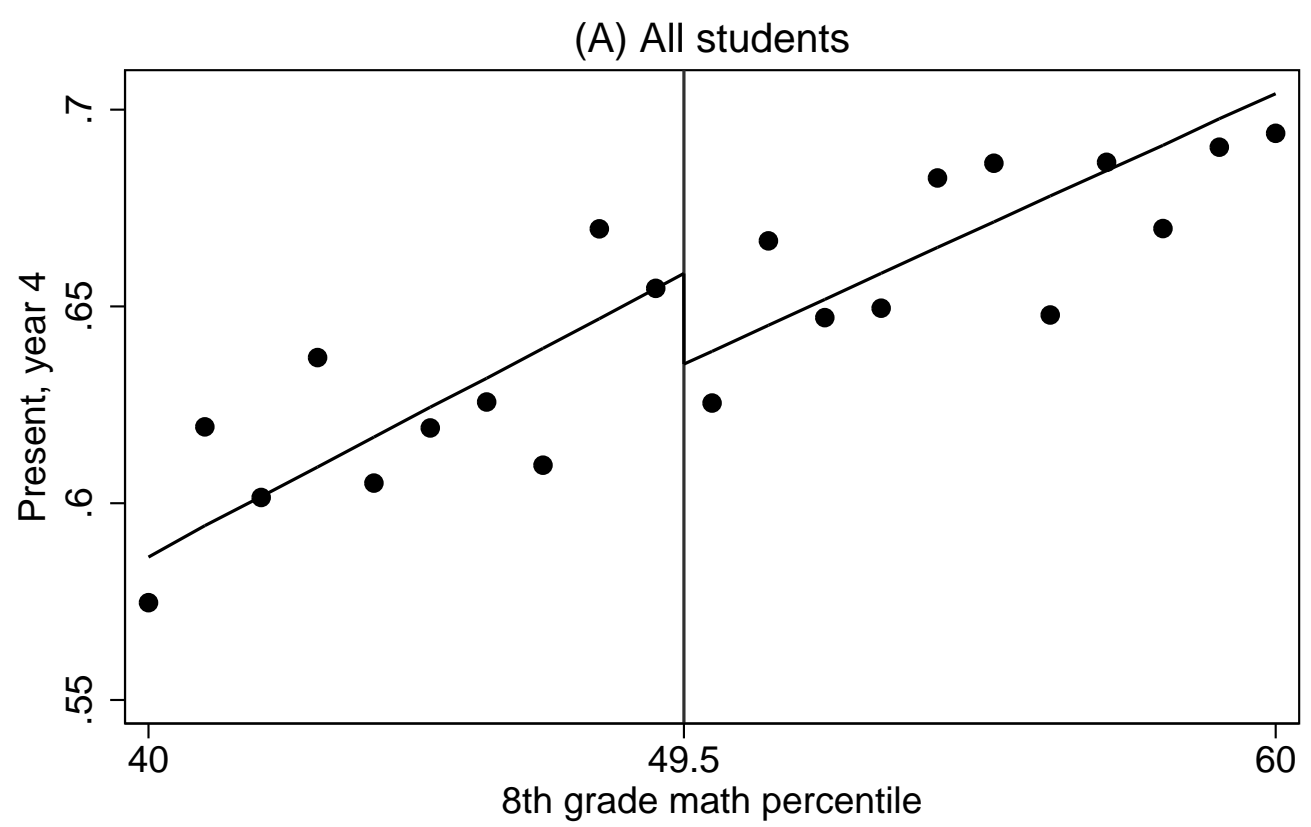

(B) Poor readers

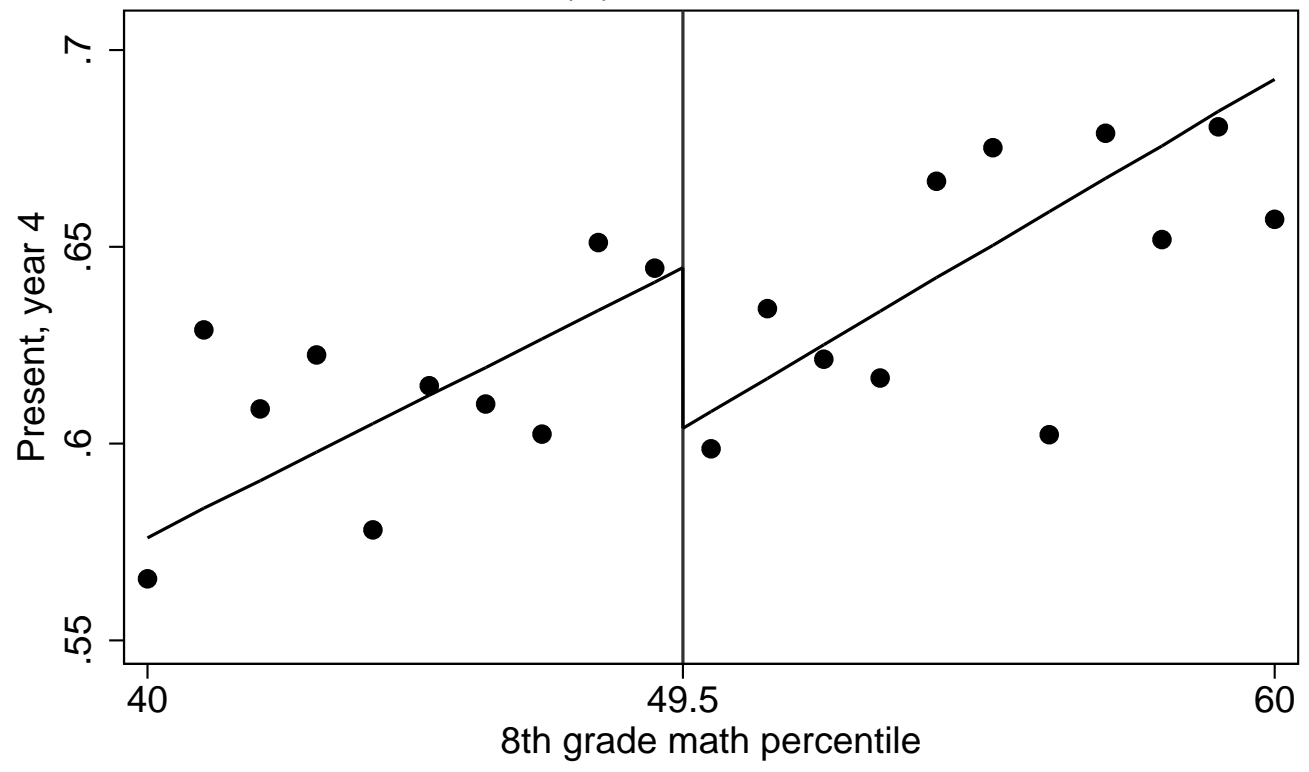

Notes: Panel A shows the probability of being present in the fourth year of high school by 8th grade math score for all students. Panel B limits the sample to students with 8th grade reading scores below the 50th percentile. Both panels show predicted values generated by the default regression specification described in the text. 
Figure A.5: Math Test Scores, Fall 10th Grade

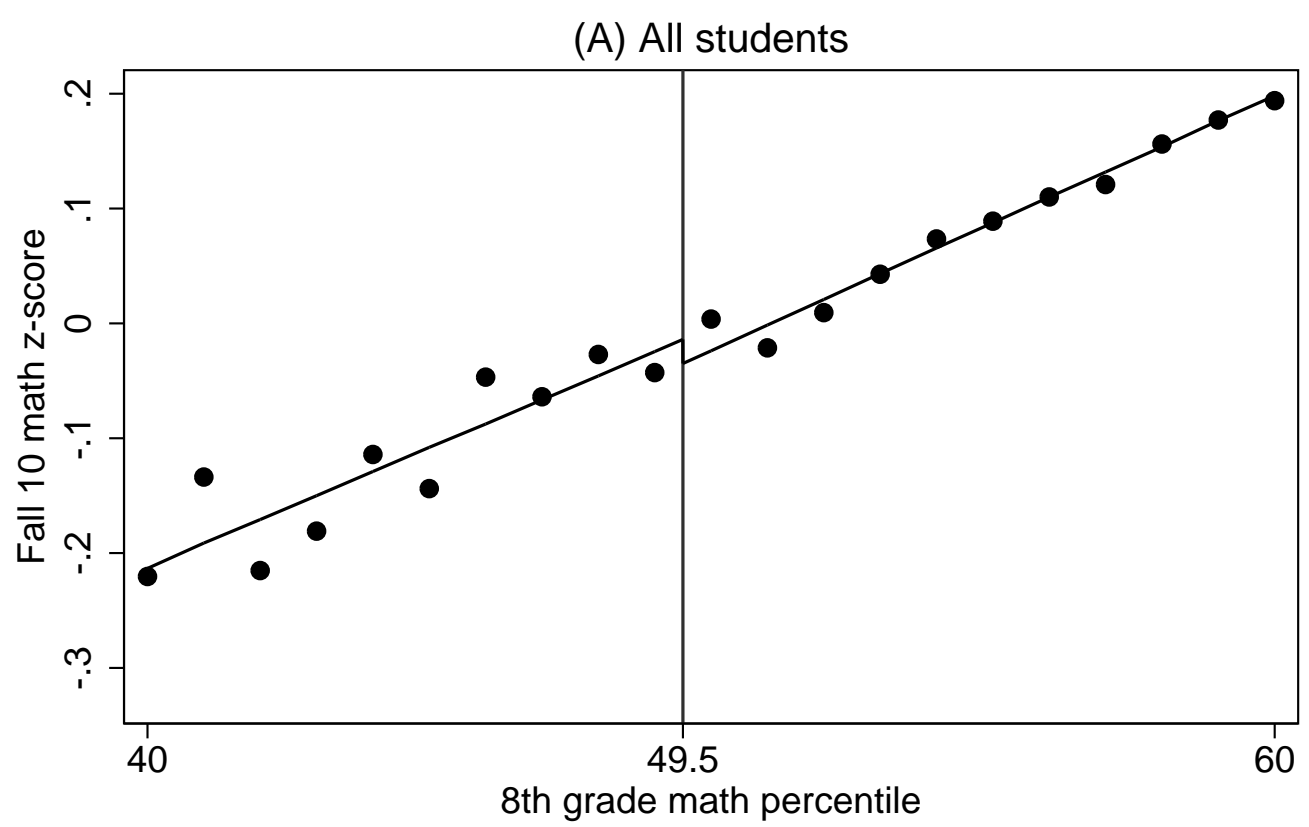

(B) Poor readers

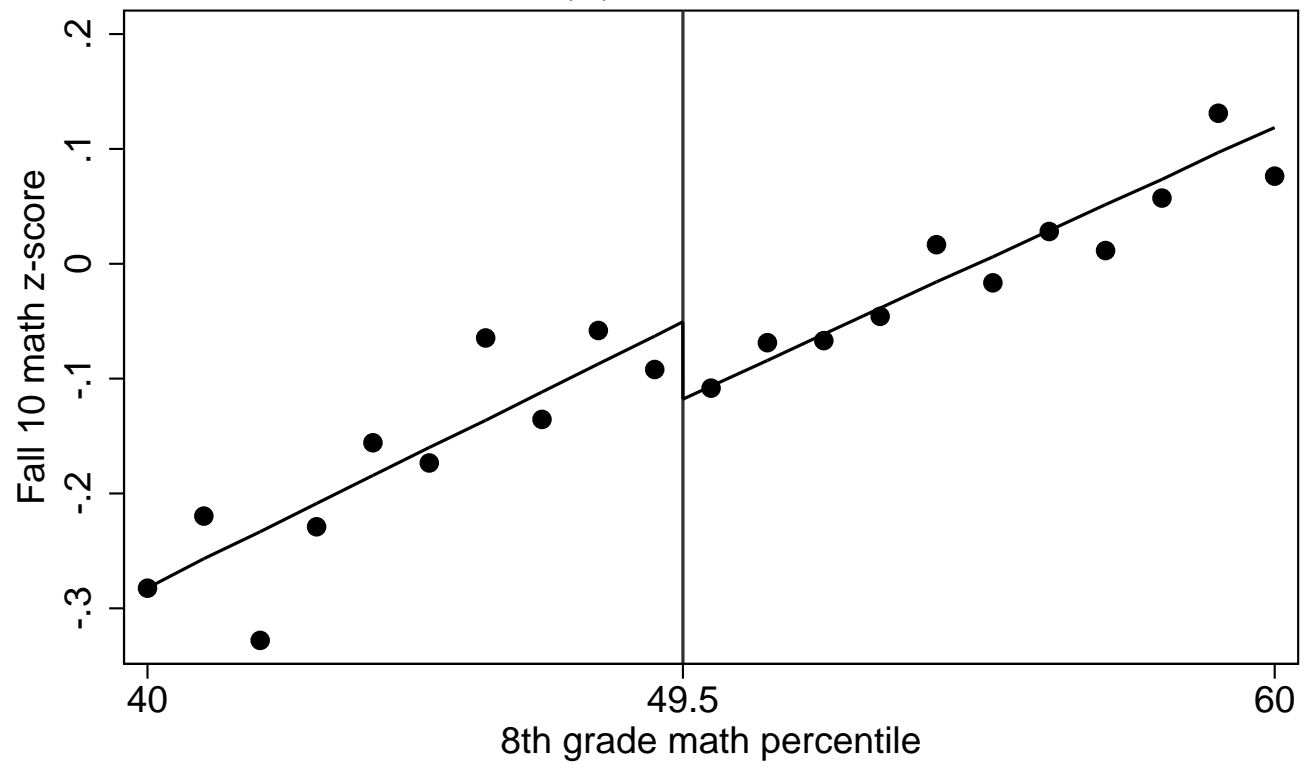

Notes: Panel A shows the mean fall 10th grade math score by 8th grade math score for all students who took the exam. Panel B limits the sample to students with 8th grade reading scores below the 50th percentile. Both panels show predicted values generated by the default regression specification described in the text. 
Figure A.6: ACT Math Scores, Spring 11th Grade

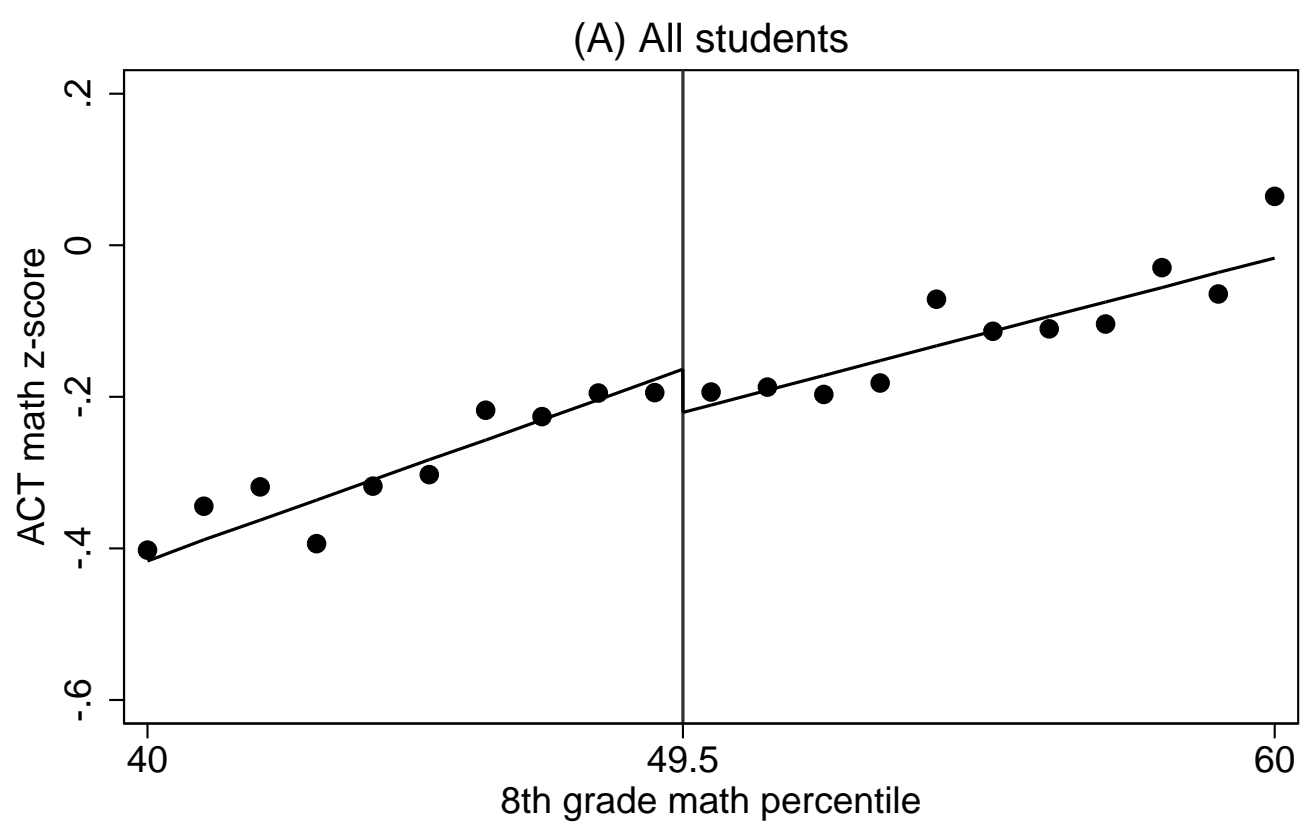

(B) Poor readers

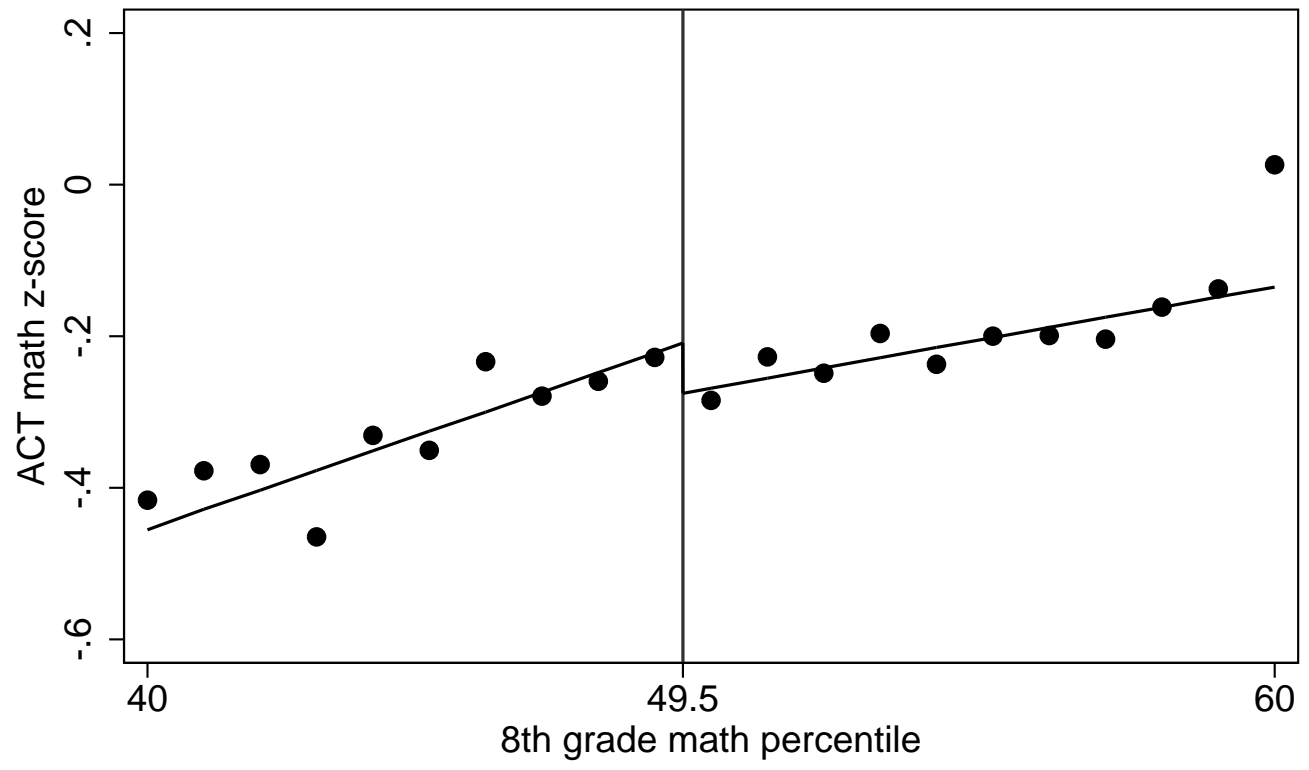

Notes: Panel A shows the mean ACT math score by 8th grade math score for all students who took the exam. Panel B limits the sample to students with 8th grade reading scores below the 50th percentile. Both panels show predicted values generated by the default regression specification described in the text. 


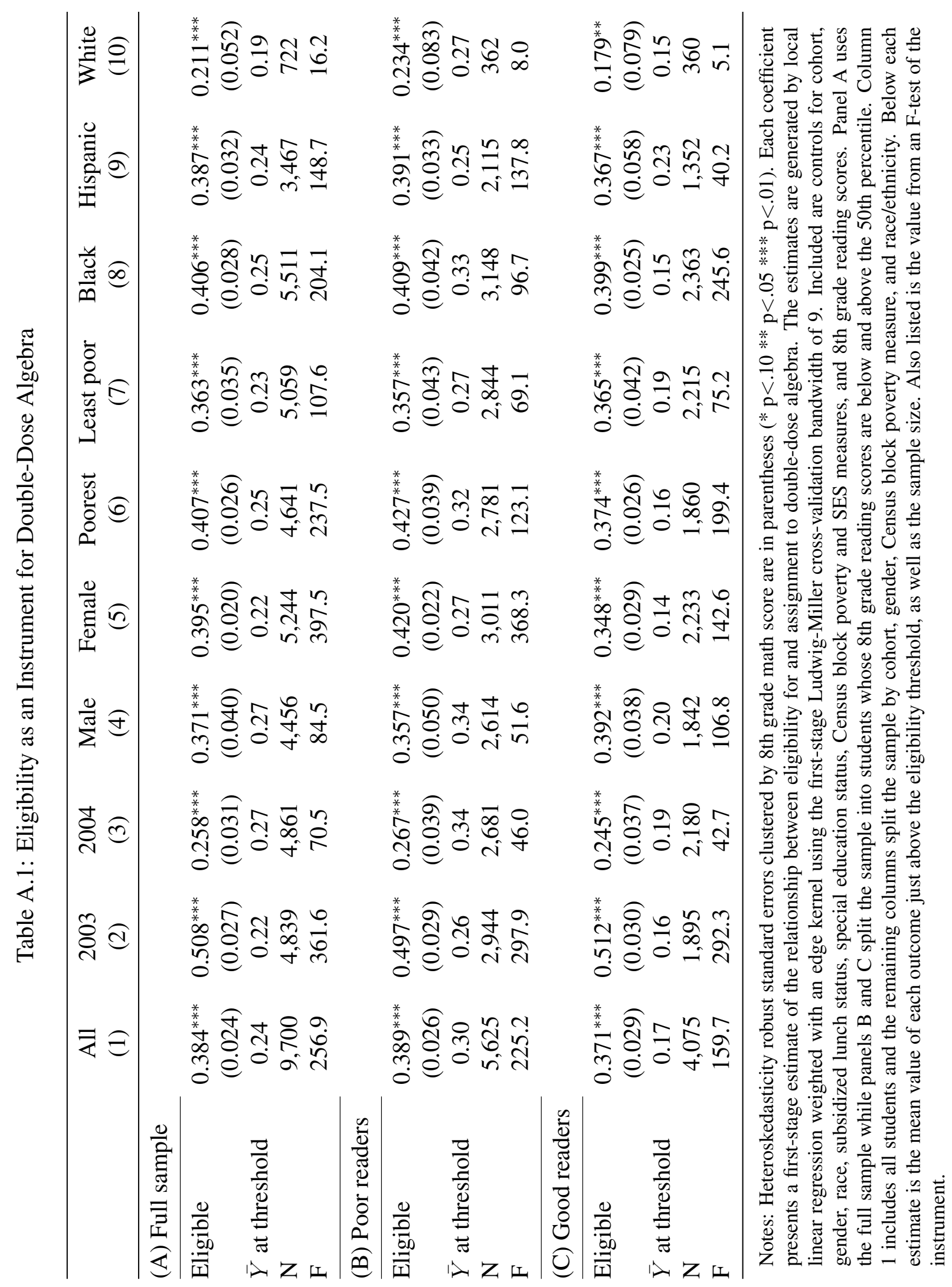




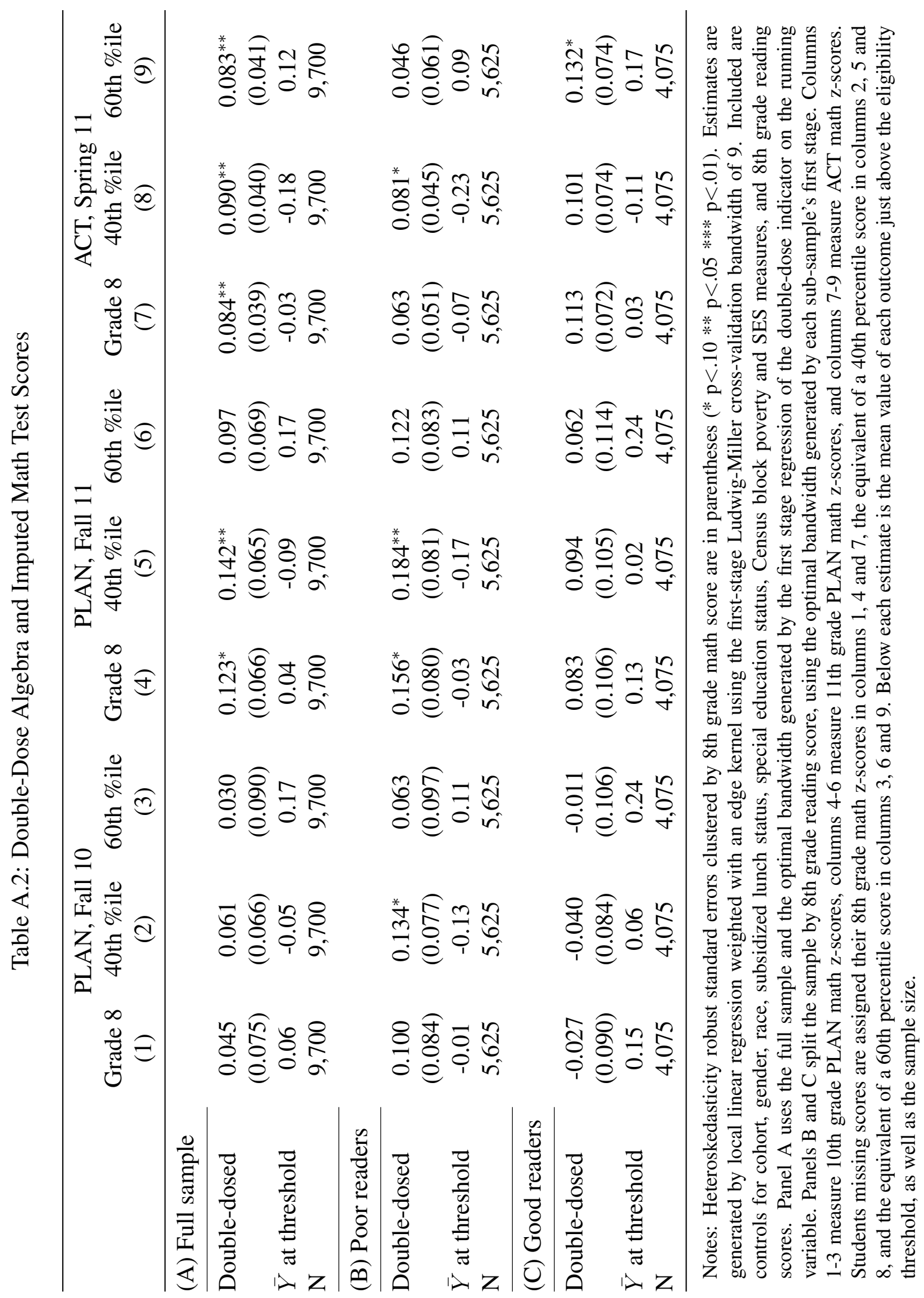


Table A.3: Heterogeneity by Gender, Income and Race

\begin{tabular}{|c|c|c|c|c|c|c|}
\hline & $\begin{array}{l}\text { Passed } \\
\text { algebra } \\
\text { (1) }\end{array}$ & $\begin{array}{c}\text { Passed } \\
\text { geometry } \\
(2)\end{array}$ & $\begin{array}{c}\text { Total } \\
\text { credits } \\
\text { earned } \\
\quad(3)\end{array}$ & $\begin{array}{c}\text { Graduated } \\
\text { HS within } \\
5 \text { years } \\
\text { (4) }\end{array}$ & $\begin{array}{c}\text { Enrolled } \\
\text { in any } \\
\text { college } \\
(5)\end{array}$ & $\begin{array}{c}\text { Enrolled } \\
\text { in 2-year } \\
\text { college } \\
(6)\end{array}$ \\
\hline \multicolumn{7}{|l|}{ (A) By gender } \\
\hline Double-dosed $*$ female & $\begin{array}{c}0.085^{*} \\
(0.048)\end{array}$ & $\begin{array}{l}0.104^{* *} \\
(0.049)\end{array}$ & $\begin{array}{c}1.345 \\
(0.860)\end{array}$ & $\begin{array}{c}0.137^{* * *} \\
(0.042)\end{array}$ & $\begin{array}{c}0.123^{* *} \\
(0.049)\end{array}$ & $\begin{array}{l}0.098^{* *} \\
(0.037)\end{array}$ \\
\hline Double-dosed $*$ male & $\begin{array}{c}0.101 \\
(0.064)\end{array}$ & $\begin{array}{c}0.133^{* *} \\
(0.063)\end{array}$ & $\begin{array}{c}1.628 \\
(1.186)\end{array}$ & $\begin{array}{c}0.102 \\
(0.065)\end{array}$ & $\begin{array}{c}0.089 \\
(0.057)\end{array}$ & $\begin{array}{c}0.031 \\
(0.034)\end{array}$ \\
\hline $\mathrm{p}\left(\beta^{\text {Female }}=\beta^{\text {Male }}\right)$ & 0.729 & 0.469 & 0.757 & 0.486 & 0.453 & 0.028 \\
\hline \multicolumn{7}{|l|}{ (B) By income } \\
\hline Double-dosed $*$ poorest & $\begin{array}{c}0.103^{*} \\
(0.052)\end{array}$ & $\begin{array}{l}0.106^{* *} \\
(0.052)\end{array}$ & $\begin{array}{c}1.667^{*} \\
(0.852)\end{array}$ & $\begin{array}{c}0.122^{* * *} \\
(0.045)\end{array}$ & $\begin{array}{c}0.099 * \\
(0.050)\end{array}$ & $\begin{array}{c}0.062^{*} \\
(0.033)\end{array}$ \\
\hline Double-dosed $*$ least poor & $\begin{array}{c}0.071 \\
(0.055)\end{array}$ & $\begin{array}{l}0.157^{* *} \\
(0.061)\end{array}$ & $\begin{array}{c}0.968 \\
(1.213)\end{array}$ & $\begin{array}{l}0.123^{* *} \\
(0.059)\end{array}$ & $\begin{array}{l}0.133^{* *} \\
(0.050)\end{array}$ & $\begin{array}{l}0.082^{* *} \\
(0.041)\end{array}$ \\
\hline $\mathrm{p}\left(\beta^{\text {Poor }}=\beta^{\text {Nonpoor }}\right)$ & 0.318 & 0.163 & 0.290 & 0.975 & 0.223 & 0.410 \\
\hline \multicolumn{7}{|l|}{ (C) By race } \\
\hline Double-dosed $*$ black & $\begin{array}{c}0.077 \\
(0.055)\end{array}$ & $\begin{array}{c}0.143^{* * *} \\
(0.047)\end{array}$ & $\begin{array}{c}1.244 \\
(0.885)\end{array}$ & $\begin{array}{l}0.126^{* *} \\
(0.049)\end{array}$ & $\begin{array}{c}0.153^{* * *} \\
(0.050)\end{array}$ & $\begin{array}{c}0.084^{* *} \\
(0.033)\end{array}$ \\
\hline Double-dosed $*$ Hispanic & $\begin{array}{c}0.081 \\
(0.058)\end{array}$ & $\begin{array}{c}0.049 \\
(0.053)\end{array}$ & $\begin{array}{c}1.118 \\
(1.017)\end{array}$ & $\begin{array}{c}0.076 \\
(0.051)\end{array}$ & $\begin{array}{l}-0.029 \\
(0.050)\end{array}$ & $\begin{array}{c}0.018 \\
(0.032)\end{array}$ \\
\hline Double-dosed $*$ white & $\begin{array}{c}0.074 \\
(0.083)\end{array}$ & $\begin{array}{c}-0.032 \\
(0.075)\end{array}$ & $\begin{array}{c}-0.736 \\
(1.882)\end{array}$ & $\begin{array}{l}-0.022 \\
(0.101)\end{array}$ & $\begin{array}{c}0.068 \\
(0.077)\end{array}$ & $\begin{array}{c}0.064 \\
(0.056)\end{array}$ \\
\hline $\mathbf{p}\left(\beta^{\text {Black }}=\beta^{\text {Hispanic }}\right)$ & 0.870 & 0.000 & 0.815 & 0.059 & 0.000 & 0.001 \\
\hline $\mathbf{p}\left(\beta^{\text {Black }}=\beta^{\text {White }}\right)$ & 0.963 & 0.003 & 0.180 & 0.048 & 0.170 & 0.695 \\
\hline $\mathrm{p}\left(\beta^{\text {Hispanic }}=\beta^{\text {White }}\right)$ & 0.923 & 0.200 & 0.254 & 0.219 & 0.123 & 0.318 \\
\hline $\mathrm{N}$ & 9,700 & 9,700 & 9,700 & 9,700 & 9,700 & 9,700 \\
\hline
\end{tabular}

Notes: Heteroskedasticity robust standard errors clustered by 8th grade math score are in parentheses $(* \mathrm{p}<.10$ $* * \mathrm{p}<.05 * * * \mathrm{p}<.01)$. Each coefficient presents an instrumental variables estimate of the impact of double-dose algebra on the given outcome, with treatment instrumented by eligibility. The estimates are generated by local linear regression weighted with an edge kernel using the first-stage Ludwig-Miller cross-validation bandwidth of 9. Each panel interacts both the instrument and the treatment variable with group indicators, as well as controlling directly for such indicators. Below each set of estimates are the p-values from an F-test of the equality of the coefficients shown. 
Table A.4: Robustness checks

\begin{tabular}{|c|c|c|c|c|c|c|}
\hline & $\begin{array}{l}\text { Passed } \\
\text { algebra } \\
\text { (1) }\end{array}$ & $\begin{array}{c}\text { Passed } \\
\text { geometry } \\
\text { (2) }\end{array}$ & $\begin{array}{c}\text { Total } \\
\text { credits } \\
\text { earned } \\
\quad(3)\end{array}$ & $\begin{array}{c}\text { Graduated } \\
\text { HS within } \\
5 \text { years } \\
\text { (4) }\end{array}$ & $\begin{array}{l}\text { Enrolled } \\
\text { in any } \\
\text { college } \\
(5)\end{array}$ & $\begin{array}{c}\text { Enrolled } \\
\text { in 2-year } \\
\text { college } \\
\text { (6) }\end{array}$ \\
\hline \multicolumn{7}{|l|}{ (A) Full sample } \\
\hline $\mathrm{BW}=9(\mathrm{CV})$ & $\begin{array}{c}0.093^{*} \\
(0.051)\end{array}$ & $\begin{array}{c}0.117^{* *} \\
(0.052)\end{array}$ & $\begin{array}{c}1.474 \\
(0.914)\end{array}$ & $\begin{array}{l}0.121^{* *} \\
(0.048)\end{array}$ & $\begin{array}{c}0.108^{* *} \\
(0.048)\end{array}$ & $\begin{array}{c}0.067^{* *} \\
(0.033)\end{array}$ \\
\hline $\mathrm{BW}=9(\mathrm{CV})$, no controls & $\begin{array}{c}0.078 \\
(0.055)\end{array}$ & $\begin{array}{l}0.101^{* *} \\
(0.048)\end{array}$ & $\begin{array}{c}1.116 \\
(0.915)\end{array}$ & $\begin{array}{l}0.101^{* *} \\
(0.049)\end{array}$ & $\begin{array}{c}0.082^{*} \\
(0.047)\end{array}$ & $\begin{array}{l}0.059^{*} \\
(0.031)\end{array}$ \\
\hline Bandwidth = 12.7 (IK) & $\begin{array}{c}0.069^{*} \\
(0.041)\end{array}$ & $\begin{array}{c}0.074^{*} \\
(0.041)\end{array}$ & $\begin{array}{c}0.946 \\
(0.725)\end{array}$ & $\begin{array}{l}0.079^{* *} \\
(0.039)\end{array}$ & $\begin{array}{c}0.089^{* *} \\
(0.042)\end{array}$ & $\begin{array}{l}0.072^{* *} \\
(0.029)\end{array}$ \\
\hline Bandwidth $=5$ & $\begin{array}{c}0.120^{*} \\
(0.066)\end{array}$ & $\begin{array}{l}0.216^{* *} \\
(0.087)\end{array}$ & $\begin{array}{l}2.759^{* *} \\
(1.248)\end{array}$ & $\begin{array}{l}0.151^{* *} \\
(0.065)\end{array}$ & $\begin{array}{l}0.137^{* *} \\
(0.055)\end{array}$ & $\begin{array}{l}0.074^{*} \\
(0.039)\end{array}$ \\
\hline Untreated cohorts (RF) & $\begin{array}{c}0.001 \\
(0.016)\end{array}$ & $\begin{array}{c}0.012 \\
(0.024)\end{array}$ & $\begin{array}{c}0.137 \\
(0.397)\end{array}$ & $\begin{array}{c}-0.006 \\
(0.015)\end{array}$ & $\begin{array}{c}0.003 \\
(0.020)\end{array}$ & $\begin{array}{c}0.024 \\
(0.014)\end{array}$ \\
\hline \multicolumn{7}{|l|}{ (B) Poor readers } \\
\hline $\mathrm{BW}=9(\mathrm{CV})$ & $\begin{array}{c}0.132^{*} \\
(0.066)\end{array}$ & $\begin{array}{c}0.183^{* *} \\
(0.069)\end{array}$ & $\begin{array}{l}3.072^{* *} \\
(1.365)\end{array}$ & $\begin{array}{c}0.179^{* * *} \\
(0.054)\end{array}$ & $\begin{array}{c}0.111 \\
(0.088)\end{array}$ & $\begin{array}{c}0.030 \\
(0.073)\end{array}$ \\
\hline $\mathrm{BW}=9(\mathrm{CV})$, no controls & $\begin{array}{c}0.125^{*} \\
(0.068)\end{array}$ & $\begin{array}{c}0.170^{* * *} \\
(0.063)\end{array}$ & $\begin{array}{l}2.970^{* *} \\
(1.305)\end{array}$ & $\begin{array}{c}0.162^{* * *} \\
(0.055)\end{array}$ & $\begin{array}{c}0.094 \\
(0.080)\end{array}$ & $\begin{array}{c}0.024 \\
(0.068)\end{array}$ \\
\hline Bandwidth = 12.7 (IK) & $\begin{array}{c}0.096^{*} \\
(0.053)\end{array}$ & $\begin{array}{l}0.130^{* *} \\
(0.055)\end{array}$ & $\begin{array}{l}2.244^{* *} \\
(1.077)\end{array}$ & $\begin{array}{c}0.136^{* * *} \\
(0.045)\end{array}$ & $\begin{array}{c}0.102 \\
(0.069)\end{array}$ & $\begin{array}{c}0.058 \\
(0.057)\end{array}$ \\
\hline Bandwidth $=5$ & $\begin{array}{c}0.158 \\
(0.102)\end{array}$ & $\begin{array}{l}0.275^{* *} \\
(0.112)\end{array}$ & $\begin{array}{l}5.205^{* *} \\
(2.007)\end{array}$ & $\begin{array}{c}0.232^{* * *} \\
(0.079)\end{array}$ & $\begin{array}{c}0.153 \\
(0.126)\end{array}$ & $\begin{array}{c}0.015 \\
(0.108)\end{array}$ \\
\hline Untreated cohorts (RF) & $\begin{array}{c}0.008 \\
(0.023)\end{array}$ & $\begin{array}{c}0.003 \\
(0.030)\end{array}$ & $\begin{array}{c}0.088 \\
(0.536)\end{array}$ & $\begin{array}{l}-0.000 \\
(0.024)\end{array}$ & $\begin{array}{c}0.006 \\
(0.023)\end{array}$ & $\begin{array}{c}0.012 \\
(0.017)\end{array}$ \\
\hline
\end{tabular}

Notes: Heteroskedasticity robust standard errors clustered by 8 th grade math score are in parentheses $(* \mathrm{p}<.10$ $* * \mathrm{p}<.05 * * * \mathrm{p}<.01)$. Each coefficient is an instrumental variables estimate of the impact of double-dose algebra on the given outcome, with treatment instrumented by eligibility. The estimates are generated by local linear regression weighted with an edge kernel using various bandwidths. Panel A uses the full sample while panel B includes only students whose 8th grade reading scores are below the 50th percentile. The first uses our default specification, with the first stage's Ludwig-Miller cross-validation bandwidth of 9 and controls for cohort, gender, race, subsidized lunch status, special education status, Census block poverty and SES measures, and 8th grade reading scores. The second row replicates the first row but without those controls. The third row replicates the first row using the first stage's Imbens-Kalyanaraman optimal bandwidth of 12.7. The fourth row replicates the first row using a bandwidth of 5 . The fifth row shows reduced form estimates generated by the pre-treatment cohorts of 2001 and 2002, using a bandwidth of 9 . 
Table A.5: Compliance with Implementation Guidelines

\begin{tabular}{|c|c|c|c|c|c|c|}
\hline & $\begin{array}{l}\text { Passed } \\
\text { algebra } \\
\text { (1) }\end{array}$ & $\begin{array}{c}\text { Passed } \\
\text { geometry } \\
(2)\end{array}$ & $\begin{array}{c}\text { Total } \\
\text { credits } \\
\text { earned } \\
\text { (3) }\end{array}$ & $\begin{array}{c}\text { Graduated } \\
\text { HS within } \\
5 \text { years } \\
\text { (4) }\end{array}$ & $\begin{array}{c}\text { Enrolled } \\
\text { in any } \\
\text { college } \\
(5)\end{array}$ & $\begin{array}{c}\text { Enrolled } \\
\text { in 2-year } \\
\text { college } \\
(6)\end{array}$ \\
\hline \multicolumn{7}{|l|}{ (A) By compliance } \\
\hline Double-dosed & $\begin{array}{l}0.111^{* *} \\
(0.055)\end{array}$ & $\begin{array}{l}0.124^{* *} \\
(0.057)\end{array}$ & $\begin{array}{c}1.667 \\
(1.007)\end{array}$ & $\begin{array}{l}0.126^{* *} \\
(0.052)\end{array}$ & $\begin{array}{l}0.113^{* *} \\
(0.050)\end{array}$ & $\begin{array}{l}0.073^{* *} \\
(0.034)\end{array}$ \\
\hline Double-dosed * compliance & $\begin{array}{c}-0.223^{* *} \\
(0.110)\end{array}$ & $\begin{array}{c}-0.084 \\
(0.107)\end{array}$ & $\begin{array}{l}-2.345 \\
(2.009)\end{array}$ & $\begin{array}{c}-0.061 \\
(0.092)\end{array}$ & $\begin{array}{c}-0.066 \\
(0.092)\end{array}$ & $\begin{array}{c}-0.062 \\
(0.063)\end{array}$ \\
\hline \multicolumn{7}{|l|}{ (B) By treatment cohort } \\
\hline Double-dosed & $\begin{array}{c}0.063 \\
(0.047)\end{array}$ & $\begin{array}{c}0.119^{* * *} \\
(0.044)\end{array}$ & $\begin{array}{c}1.385 \\
(0.837)\end{array}$ & $\begin{array}{c}0.117^{* * *} \\
(0.042)\end{array}$ & $\begin{array}{c}0.109^{* *} \\
(0.046)\end{array}$ & $\begin{array}{c}0.051 \\
(0.032)\end{array}$ \\
\hline Double-dosed $* 2004$ & $\begin{array}{c}0.089 * \\
(0.048)\end{array}$ & $\begin{array}{l}-0.006 \\
(0.051)\end{array}$ & $\begin{array}{c}0.265 \\
(1.157)\end{array}$ & $\begin{array}{c}0.013 \\
(0.065)\end{array}$ & $\begin{array}{l}-0.003 \\
(0.055)\end{array}$ & $\begin{array}{c}0.050 \\
(0.043)\end{array}$ \\
\hline $\mathrm{N}$ & 9,700 & 9,700 & 9,700 & 9,700 & 9,700 & 9,700 \\
\hline
\end{tabular}

Notes: Heteroskedasticity robust standard errors clustered by 8th grade math score are in parentheses $(* \mathrm{p}<.10$ $* * \mathrm{p}<.05 * * * \mathrm{p}<.01)$. Each coefficient is an instrumental variables estimate of the impact of double-dose algebra on the given outcome, with treatment instrumented by eligibility. The estimates are generated by local linear regression weighted with an edge kernel using the first-stage Ludwig-Miller cross-validation bandwidth of 9. Each panel interacts both the instrument and the treatment variable with the given measure, as well as controlling directly for that measure. In panel A, the measure is a de-meaned average of three compliance measures, each of which runs from 0 to 1 . The three measures are the fraction of double-dosed students in the school with the same teacher for both classes, the fraction with both periods consecutive, and the fraction of algebra peers who are also doubledosed. In panel B, the main coefficient measures the impact of double-dosing on the 2003 cohort, while the interaction measures the difference in effect size between 2004 and 2003. 